RUNNING HEAD: HEALTH CARE PROVIDERS AND HIV

HEALTH CARE PROVIDER ATTITUDES AND BELIEFS ABOUT PEOPLE LIVING WITH HIV: A MIXED METHOD INVESTIGATION

\author{
by \\ Anne C. Wagner \\ Master of Arts, Ryerson University, 2009 \\ A dissertation \\ presented to Ryerson University \\ in partial fulfillment of the \\ requirements for the degree of \\ Doctor of Philosophy \\ in the program of \\ Psychology
}

Bachelor of Arts (Honours), University of Western Ontario, 2007

Toronto, Ontario, Canada, 2013

C)Anne C. Wagner, 2013 
HEALTH CARE PROVIDERS AND HIV

\section{Author's Declaration}

I hereby declare that I am the sole author of this dissertation. This is a true copy of the dissertation, including any required final revisions, as accepted by my examiners.

I authorize Ryerson University to lend this dissertation to other institutions or individuals for the purpose of scholarly research.

I further authorize Ryerson University to reproduce this dissertation by photocopying or by other means, in total or in part, at the request of other institutions or individuals for the purpose of scholarly research.

I understand that my dissertation may be made electronically available to the public. 
HEALTH CARE PROVIDERS AND HIV

\begin{abstract}
Health Care Provider Attitudes and Beliefs about People Living with HIV: A Mixed Method Investigation
\end{abstract}

Doctor of Philosophy, 2013

Anne C. Wagner

Psychology, Ryerson University

The current investigation seeks to examine the attitudes and beliefs of health care providers in Canada about people living with HIV. The line of research consists of three studies. Study 1 was a qualitative study conducted with a critical lens. The critical lens was used in a series of four focus groups when qualitatively soliciting opinions about the range of attitudes, behaviours and cognitions health care providers may have towards people living with HIV. Study 2 used the information gathered from Study 1 to develop a scale to assess HIV stigma in health care providers. Items were created from examples and themes found in the qualitative study, and were tested via exploratory factor analysis, confirmatory factor analysis, test-retest reliability analysis, and assessed for convergent and divergent validity. Study 3 examined the newly developed scale's relationship to proposed overlapping stigmas and attitudes, and tested the adapted intersectional model of HIV-related stigma with health care trainees using the newly developed HIV stigma scale as an outcome measure. The line of research found that HIV stigma continues to be a significant problem in the health care system. The scale developed in Study 2 demonstrates that HIV stigma can be conceptualized and assessed as a tripartite model of discrimination, stereotyping and prejudice, and that this conceptualization of HIV stigma supports an intersectional model of overlapping stigmas with homophobia, racism, stigma against injection drug use and stigma against sex work. 
HEALTH CARE PROVIDERS AND HIV

\section{Acknowledgements}

A heartfelt thank you to my supervisor, Dr. Trevor Hart, and to Dr. Kelly McShane, my supervisory committee member, who provided invaluable guidance throughout the dissertation process and my doctoral degree. A huge debt of gratitude is owed to my community mentor, Shari Margolese, for her wisdom and expertise. Dr. Todd Girard's thoughtful review and helpful suggestions helped improve this dissertation immensely. My sincere thank you to my examining committee, as well as Ryerson's Department of Psychology and the HIV Prevention Lab. This work has been, and continues to be, inspired by the incredible people who volunteer their time to participate in these studies, both individuals living with HIV and health care providers. My hope is that this work will help to create lives lived with a little less stigma and a great deal more understanding. 
HEALTH CARE PROVIDERS AND HIV

Dedication

For my family, natural and chosen. 
HEALTH CARE PROVIDERS AND HIV

Table of Contents

1. Summary Introduction 1

a. References 4

2. Study 1: Health Care Provider Attitudes and Beliefs about People Living with HIV: A Critical Qualitative Investigation 5

a. Introduction 5

$\begin{array}{ll}\text { i. Effects of HIV-related stigma } & 7\end{array}$

ii. Health care providers and HIV-related stigma 8

$\begin{array}{lr}\text { iii. Current study } & 10\end{array}$

$\begin{array}{ll}\text { b. Methods } & 10\end{array}$

$\begin{array}{ll}\text { i. Participants } & 10\end{array}$

$\begin{array}{ll}\text { ii. Procedure } & 12\end{array}$

$\begin{array}{ll}\text { iii. Lens and data coding } & 12\end{array}$

$\begin{array}{ll}\text { c. Results } & 16\end{array}$

i. Components of stigma 20

ii. HIV-specific experiences 24

$\begin{array}{ll}\text { d. Discussion } & 30\end{array}$

e. References 37

3. Study 2: Health Care Provider Attitudes and Beliefs about People Living with HIV: Initial Validation of the Health Care Provider HIV/AIDS Stigma Scale (HPASS) 43

a. Introduction 43

i. Divergent theories of HIV stigma 44

ii. HIV stigma and health care providers 49 
HEALTH CARE PROVIDERS AND HIV

b. Methods 52

i. Scale development 52

1. Participants 52

2. Procedure 52

3. Conceptualization 53

ii. Scale psychometric assessment 54

1. Participants 54

2. Procedure 58

3. Measures 58

4. Analytic plan $\quad 59$

$\begin{array}{ll}\text { c. Results } & 65\end{array}$

i. Item redundancy 65

ii. Factor structure 65

1. EFA 65

2. CFA 70

$\begin{array}{lll}\text { iii. } & \text { Reliability } & 70\end{array}$

$\begin{array}{ll}\text { 1. Internal consistency } & 70\end{array}$

2. Test-retest reliability 71

$\begin{array}{ll}\text { iv. Convergent and divergent validity } & 71\end{array}$

$\begin{array}{ll}\text { d. Discussion } & 72\end{array}$

i. Prejudice, stereotyping and discrimination 73

ii. Future directions and limitations $\quad 74$

$\begin{array}{ll}\text { iii. Conclusion } & 75\end{array}$ 
HEALTH CARE PROVIDERS AND HIV

e. References

4. Study 3: HIV-Related Stigma and Overlapping Stigmas among Health Care Trainees in

Canada

a. Introduction $\quad 82$

i. Who HIV affects - the context for stigmatization 82

ii. HIV and overlapping stigmas $\quad 84$

iii. Integrative frameworks - HIV stigma and the role of intersectionality 85

iv. Current study $\quad 86$

$\begin{array}{ll}\text { b. Methods } & 87\end{array}$

$\begin{array}{ll}\text { i. } & \text { Measures } \\ \end{array}$

ii. Analytic plan 94

c. Results 95

$\begin{array}{ll}\text { d. Discussion } & 102\end{array}$

$\begin{array}{ll}\text { e. References } & 107\end{array}$

5. Summary Discussion 112

$\begin{array}{lr}\text { a. References } & 122\end{array}$ 
HEALTH CARE PROVIDERS AND HIV

List of Tables

Study 1.

Table 1. Categories and themes.

Study 2 .

Table 1. Sociocognitive and structural factors (Mahajan et al., 2008).

Table 2. Descriptive characteristics.

Table 3. Item factor loadings.

Study 3.

Table 1. Descriptive characteristics.

Table 2. Correlations between demographic characteristics and HPASS total.

Table 3. Correlations between overlapping stigmas and HPASS total.

Table 4. Correlations between overlapping stigmas and HPASS subscales.

Table 5. Summary of additional regression analyses.

Table 6. Four variable overlapping stigmas regression model. 
HEALTH CARE PROVIDERS AND HIV

\section{List of Figures}

Study 2.

Figure 1. Scree plot for unrestricted factor loadings.

Figure 2. Scree plot for restricted four factor item loadings. 
HEALTH CARE PROVIDERS AND HIV

\section{List of Appendices}

Appendix A: Informed Consent for Study 1.

Appendix B: Focus Group Questions.

Appendix C: Debriefing Form for Study 1.

Appendix D: Informed Consent for Studies 2 and 3.

Appendix E: Debriefing Form for Studies 2 and 3.

Appendix F: Informed Consent for Test-Retest Assessment of the HPASS. 
HEALTH CARE PROVIDERS AND HIV

Summary Introduction

The current study is a multi-method investigation of HIV stigma in the health care system in Canada. The goal of the study was to use findings derived from focus groups conducted from a qualitative, critical psychology perspective to develop a contextually and temporally relevant scale to assess HIV stigma among health care providers. This scale was then tested with health care trainees, and the outcome measure of HIV stigma was used in an assessment of overlapping stigmas. The model of overlapping stigmas was a preliminary quantitative investigation of an intersectional model of HIV stigma.

A mixed-methods design highlights the ultimate ability to use multiple sources of information, incorporating both the value-acknowledging aspects of critical theory and the methodological standardization of evaluation with a positivist approach (Greene, Caracelli, \& Graham, 1989). Using critical theory to conduct the focus groups that elucidate item stems and themes for scale development and assessment of these themes in a positivist manner adds methodological rigour to scale development and a unique assessment as to whether or not these views hold and are endorsed, and in what patterns, in a larger-scale evaluation. The mixedmethods approach allows for the phenomena established via qualitative analysis to be tested in a large, standardized format in quantitative analysis. This speaks to the pragmatism highlighted in the literature on mixed-methods approaches, allowing context to be infused in quantitative research and accessibility to the findings derived in qualitative research (Johnson \& Onwuegbuze, 2004).

Using a framework and lens to guide the qualitative, investigative portion of the study gives greater methodological rigour to scale development and construct delineation (Yardley \& Bishop, 2008). Most stigma scales are created without specific reference to HIV stigma theories. 


\section{HEALTH CARE PROVIDERS AND HIV}

As such, some measures may not fully examine the social and individual level variables that impact on HIV stigma, and may therefore only capture narrow aspects of the HIV stigma construct. Subsequently using the outcome measure of HIV stigma from this scale to assess an intersectional model of overlapping stigmas allows for a contextually relevant and ground up assessment of the model.

The use of a critical psychology lens to begin the assessment necessitates reflexivity regarding the researcher's position and location in relation to the topic (e.g., Maton, 2003). The author's position as a young, female researcher of European descent, reflecting a Western education and bias in terms of privilege and power in comparison to participants is acknowledged as her vantage point. The author acknowledges that she approached the study with a flexible assumption that HIV stigma continues to exist in the Canadian healthcare system. This bias has been informed by the author's involvement in HIV research over the past six years, and with ongoing communication and relationships with individuals living with HIV within this context. Additionally, the author acknowledges that she has been trained in a positivist, predominantly quantitative tradition of psychology which historically depoliticizes research and assumes of position of "value-neutrality", which the author questions.

Overarchingly, the study is intended to examine HIV stigma in the health care system in Canada. The use of the term "people living with HIV" throughout the study is purposeful so as to not medicalize or make reductionistic the experience of people living with HIV by using an acronym. Additionally, it is noted that people living with HIV are not a homogenous group, and that sex and gender, as well as sexuality, are hugely important aspects to consider in understanding the experience of people living with HIV. In the context of this study, individuals 


\section{HEALTH CARE PROVIDERS AND HIV}

living with HIV are referred to as a collective, representing the literature up until this point, but findings are highlighted that emphasize intra-group differences and individual experiences.

The study aims to harness the benefits of a critical underpinning to understand the current status of HIV stigma in the health care system, and uses this approach to inform the subsequent psychometric and quantitative assessments of HIV stigma and overlapping stigmas. 
HEALTH CARE PROVIDERS AND HIV

\section{References}

Greene, J.C., Caracelli, V.J., \& Graham, W.F. (1989). Toward a conceptual framework for mixed-method evaluation designs. Educational Evaluation and Policy Analysis, 11, 255-274. doi: $10.3102 / 01623737011003255$

Johnson, R.B., \& Onwuegbuzie, A.J. (2004). Mixed methods research: a research paradigm whose time has come. Educational Researcher, 33, 14-26. doi: $10.3102 / 0013189 \times 033007014$

Maton, K. (2003). Reflexivity, relationism, \& research: Pierre Bourdieu and the epistemic social scientific knowledge. Space and Culture, 6, 52-65. doi: 10.1177/1206331202238962

Yardley, L., \& Bishop, F. (2008). Mixing qualitative and quantitative methods: a pragmatic approach. In C. Willig \& W. Stainton-Rogers (Eds.), Qualitative Research in Psychology (pp. 352-370). Thousand Oaks, CA: SAGE Publications Inc. 


\section{HEALTH CARE PROVIDERS AND HIV}

Study 1: Health Care Provider Attitudes and Beliefs about People Living with HIV:

\section{A Critical Qualitative Investigation}

HIV-related stigma is a ubiquitous, complex and distressing public health problem. It is linked with poor psychological, social, and physical health outcomes (e.g., Herek, Capitanio, \& Widaman, 2002; Greig, Peacock, Jewkes, \& Msimang, 2008; Peretti-Watel et al., 2006). HIVrelated stigma is especially problematic within the health care system. If a patient feels stigmatized by a health care provider, this may impact care, quality of life, and engagement in the health care process (Kinsler, Wong, Sayles, Davis, \& Cunningham, 2007). Recent literature highlights current problems with HIV-related stigma in the health care system, such as findings showing that women living with HIV are still feeling stigmatized by health care providers in Canada when pursuing pregnancy, and that stigma can be used as a mechanism of social control over people living with HIV (Wagner, Hart, Mohammed, Ivanova, Wong, \& Loutfy, 2010; Mill, Edwards, Jackson, MacLean, \& Chaw-Kant, 2010). The majority of research on health care provider attitudes towards people living with HIV ceased around the year 2000, creating a gap in the literature due to the tremendous advances and changes in the treatment and management of HIV. These changes include anti-retroviral medications that are more effective, easier to take, and with fewer side effects than earlier forms of medication, and medications that are safe for women living with HIV who are pregnant (Andany \& Loutfy, 2013). Additionally, unlike before 1996 and the advent of combination antiretroviral therapies, health care providers, especially in countries with advanced HIV medical care, now provide care for people living with HIV throughout a full lifespan.

A power dynamic exists between patients and health care providers because of the expert role the provider plays and the patient's relative vulnerability (e.g., Worthington \& Myers, 2003). 


\section{HEALTH CARE PROVIDERS AND HIV}

This power differential can be due to differences in knowledge, differences in perceived status within the relationship, and differences in control over relational interactions. The power dynamic between patients living with HIV and providers therefore has a lengthier and more complex trajectory with HIV becoming a chronic as opposed to an acute illness. This dynamic is also influenced by the sex of the individual living with HIV, as well as other intersectional stigmas, such as homophobia and stigma against injection drug use (e.g., Logie, James, Tharao, \& Loutfy, 2012; Reidpath \& Chan, 2005). To keep up with the changes in medical treatment, current investigations must recalibrate and determine attitudes and behaviours of providers at this point in time, taking into consideration HIV's present socio-political context. Additionally, significant advances have been made in the conceptualization of HIV-related stigma that acknowledge its unique presentation compared to other forms of stigma and compared to other chronic health conditions (e.g., Earnshaw and Chaudoir, 2009; Skelton, 2006).

The structural context of HIV stigma in the health care system, and particularly in terms of power dynamics between providers and patients, creates an environment where stigma in its various forms can be insidious, couched in terms of safety and embedded within policy and practice, as opposed to understanding where these policies derived from initially (e.g., Mahajan et al., 2008). Fear and outdated information, such as the need for extreme precautions beyond typical standards of protection and care regarding the transmission of infectious diseases, or the disclosure of HIV status in the name of precaution for health care providers, may feed this fear and further reify the need for social control of individuals living with HIV to mitigate it (e.g., Mill et al., 2010). This structural context informs the experience of the person living with HIV as well as the provider, and needs to be considered as context even when examining stigma from an individual-level perspective. 
HEALTH CARE PROVIDERS AND HIV

A critical framework in psychology calls for the challenging of existing social beliefs, and therefore fosters real change (Prilleltensky, 1989). HIV as a topic, an illness, and the source of much activism and advocacy, is inherently value-laden. A critical framework allows the researcher to acknowledge that the researchers themselves and the topic are value-laden, and requires that researchers pay attention to issues of power dynamics and social injustice (Fox, Prilleltensky, \& Austin, 2009). A purported value-neutral stance depoliticizes inherently political issues, and accepts research findings without acknowledging the perspective or biases that may be inherent in other researchers' designs or the politics of the time. This viewpoint may in fact further marginalize and oppress the population that it seeks to research, as highlighted by the greater involvement of people with HIV/AIDS (GIPA) principle, by assuming that values of individualism and political "neutrality" are correct for everyone and for every problem. A critical framework posits that the complexity of the issues at hand need to be captured, as well as acknowledging the societal and historical forces shaping these beliefs (Prilleltensky, 1989).

It is therefore necessary to re-examine from a critical perspective HIV-related stigma within the health care system in light of these new developments. The current study seeks to examine the current range of attitudes, behaviours, and cognitions held by health care providers about people living with HIV from the perspectives of health care providers, medical and nursing students, men living with HIV, and women living with HIV.

\section{Effects of HIV-related stigma}

HIV-related stigma affects numerous areas of functioning for people living with HIV. HIV-related stigma negatively impacts quality of life for people living with HIV (Herek et al., 2002), the effectiveness of prevention efforts (Brown, Trujillo, \& Macintyre, 2001), and the structural and institutional policies that govern daily life for people living with HIV, such as 
HEALTH CARE PROVIDERS AND HIV

regulations around disclosure and criminalization of non-disclosure to sexual partners (Klitzman et al., 2004). The threat of HIV-related stigma can decrease the likelihood that a person living with HIV will disclose his or her status to family members and friends, thereby also decreasing the likelihood he or she will be able to access strong networks of positive social support in times of distress and ill health (Derlega, Winstead, Greene, Serovich, \& Elwood, 2004; Peretti-Watel et al., 2006). Additionally, perceived stigmatization may reduce adherence to medication regimens (Peretti-Watel et al., 2006) and other health promoting behaviours specific to HIV (such as regular HIV clinic visits, regular condom use, and not breastfeeding after childbirth), as these behaviours may inadvertently disclose HIV status and therefore engender stigmatization (Greig et al., 2008; Kebaabetswe, 2007; Varga \& Brookes, 2008).

Stigmatization after disclosure is associated with a decrease in social support (Emlet, 2006), as well as decreased mental health, well-being and quality of life (Freeman, Nikomo, Kafaar, \& Kelly, 2007; Herek et al., 2002; Logie \& Gadalla, 2009). Beyond social support, HIVrelated stigma may reinforce gender stereotypes and patriarchal power dynamics where women cannot negotiate safer sexual practices in male-privileged societies (Dworkin \& Ehrhardt, 2007; Greig et al., 2008; Skovdal, Campbell, Nyamukapa, \& Gregson, 2011; Thorsen, Sundby \& Martinson, 2008). Perceived stigmatization from health care providers also decreases the likelihood that people living with HIV will access appropriate and adequate health care (Kinsler et al., 2007). The impact of HIV-related stigma is well-documented and detrimental to the lives of people living with HIV (e.g., Emlet, 2006; Freeman et al., 2007; Herek et al., 2002).

\section{Health care providers and HIV-related stigma}

As the nature of the HIV/AIDS pandemic changes over time, and people living with HIV can live for a full lifetime with appropriate care (UNAIDS, 2010), the nature of the relationship 


\section{HEALTH CARE PROVIDERS AND HIV}

between people living with HIV and their health care providers has also changed. With HIV now a chronic as opposed to an acute and fatal illness, the relationship with health care providers is all the more important, as more ongoing contact will occur. Additionally, with the illness being reconceptualized as chronic, this means people living with HIV need to be seen in different ways, as the delivery of health care impacts how people living with HIV live and interact on a daily basis. The relationship with health care personnel is extremely important to people living with HIV (Mill et al., 2010; Wagner et al., 2010).

Most medical and nursing students who are currently in training to become physicians and registered nurses in countries with advanced health care systems will see their HIV-positive patients live a full lifespan. For example, the introduction of combination antiretroviral therapy and the development of pregnancy guidelines for women living with HIV have hugely impacted the mortality rate for people living with HIV and the vertical transmission rate of HIV, respectively (UNAIDS, 2010). Coupled with medical and policy advances, current research on the perceptions of people living with HIV regarding stigma indicate that stigmatizing attitudes held by and displayed in interactions with health care providers are of particular concern (e.g., Kinsler et al., 2007; Wagner et al., 2010). While HIV-related stigma has been documented in the health care system, determining the full range of attitudes and behaviours is important, as perhaps not only the presence of overtly negative indicators is important, but potentially the lack of positive indicators as well, such as provider behaviours that are interpreted as caring and supportive. Additionally, identifying attitudes that are perceived as positive is extremely important as targets for intervention to increase their frequency and potency.

HIV-related stigma is experienced and defined differently for people living with HIV versus for individuals who are HIV-negative (Link \& Phelan, 2001; Parker \& Aggleton, 2003). 
HEALTH CARE PROVIDERS AND HIV

Further, populations of HIV-negative individuals may be general community members or a more specific population such as health care providers to people living with HIV. For example, health care providers are obligated to provide care, but yet many may have attitudes that could interfere with giving the best possible care, including creating an environment that supports good mental as well as physical health for people living with HIV. Examining HIV-related stigma specifically in reference to health care providers is therefore extremely important.

\section{Current Study}

The goal of the current study is to develop a comprehensive, current view of the perceived attitudes and beliefs held by health care providers towards people living with HIV, examined from a critical perspective focusing on power dynamics between patient and provider. A qualitative approach is employed to ensure new information is gathered regarding the range of attitudes and beliefs held by health care providers about HIV at present, instead of relying on established quantitative research with health care providers some 15 years ago. HIV, as a relatively recently defined "chronic" illness, has historically elicited stigmatizing attitudes far beyond those towards other chronic illnesses, such as diabetes or other sexually transmitted infections. The current study will examine whether or not, and in what ways, this stigmatization continues to exist.

\section{Methods}

\section{Participants}

A total of 26 participants were recruited for the focus groups. The groups consisted of 1) women living with HIV (five participants), 2) men living with HIV (six participants), 3) HIV health care providers (six participants), and 4) medical and nursing students (nine participants).

To be included in the study, participants in all groups could be any age and had to speak English 


\section{HEALTH CARE PROVIDERS AND HIV}

well enough to conduct a conversation. Participants in the women living with HIV group had to meet the following inclusion criteria: self-identify as female (cisgender or transgender) and selfidentify as being HIV-positive. Participants in the men living with HIV group had to meet the following inclusion criteria: self-identify as male (cisgender or transgender) and self-identify as being HIV-positive. Participants in the HIV health care provider group had to meet the following inclusion criteria: in a profession that provides clinical services to people living with HIV (e.g., medicine, nursing, midwifery, psychology, support workers) and have been providing services for at least two years. Participants were excluded from this group if they were still trainees or had not been providing services for at least two years. Finally, participants in the medical and nursing student group also had to meet the following inclusion criterion: enrollment in a medical or nursing degree program for at least one year.

Targeted recruitment techniques were used to recruit participants. These techniques included focused emails through key informants (consisting of medical providers with expertise in infectious diseases, people living with HIV with research experience, and AIDS Service Organization employees and volunteers), and email distribution to AIDS Service Organization listserv and student networks. Group recruitment had two aims: 1) relative homogeneity in terms of one common characteristic, and 2) heterogeneity within that group of shared experience. The four groups had the following distinct shared lived experiences: 1) the lived experience of being a woman living with HIV, 2) the lived experience of being a man living with HIV, 3) the experience of being a health care provider, and 4) the experience of being a health care trainee. The importance of recruiting a range of opinions across groups, and separating providers from patients and from trainees, was intended to acknowledge the power dynamics inherent in these designations, and to address them structurally to allow maximum freedom of expression within 


\section{HEALTH CARE PROVIDERS AND HIV}

the groups. Recruitment efforts also intended to create heterogeneity within the groups by recruiting for all ages, all ethnicities, all socio-economic brackets, and within the provider group, all professions and gender orientations. Additionally, aiming for maximum variation within the groups aimed to capture the variety and range of experiences held by individuals with a common characteristic (e.g., Marshall, 1996). In order to capture all of these perspectives, a range of recruitment techniques were used. AIDS service organization listservs reach a diverse crosssection of both people living with HIV as well as providers and trainees. Student organization listservs were chosen because they reach all students in certain programs. Finally, targeted recruitment emails serve to ensure specific groups who may be less inclined to participate from larger email listservs feel welcome and encouraged to participate.

\section{Procedure}

The study took place in a quiet and private seminar room on an urban university campus with the first author and a research assistant present. Participants provided informed consent after having heard the benefits and risks of participating (see Appendix A). The focus groups lasted between 60 and 75 minutes and were audiotaped. The focus groups were each posed four openended questions with additional probing by the first author (as facilitator) to encourage discussion and to further elucidate points (see Appendix B for focus group questions). Participants were debriefed at the end of the session (see Appendix C). All participants were compensated $\$ 35$ for their time as well as $\$ 15$ for travel and childcare costs (for a total of $\$ 50$ per participant). The study was approved by Ryerson University's Research Ethics Board.

\section{Lens and Data Coding}

Quantitative research about HIV uses a positivist perspective that assumes the researcher has a value-neutral position and that the truth is measurable as long as the methods are rigorous 


\section{HEALTH CARE PROVIDERS AND HIV}

(Prilleltensky, 1989). This approach, however, does not capture the complexity of HIV as a social problem, and the factors that influence the experience of HIV-stigma, including social injustice and structural factors, as described previously (e.g., Mahajan et al., 2008; Parker \& Aggleton, 2003). As described earlier, a critical psychology framework encourages acknowledgment that researchers have their own values, and that the topics being studied are laced with inherent questions regarding values (Fox, Prilleltensky, \& Austin, 2009). A critical framework views mainstream psychology in North America as being satisfied with the status quo. This status quo, which embodies an individualized, apolitical and self-improving approach to research and practice, does not reflect society. Depoliticizing the topic of HIV by assuming a "value-neutral" stance as a researcher ignores the biases and underlying factors influencing research and conclusions drawn. Such politics may determine the thrust of the literature due to decisions on what research gets funded and published, at the very minimum (Fox et al., 2009; Prilleltensky, 1989).

A critical framework suggests the use of immersion/crystallization thematic analysis of the data that allows for theme development from the data itself as opposed to preemptively imposing themes on the data (Madill, Jordan, \& Shirley, 2000). These themes are created with the knowledge that the researcher approaches the data with a lens acknowledging power differences, social injustice, and the likelihood that the status quo is not helpful for the population in question, namely the marginalized population of people living with HIV (Prilleltensky, 1989). The use of a strict coding scheme may overlook themes not already defined in a coding manual, hence replicating the problems found with the positivist approach, which has been criticized for not allowing for the complexity of the data to emerge (Madill et al., 2000). For critical theory, imposing such a structure on the data could temper the conclusions drawn 


\section{HEALTH CARE PROVIDERS AND HIV}

from the data, and hence perpetuate a potentially unidimensional, value-laden view derived from the literature, without the benefit of having had that value-laden view actually being defined or examined critically (Prilleltensky, 1989).

Focus groups are typically used to determine the validity of some construct and its components (e.g., HIV stigma and the description of discrimination, stereotyping and prejudice), and to provide specific examples of such incidents by means of discussion and interaction between the participants (Kitzinger, 1995). In the context of a critical framework, focus groups elicit multiple different viewpoints, allowing for multiple understandings of the phenomenon to be examined. In the current study, those sources of information are medical and nursing students, health care providers, men living with HIV and women living with HIV.

The transcripts of the focus groups were coded thematically by the author and another graduate student using an immersion/crystallization approach to thematic analysis with a critical lens paying attention to context, inequality and social injustice. Analyses were first done by hand and were subsequently entered into NVivo (QSR International Pty Ltd. Version 10, 2012). The immersion/crystallization approach to data analysis involves the researcher immersing him or herself into the data, taking time to understand the themes that are therein, and emerging after reflection with a crystallized interpretation and results (Borkan, 1999). Key to the utilization of the immersion/crystallization approach is the researcher's openness to uncertainty, reflection and experience that the data may provide insights and the researcher interpretations previously unconsidered (Borkan, 1999).

Approaching immersion/crystallization from a critical lens communicates that the researcher brings their own values and bias into the process, particularly highlighting and paying attention to themes of power differences and social injustice (Fox et al., 2009). The researcher is 


\section{HEALTH CARE PROVIDERS AND HIV}

not removed from the data, but rather engages with the material and monitors their own emotional responses, while the data is not only the transcript of the recording but also the researcher's experience of the data (focus groups) (Borkan, 1999). The interpretations were formed in terms of themes. The author acknowledged that her bias reflected a belief that HIVrelated stigma likely exists in the healthcare system, and that this bias was derived from ongoing work and connection with individuals living with HIV and their stories of healthcare engagement. Additionally, the author acknowledged a bias that psychology as a discipline teaches acceptance of a scientific, positive view of reality which may hinder a full understanding of the complexity of HIV stigma should the status quo be accepted as truth and reality.

The process of immersion/crystallization was iterative, including description and crystallization of ideas throughout data collection (Borkan, 1999). During exploration of the data after collection, immersion and crystallization of insights occurred, as well as explanation and creative synthesis and the consideration of alternatives (Borkan, 1999; Thurston, Cove, \& Meadows, 2008). After theme crystallization, member checking occurred by engaging in an iterative process of theme refinement with a reference group (consisting of the first author, a $\mathrm{PhD}$ level psychologist with over 15 years of HIV clinical and research experience, a woman living with HIV with over a decade of involvement in HIV research, two graduate students and an undergraduate-level research assistant with training in HIV research). Member checking facilitated a check of the author's biases, to ensure that while a critical perspective was maintained, that conclusions drawn were not biased beyond the scope of the data. Validity of the research, defined as the strength and veracity of the procedure and outcomes, was established by the rigour and intellectual honesty of the interpretations drawn (Borkan, 1999). 
HEALTH CARE PROVIDERS AND HIV

Gender-based analyses were considered for interpretation of the results, and many differences in experiences were noted in the reports of the participants. However, each of the focus groups also demonstrated significant intra-group differences, particularly based on ethnicity, geographic location of the participant, time since diagnosis, and degree of illness progression. Due to the small sample size, the results are therefore discussed as a whole, with emphasis on examples from each of the groups aimed to expose these differences, similarities and overlapping constructs.

\section{Results}

Two distinct categories of themes emerged from the data: 1) Components of Stigma, and 2) HIV-Specific Experiences. The Components of Stigma category has four elements:

Discrimination, Stereotyping, Prejudice and Institutional Factors. These elements describe the ways in which stigma is displayed and the components that comprise the perception of "stigma" as a construct. The HIV-Specific Experiences category consists of ten themes and describes specific types of experiences and occurrences unique to HIV. The categories and themes are summarized in Table 1. Both categories and each theme existed across all four participant groups. 
Table 1. Categories and themes.

\begin{tabular}{|c|c|}
\hline \multicolumn{2}{|r|}{ Components of Stigma } \\
\hline Component & Description \\
\hline $\begin{array}{l}\text { Discrimination } \\
\text { (presence and effects) }\end{array}$ & $\begin{array}{l}\text { a) Health care providers avoiding interaction with HIV+ } \\
\text { patients; Health care providers discriminate } \\
\text { b) Separating HIV+ individuals as different than people who are } \\
\text { HIV- } \\
\text { c) Upsetting witnessing others discriminate; Negative } \\
\text { consequences of discrimination }\end{array}$ \\
\hline $\begin{array}{l}\text { Stereotypes (contraction } \\
\text { and transmission) }\end{array}$ & $\begin{array}{l}\text { a) Gay men stereotype (all people who have HIV are gay men); } \\
\text { Love triangle stereotype (Men have sex with other men in secret } \\
\text { and then transmit it to their female partners); Risk-taking } \\
\text { stereotype; Children in Africa stereotype (idea that people who } \\
\text { have HIV are children in Africa); Sex worker stereotype; Drug } \\
\text { user stereotype } \\
\text { b) Rejecting stereotypes of who has HIV; HIV is inclusive; } \\
\text { Many groups are affected by HIV; Dismissal of stereotypes of } \\
\text { assumed mode of transmission; Dismissal of risk-taking } \\
\text { stereotype; Many factors leading to someone contracting HIV; } \\
\text { Assuming someone is HIV-, therefore for example not asking } \\
\text { the right questions } \\
\text { c) Stereotype of assumed mode of transmission (i.e., anal } \\
\text { intercourse); Acknowledgement of blood transfusion as mode of } \\
\text { transmission }\end{array}$ \\
\hline Prejudice & $\begin{array}{l}\text { a) Attitudes that are prejudicial towards people living with HIV } \\
\text { b) Job versus personal beliefs (Health care providers will do } \\
\text { their job despite their own personal beliefs); Equality } \\
\text { responsibility (Health care providers must treat all patients } \\
\text { equally); Providers should not hold opinions about their patients } \\
\text { c) Fear about HIV; Fear leading to stigma } \\
\text { d) Anger towards people who, they assume, knowingly put } \\
\text { people at risk of contracting HIV; Resentment towards people } \\
\text { who "do this to themselves" } \\
\text { e) Dismissal of assumption people are wholly responsible for the } \\
\text { contraction of HIV }\end{array}$ \\
\hline Institutional factors & $\begin{array}{l}\text { a) Institutional/community policies that can be interpreted as } \\
\text { othering; Hiring discrimination; Stigma across settings (e.g., } \\
\text { hospitals, clinics, independent doctors' offices); Undue emphasis } \\
\text { within institutional context (HIV highlighted more than is } \\
\text { necessary in the institutional context) } \\
\text { b) Stereotypes propagated by the educational system; } \\
\text { Stereotypes in the media (about who has HIV) } \\
\text { c) Location such as urban versus rural impacting experience of } \\
\text { living with HIV } \\
\text { d) Providers use inaccessible language that ends up being }\end{array}$ \\
\hline
\end{tabular}




\begin{tabular}{|c|c|}
\hline & $\begin{array}{l}\text { alienating for patients; There is not enough accessible } \\
\text { information for patients } \\
\text { e) Involvement in different aspects of care and research } \\
\text { f) Time equates to change and lack of change in attitudes; } \\
\text { Positive societal/temporal change in attitudes (Positive changes } \\
\text { in attitudes over time in society; Reduction of fear; HIV is not as } \\
\text { fear-provoking as it once was } \\
\text { g) If a patient had an earlier diagnosis of HIV, may have } \\
\text { experienced more overtly stigmatizing situations }\end{array}$ \\
\hline \multicolumn{2}{|r|}{ HIV-Specific Experiences } \\
\hline Theme & Description \\
\hline $\begin{array}{l}\text { Patient experiences } \\
\text { influencing subsequent } \\
\text { health care interactions }\end{array}$ & $\begin{array}{l}\text { a) Patient assumption of negative health care provider attitudes; } \\
\text { Patient defensiveness or resistance (Patient is defensive with } \\
\text { providers) } \\
\text { b) Approach of both the patients and the provider will interact } \\
\text { and mutually influence the others' attitude and opinion } \\
\text { c) Patient's experience will depend on how long it has been } \\
\text { since diagnosis and the amount and quality of provider } \\
\text { interaction they have had } \\
\text { d) Patients need to be their own advocates and if they are } \\
\text { sick/cannot be for any reason, they are put at a disadvantage and } \\
\text { made vulnerable } \\
\text { e) Negative experiences with providers leading to risky } \\
\text { behaviours such as not getting tested }\end{array}$ \\
\hline $\begin{array}{l}\text { Individual needs and } \\
\text { quality of life }\end{array}$ & $\begin{array}{l}\text { a) Acknowledgement of the whole person, rather than simply a } \\
\text { focus on the diagnosis of HIV as the individual's defining } \\
\text { feature; Huge emotional impact on the patient; } \\
\text { Acknowledgement of psychological impact on patients; Cultural } \\
\text { differences between people } \\
\text { b) Need support for patients } \\
\text { c) It is not one big community - different populations, don't all } \\
\text { need the same resources, etc. }\end{array}$ \\
\hline Knowledge & $\begin{array}{l}\text { a) We do not yet know everything about HIV } \\
\text { b) Increase provider knowledge; Providers have more HIV } \\
\text { knowledge now than they have had in the past; Prior generation } \\
\text { of providers not wanting to integrate new knowledge/attitudes; } \\
\text { New generation of providers integrating new } \\
\text { knowledge/attitudes; less knowledge = potential for more } \\
\text { prejudice) }\end{array}$ \\
\hline $\begin{array}{l}\text { Cycles of stigma - } \\
\text { temporal and } \\
\text { perpetuating factors }\end{array}$ & $\begin{array}{l}\text { a) Discrimination occurs less due to judgment from others } \\
\text { b) Subtlety of stigma can be insidious } \\
\text { c) Not acknowledging that stigma exists, or its prevalence } \\
\text { d) Need to break the cycle to prevent stigma from increasing } \\
\text { e) Stigma existed previously and continues to } \\
\text { f) There are multiple forms of stigma affecting individuals who } \\
\text { are HIV+ }\end{array}$ \\
\hline
\end{tabular}




\begin{tabular}{|c|c|}
\hline $\begin{array}{l}\text { Positive provider } \\
\text { attributes }\end{array}$ & $\begin{array}{l}\text { a) Providers can be open-minded, compassionate, understanding, } \\
\text { knowledgeable, tolerant; positive actions by providers } \\
\text { b) HIV care is now focusing on prevention efforts; testing } \\
\text { advocated for all; harm reduction } \\
\text { c) Health care providers can advocate for their patients }\end{array}$ \\
\hline $\begin{array}{l}\text { Beliefs about } \\
\text { susceptibility }\end{array}$ & $\begin{array}{l}\text { a) Health care providers need extra protection to protect against } \\
\text { HIV infection; Reasoning that health care providers and others } \\
\text { need to be protected from HIV } \\
\text { b) Someone who is HIV+ is more likely to give you HIV than } \\
\text { someone who has another communicable disease is likely to give } \\
\text { you another disease } \\
\text { c) Contraction has a very high cost } \\
\text { d) Perception of low risk; Contraction through workplace } \\
\text { incident not likely; Dismissal of need for extra protection; No } \\
\text { need to protect self more with an HIV+ patient; Dismissal of } \\
\text { high transmission risk of HIV } \\
\text { e) Universal threat/precautions for health care providers; All } \\
\text { patients are potentially a threat/need to be guarded against for } \\
\text { transmission of illness }\end{array}$ \\
\hline $\mathrm{HIV}$ is & $\begin{array}{l}\text { a) HIV is a complex and chronic disease } \\
\text { b) Dismissal/HIV viewed as a peripheral issue; HIV is no longer } \\
\text { a major concern/major problem } \\
\text { c) Having HIV means you will inevitably die from it/dismissal } \\
\text { of this myth } \\
\text { d) All of an HIV+ patient's problems are related to HIV }\end{array}$ \\
\hline Discl & $\begin{array}{l}\text { a) It is not necessary to disclose being HIV+ by default } \\
\text { b) It is necessary to disclose to others } \\
\text { c) Positive or negative reactions to disclosure or patient request } \\
\text { for an HIV test } \\
\text { d) Disclosing patient's HIV status; not maintaining } \\
\text { confidentiality }\end{array}$ \\
\hline $\begin{array}{l}\text { Assumptions (and their } \\
\text { dismissal) }\end{array}$ & $\begin{array}{l}\text { a) Contraction of HIV due to a bad act; Conservative views; } \\
\text { Judgmental attitudes } \\
\text { b) Assuming people know of risks for contraction and act } \\
\text { despite these risks } \\
\text { c) Sex is taboo in society; Sex-phobic ideas and mandates }\end{array}$ \\
\hline $\begin{array}{l}\text { Experience working } \\
\text { with people living with } \\
\text { HIV }\end{array}$ & $\begin{array}{l}\text { a) Experience leading to comfort; More experience working with } \\
\text { HIV+ patients equates to increased comfort } \\
\text { b) Inexperience leading to tentativeness; Less experience } \\
\text { working with HIV+ patients equates to being tentative } \\
\text { c) Positive personal attitude change with experience; More } \\
\text { exposure to people living with HIV, more positive attitudes }\end{array}$ \\
\hline
\end{tabular}


HEALTH CARE PROVIDERS AND HIV

The following examples describe the categories, highlight the themes and describe their presentation in the groups:

\section{Components of Stigma}

The Components of Stigma category captures the cognitive, behavioural, emotional and institutional components of stigma, as well as their depiction and interpretation through the experience of the patients and providers. The Components of Stigma category has four themes within it, and is informed by the work of Earnshaw and Chaudoir (2009) and Mahajan and colleagues (2008), drawing on conceptualizations of individual level and institutional stigma.

The insidious nature and prevalence of stigma were discussed within these themes, and demonstrated by the quotes below:

"And for sure prejudice and stereotyping are much more present or prevalent, than discrimination right? ...not sure why, maybe because if you discriminate than other people might look badly upon you, like 'Why are you discriminating against that patient?' But if you think the thoughts, like prejudice and stereotyping, other people can't really say anything to you right?"

- Student

“...it can be very insidious, as opposed to you, you know, having your feelings about, 'Well, if this guy's HIV positive, he must be gay. I have to treat him, because I'm a health care provider, but bare minimum will do.' So... it can be that insidious, underlying, where you're not really overtly dismissing the person because they have HIV/AIDS, but you're not being as compassionate as you could be to someone else who's got...cancer."

- Health Care Provider

Discrimination. Discrimination by providers, as a behavioural act, was widely discussed, including acts of "othering" (creating an "us versus them" dynamic). All groups acknowledged that discrimination continues to be present and is a significant concern for people living with HIV. Women and men living with HIV gave examples of blatant acts of discrimination perpetrated by health care providers, and women in particular gave unique examples of discrimination around childrearing, childbearing and breastfeeding. The students spoke about their impression that discrimination was becoming more covert in the health care system. The 


\section{HEALTH CARE PROVIDERS AND HIV}

range of discriminatory behaviours encompassed overt and covert instances of discrimination,

with more recent examples of discrimination generally being more covert.

"when I thought I could be HIV positive, I went to her, and she said "You do not come here." She said "You have to go downtown, to a downtown clinic. That's where people with HIV or AIDS go, downtown." - Woman Living With HIV

"I remember a patient, wasn't directly mine, but she was HIV positive, but bordering on, like, two hundred. And she came in, with respiratory issues. And the precautions put on her were incredible. And they were exceeding the precautions that were designed to protect her, and they were above and beyond. And it took some education, on everyone's behalf, to get her stepped down, so visitors could come and see her, things like that. So that wasn't maliciously done." - Health Care Provider

"...the one guy in the ambulance kept looking at me, and angrily telling me I'm sick. And I kept saying, "I'm not sick. I'm HIV positive. I'm not -" (raises voice) "Yes, you're sick." And I just was like, 'Whoa."” - Man Living With HIV

"I had one experience where I was providing front line health care. And one of my coworkers said that the only patients she wouldn't work with were, ah, people who were HIV positive. I didn't tell her I was. (laugh)” — - Man Living With HIV

“...nurses don't go in to talk to them as often, or don't go in to do, I don't know, bathing, or like anything that requires interaction with the patient, other than giving meds, which has to be on time... And it's very subtle, cause when you're busy, you don't notice these things. But as a student, when you sit around and you kind of observe the different nurses and their attitudes, you start to see these little things and it's kind of, it's yeah, disheartening." - Student

Stereotypes. All groups discussed stereotypes, defined as cognitions about who contracts HIV, with different emphasis in the stereotypes placed on the sex of the person living with HIV. Particular emphasis was placed on assumption of mode of transmission of HIV. The groups also discussed the rejection of these stereotypes, and providers who did not engage in perpetuating them.

Stereotypes that came out across all groups that people living with HIV are: gay men, injection drug users (particularly if female), engage in risky behaviour, and/or are promiscuous. 


\section{HEALTH CARE PROVIDERS AND HIV}

Women living with HIV also discussed the stereotype they often faced that if you were married, you could not have contracted HIV.

"They always assume I'm a junkie. Because I'm a white girl, right? "What did you, oh did you use drugs?" And I have scars on my arms, and they always say "Oh, did you inject?" right? "Did you inject drugs?" Always. No matter what."

- Woman Living With HIV

"Yeah, there's still that loose, 'it's because of your loose morals." - Man Living With HIV

"They give us a case and we work through it. And I remember in my first year, it was the HIV positive patient was always a homosexual man. ... But the students, all, like some of the students in my class became very upset about that, and said there could be HIV positive women, and you can't just keep having this stereotype. So I think we're trying to move away, from the fact that HIV positive automatically means it's, you're dealing with a homosexual male. It could be a heterosexual male. It could be a heterosexual female, a homosexual female, anyone"

- Student

Prejudice. Prejudice was discussed in reference to emotionally valenced and emotionally loaded attitudes. Students and providers spoke about the obligation to treat patients equally, regardless of personal beliefs. This was discussed in the context of creating internal struggles with prejudice and fear. The prejudice was also expressed emotionally as fear, such as fear of not having enough knowledge, fear of being afraid of HIV transmission, and fear of harming the patient or other patients. All groups discussed the ideas of blame for contracting HIV, choice in behaviours, and taking responsibility for HIV. As within the stereotypes, examples were also given of dismissal of fear and rejection of feelings of resentment and anger of people living with HIV for contracting the virus.

"You're not supposed to be opinionated to begin with, 'cause you're health care providers."

- Health Care Provider

"[The doctor would]...Laugh at you, or just give you a sense that you're very lucky that they would bother to treat somebody like you." - Woman Living With HIV

"I think a lot of the emotions, whether it's anger or any other emotions, centralizes in, like fear, because they're rude to the patient or they look down on the patient because of 
HEALTH CARE PROVIDERS AND HIV

their fear of, um, getting HIV, or whatever their fear might be, relating to HIV or the patient [himself or herself]."

- Student

Institutional Factors. Institutional factors, as a category, are defined as the factors beyond the individual level of influence, the structural determinants of health. They are factors controlled by and implemented by a collection of individuals with their own entity as a structure and representing the practices and policies of the group, as opposed to each actor participating individually. These institutional factors, such as policies and procedures in hospitals and clinics with varying expertise in subgroups of people living with HIV, were discussed at length.

Providers and students spoke about institutional practices engendering discrimination, and not being aware that they are discriminating when procedures and protocol come from the institution. Stereotypes that are propagated by institutions and the media, such as all people living with HIV are men who have sex with men, were prevalent. Women and men living with HIV discussed the differences people living with HIV encounter in different facilities, such as certain hospitals, clinics, or organizations. They also spoke about the difference in experience in urban versus rural versus suburban care, and the vast majority felt most comfortable accessing services in urban centers. Additionally, date of diagnosis and time since diagnosis were discussed as major influences on the experience of people living with HIV and on their interactions with their providers. Individuals who were diagnosed with HIV closer to the beginning of the epidemic described not only more experiences of stigma, but also increased intensity, particularly when fear about the illness was rampant and information was scarce. Greater time since diagnosis also offered perspective and the ability to foster resiliency resources to cope with potentially stigmatizing interactions.

People living with HIV discussed the inaccessible language of medical information (and the assumption that everyone reads and speaks English) and a lack of appropriate and accessible 


\section{HEALTH CARE PROVIDERS AND HIV}

resources. These groups also discussed wanting involvement in their own health care decisions, as well as the need for access to mental health care and a focus by providers on quality of life for people living with HIV. The women's group spoke specifically about the isolation of being a woman living with HIV, and feeling as if the health care institutions and providers did not know how to deal with them, and that there are a lack of appropriate resources for women living with HIV. Students focused on discriminatory policies found in institutional settings, and discussed how they believed that advances were being made. The providers spoke about institutional requirements such as documenting HIV status, testing for HIV, and legal issues.

"It's not appropriate to overtly discriminate against people with HIV. But I think that there's probably a lot of systemic discrimination that still happens, and that people aren't aware of it."

- Health Care Provider

\section{HIV-Specific Experiences}

The HIV-Specific Experiences category captures the experience of the individual in terms of perspectives on susceptibility and disclosure. It examines the interaction between the patient and the provider, as well as the impact of knowledge and experience on this interaction. It also addresses the cyclical nature of stigma through individual perpetuation as well as temporally. The HIV-Specific Experiences category consists of ten themes:

Patient Attitudes and Experiences. Patient attitudes and experiences discussed the range of views held by patients regarding providers. These attitudes varied greatly, often with positive and negative examples within the same patient. Experiences with providers greatly influenced patient attitudes, particularly if early experiences with providers soon after HIV diagnosis were perceived as being stigmatizing. The interaction between the patient and the provider was central to this interpretation of provider attitudes, including patients believing they are being listened to by their provider, that time is being taken with them, and that they are seen 


\section{HEALTH CARE PROVIDERS AND HIV}

as whole people, rather than only as an HIV diagnosis. Assumptions that patients make, categorizing providers into larger frameworks of "stigmatizing" or "not stigmatizing", as well as entering interactions with providers assuming they will be stigmatized, and therefore influencing the interaction by being distrustful or interpreting neutral interactions as negative, were also highlighted.

Within this theme, patient attitudes towards providers changing over time was also discussed. Examples were given of some patients becoming empowered and taking ownership over their interactions with providers, regardless of their interpretation of provider attitudes. Other examples described patients feeling increasingly alienated by providers and distrustful of them due to their negative experiences. Patient vulnerability to providers' power and expertise was also discussed, and the nature of this vulnerability in light of patients' need to constantly, and forever, be in provider care when living with a chronic illness. Finally, examples of patients' internalized stigma were highlighted, and this internalized stigma impacts not only well-being, but also interactions and therefore services and care received from providers.

Women living with HIV and men living with HIV spoke about the power dynamic between providers and patients, and that previous negative experiences with providers had the possibility of causing negative interpretations and defensive reactions towards providers in future encounters.

"When you get any kind of judgment, then if you're positive, or gay or marginalized in any way, your guard is up. And you have to be more careful.”- Man Living With HIV

Individual Needs and Quality of Life. The importance of considering the whole person, as opposed to focusing exclusively or uniformly on the HIV diagnosis, was discussed at great length. Particularly important was a focus on quality of life, and being aware that while "protective" and "risk" behaviours are widely touted in HIV prevention and care, that the 


\section{HEALTH CARE PROVIDERS AND HIV}

experiences of individuals are more complex than these categories, and decisions around health are based on these individualized needs. Additionally, the notion that there is a homogenous "HIV+ community" was challenged. Rather, it was emphasized that there are many different subgroups and individuals with different concerns and needs living with HIV.

All groups discussed how people living with HIV have different experiences and many different factors influencing their overall quality of life. Key highlights from the providers' group were being aware of a multiplicity of issues a person with HIV may be facing, including basic problems such as finding housing and employment.

"It's not only that [having HIV], it's your mental health issues; it's your housing issues; it's your medication issues. It's the supports and services you need."

- Health Care Provider

The men living with HIV group discussed medication adherence. The women living with HIV group spoke extensively about a lack of support for women living with HIV, including a lack of peer support and lack of services specifically for women. The women's group also discussed cultural differences, specifically in relation to being of African, Caribbean, or Latina heritage.

Knowledge. The need for improved and increased health care provider knowledge and education about HIV and the factors influencing the experiences of people living with HIV were uniformly endorsed. Increased knowledge was frequently linked to better outcomes and experiences for people living with HIV, often being associated with increased acceptance and reduction in discomfort, confusion or unease.

Men and women living with HIV discussed how knowledgeable providers provided better care than those who were less knowledgeable about HIV, and that the majority of those who provided the best care were younger providers. Women living with HIV believed that there 


\section{HEALTH CARE PROVIDERS AND HIV}

was not enough specific knowledge about their needs. Both providers and students reiterated that more knowledge about HIV was better for providers, and that this knowledge increases the providers' comfort working with people living with HIV and reduces stigma.

"I'm not too sure, because these nurses are a little older, ah, I feel like they're less receptive, in terms of the new research, the new knowledge, they're kind of stuck in the past. I don't want to say stuck in the past, but I feel like that's hindering them from really accepting them as a patient."

- Student

Cycles of Stigma - Temporal and Perpetuating Factors. Providers and students emphasized that HIV stigma has changed over time. They discussed how prejudice and stereotyping are particularly insidious, but are a change from more overt discrimination, which used to contribute greatly to the cycle of stigma. All participants spoke of the need to break the cycle of stigma, both temporally and the perpetuating nature of the cycle of stereotyping, discrimination and prejudice. Men and women living with HIV highlighted that this cycle still exists, but that it becomes disrupted the more educated providers are about HIV. Additionally, both groups of men living with HIV and women living with HIV discussed the role of overlapping stigmas, such as homophobia and bias against injection drug users, in the cycle of HIV stigma.

"So I think that you know, hopefully we can move further in that direction, where people have less prejudices, and it leads to less of these stereotyping and discriminating behaviours. ... But I think that we, I think that we've got a long way to go still."

- Health Care Provider

Positive Provider Attributes. Despite descriptions of challenging interactions and attitudes, participants also gave many examples of providers exhibiting caring, non-judgmental and thoughtful care to their patients who are living with HIV. Participants gave examples of providers supporting prevention efforts and testing requests, and the need for sensitivity and respect around both of these activities. Participants also lauded health care providers taking an 
HEALTH CARE PROVIDERS AND HIV

active role in their patients' health and serving as advocates for them within the health care system.

Across groups, being compassionate, honest, making time for the patient, being nonjudgmental, and feeling comfortable with the patient were highlighted as positive provider attributes that impact patient care and experience.

"The first time I took him to the doctor, we stayed with the doctor for more than two hours."

- Woman Living With HIV

"I like the fact that my doctor will say "I don't know." If I have a question and he doesn't know, to me, that's the sign of a good doctor." - Man Living With HIV

Beliefs about Susceptibility. Beliefs about how susceptible people are to contracting HIV centered on discussions of the need for extra protection, or not, for health care providers and other patients who might come into contact with people living with HIV, despite people living with HIV not being a homogenous group. Whether or not HIV had a higher transmission risk than other infectious diseases, or behaving in a manner to "better be safe than sorry", was discussed, as well as the high personal cost of contracting HIV. Conversations around universal risk and threat noted the need to treat all patients with the same precautions. Beliefs about susceptibility to HIV and how to dispel myths related to ease of transmission were a central topic of discussion for the medical and nursing students.

"[Describing a colleague's actions] The doctor feels the need to take that, even just little bit of extra precaution [with HIV+ patients], even though it's not necessary."

- Health Care Provider

HIV is Complicated. The topic that HIV is a complicated illness with many different medically-related elements contributing to the experience of people living with HIV and their care was discussed substantially by all groups. The complexity and chronicity of the illness, as well as the rejection of the myth that "HIV is a death sentence", were highlighted. Women and 
HEALTH CARE PROVIDERS AND HIV

men living with HIV gave specific examples of particular co-occurring challenges, such as aging, childbearing and diabetes.

'Not enough doctors are saying 'you're going bald because you're fifty now', not just because of your AIDS."

- Man Living With HIV

Disclosure. The topic of disclosure, and questioning when and why patients need to or should disclose to providers, family, friends, and partners was discussed. Reactions and attitudes towards patients disclosing or requesting HIV tests were both discussed in positive and negative terms. Particularly concerning to the majority of participants was insensitivity to patient confidentiality and forced disclosure in the name of "safety", for example not putting other patients or providers "at risk" of contracting HIV through bodily fluids or blood by making the participant's HIV status public knowledge.

Men living with HIV and women living with HIV spoke about negative reactions they had experienced from health care providers after disclosing, or even suggesting that they might be, HIV positive. Women in particular spoke about disbelief from their providers, or dismissing their need for an HIV test. Men spoke about stigmatizing experiences and feeling judged for requesting HIV tests. Both groups of health care providers and students discussed that they agreed that disclosure should not be mandatory but rather serve a medical purpose.

"I disclosed to that doctor, as part of the work, and he literally just asked, questioned why I would disclose that. He had to sit down. Like, he was in shock."

- Man Living With HIV

Assumptions (and their dismissal). Assumptions held by providers and others, both about the character of people living with HIV, as well as about the level of understanding patients have or had about their own risk, were noted. Assumptions around sex, and seeing sex as being taboo, were highlighted. 
HEALTH CARE PROVIDERS AND HIV

Women and men living with HIV focused strongly on judgments regarding morality when discussing the assumptions they believed health care providers had towards people living with HIV. Providers and students made note that people who made assumptions often had more conservative and less open-minded points of view not unique to HIV.

"It's 'them, the people with HIV', but its 'them' because they did something wrong, you know? If there was no stigma, then you could easily realize that 'Oh, I could easily get HIV at any point. I would be one of "them"'

- Student

Experience Working with People Living with HIV. Experience was highlighted as having a major influence on attitudes of providers working with people living with HIV. While discussed by all groups, increased experience leading to better outcomes and reduced stigma was a huge area of emphasis in the discussions with health care providers, and was also highlighted with the students. Having had less experience working with and exposure to people living with HIV was discussed as being associated with more stigmatizing attitudes and beliefs due to fear and misunderstanding. An emphasis on the positive, de-stigmatizing role of experience working with people living with HIV was highlighted by the health care providers.

"As time went by, I kind of forgot about the HIV status, I didn't forget but I just kind of interacted with him like I would interact with the other patients..." - - Student

\section{Discussion}

To fully investigate the attitudes, behaviours and cognitions of health care providers towards people living with HIV, data were collected from focus groups of not only providers themselves, but also from providers in training and from women and men living with HIV. Integrating the data in this manner allowed for multiple perspectives to be integrated and a range of attitudes, behaviours and cognitions to be considered (Borkan, 1999; Thurston et al., 2008). Additionally, the data collected did not focus solely on stigmatizing attitudes, behaviours and cognitions, but rather on a possible range of responses including positive characteristics, attitudes 


\section{HEALTH CARE PROVIDERS AND HIV}

and beliefs. This approach led to uncovering both negative and positive examples of provider attitudes, behaviours and cognitions.

The conceptualization of this study was done with a critical psychology lens. Challenging the health system's status quo is important when patients are distressed and feeling stigmatized by their providers (e.g., Ivanova, Hart, Wagner, Aljassem, \& Loutfy, 2012; Kinsler et al., 2007; Mill et al., 2010; Wagner et al., 2010) and HIV-related stigma is still rampant (Ogden \& Nyblade, 2005). Making sense of these findings within the larger context that both patients and providers conceptualize their beliefs and live in a world dictated by the status quo allows for a more complex and nuanced analysis of the attitudes, behaviours and cognitions of health care providers towards people living with HIV. A critical psychology framework can acknowledge the politicization of HIV and the oppressive societal structures affecting the lives of people living with HIV, as well as those dictating the professional and personal lives of the health care providers (e.g., Fox et al., 2009). This perspective enables a nuanced and contextually and temporally relevant examination of HIV stigma in the health care system, as has been called for in the literature (Earnshaw \& Chaudoir, 2009). These results suggest actionable outcomes such as the development of training modules for health care trainees to address the components of stigma established in this group, as well as to reduce the perpetuation of the cycle of stigma by intervening at an individual level to create larger structural change.

The elements and interactions that create the components of stigma were discussed in each group. The focus groups consisting of women living with HIV and men living with HIV reported overt historical instances of discrimination. Currently, overt acts of discrimination were less prevalent than in the past, and students in particular felt discriminatory behaviours were often hidden. All groups reported that these acts, however, are not necessarily decreasing, but 


\section{HEALTH CARE PROVIDERS AND HIV}

rather becoming comparatively more covert, and therefore still problematic for clinical care.

Stereotyping and prejudice were viewed as more insidious, and perpetuated by both the medical and educational establishments. Significant emphasis was placed on institutional factors, with providers noting continuing larger structural issues in the health care system perpetuating stigma, such as the continued emphasis on HIV status disclosure in emergency room settings. The explicit acknowledgement of these structural issues lends the possibility of future interventions empowering providers to act as agents of change in these same institutions.

The current study's findings support evidence that HIV stigma's perpetuation and presence in the health care system are not only still present, but that they continue to occur in settings where people living with HIV seeking care are most vulnerable, such as in an emergency or after diagnosis (Kinsler et al., 2007). Point of diagnosis varies for people living with HIV, particularly by gender, and may influence the experience of stigma. These findings support previous literature that people living with HIV are reporting HIV stigma, as are providers (e.g., Rosenburg, Taliaferro, \& Ercole, 2012). Fear about HIV/AIDS still exists, but experience and knowledge can mitigate that fear. Additionally, the findings support current conceptualizations of HIV stigma, including the impact of both individual level as well as institutional factors (Earnshaw \& Chaudoir, 2009; Mahajan et al., 2008). Actions now may be more covert, as opposed to overt acts in the past. The current study moves beyond these findings to highlight the need for effective stigma reduction in the present day, and the need to bolster positive provider attributes, which may help mitigate negative perceptions of interactions. Despite significant advances in HIV medical care, the eradication of HIV stigma in the health care system continues to persist. 


\section{HEALTH CARE PROVIDERS AND HIV}

The current study has numerous strengths which lend credence to its findings.

Community consultation and involvement was sought at each stage of study development and implementation. This involvement ensured the concerns and needs of the community were being addressed in the study questions, design and interpretation of the results, and that the study was conducted in a thoughtful, inclusive and non-stigmatizing manner. Additionally, the study design draws on an existing conceptualization of HIV stigma from the literature, and extends and tests it in practice. Unique groups were included in the study, allowing multiple perspectives to be considered and ensuring different conceptualizations of stigma from each perspective were included. The study's limitations include a small, self-selecting sample of participants, which limits the ability to draw general conclusions from subsets of the sample. Additionally, genderbased questions were not specifically asked in the focus groups, but were found to be important in reviewing the results. The study captured participants from urban settings, and further extension of the study to other areas such as rural settings and areas with greater Aboriginal representation may help to extend the generalizability and applicability of the findings. The use of focus groups instead of interviews allowed for more participants to share their views, but may have lacked the detail in experience available from each participant and group dynamics may have influenced how much or how little participants were willing to disclose in the session.

While capturing different perspectives due to the inclusion of multiple populations in the study, only a small number of groups were used, making the findings quite preliminary. Additionally, the providers who were captured in this study were predominantly front-line service providers. Future studies could benefit from a more diverse provider group, and to extend the findings into more groups, such as practicing providers. The findings from the current study can help future studies determine what aspects of HIV stigma are important to assess when 


\section{HEALTH CARE PROVIDERS AND HIV}

evaluating health care providers, such as presence of prejudicial attitudes, stereotypes and discriminatory behaviours, as well as being indicative of targets for the effective reduction of stigma within this group. For example, focusing on heightening positive interactions between providers and their patients who are living with HIV could serve to greatly reduce the perception that providers are stigmatizing their patients. Increasing knowledge regarding who contracts HIV, by what means, and increasing training for the effective care of all people living with HIV, not just men who have sex with men, will greatly serve to reduce discomfort for patients living with HIV, and may increase compassion and reduce fear and discriminatory behaviours among providers. Emphasis on the heterogeneity of the group "people living with HIV", particularly intra-group differences related to gender, sexual orientation, ethnicity, location, and time since diagnosis, and the differences in experience these variables may create for people living with HIV, are of utmost importance in provider training. Further sub-analysis based on gender and ethnicity would be warranted with additional focus groups in the future.

Drawing on the findings of the current study, future interventions to decrease HIV-related stigma in health care providers could draw on the concept of "stigma-informed care", similar to the concept of "trauma-informed" care within the health care system which acknowledges the potential existence of and impact of trauma on peoples' experiences (e.g., Elliott, Bjelajac, Fallot, Markoff, \& Reed, 2005; Harris \& Fallot, 2001; Ko et al., 2008), and "stigma-informed" prevention strategies for HIV which address barriers and needs within these services (e.g., Radcliffe, Doty, Hawkins, Gaskins, Beidas, \& Rudy, 2010). Trauma-informed care considers the effect of a trauma experience on an individual's presentation, perceptions, and interactions, and this knowledge is integrated into their clinical care and how they are treated and conceptualized as clients by providers (Elliott et al., 2005). Stigma-informed care would offer the same 


\section{HEALTH CARE PROVIDERS AND HIV}

consideration in relation to the experience of stigma on a person living with HIV's experience. This "stigma-informed care" would acknowledge the privilege and power of the health care provider in the interactional relationship with the client, and that many people living with HIV have, or will, experience stigma in relation to their diagnosis. This acknowledgement can help facilitate positive, thoughtful interactions, increase providers' reflection and self-awareness within their care to people living with HIV, and can open a space for the discussion and dispelling of fears and myths regarding HIV within training. This approach to care can be implemented at a structural level within training, and therefore may facilitate broader-based change (e.g., Gupta, Parkhurst, Ogden, Aggleton, \& Mahal, 2008).

In conclusion, it appears that HIV stigma continues to exist in the health care system, and that providers have a range of attitudes, behaviours, and cognitions towards people living with HIV. The components of stigma established in this study, prejudice, stereotyping, discrimination and institutional factors can be targeted for intervention in order to improve quality of care for those living with HIV. In the era of HIV being established as a chronic as opposed to an acute illness, it appears that attitudes, influenced by fear and lack of understanding, continue to create a stigmatizing experience for people living with HIV. This stigma creates an environment fraught

with risk, including risk of sub-optimal care, risk of reduced access and usage of care, and risk of mental health sequelae for people living with HIV. Therefore despite advances in the medical treatment of HIV, equivalent advances do not appear to have occurred in the elimination of stigma. Improvement needs to occur in the delivery of this care, and to address the unique nature of HIV and the stereotypes associated with it that determine the prejudices and discrimination being described. HIV, being a unique chronic disease with a history of incredible stigma, continues to elicit stigmatizing attitudes, behaviours, and cognitions in health care providers that 


\section{HEALTH CARE PROVIDERS AND HIV}

perpetuate the cycle of stigma. Eradicating this cycle is the next crucial step in improving HIV care. 
HEALTH CARE PROVIDERS AND HIV

\section{References}

Andany, N., \& Loutfy, M. R. (2013). HIV protease inhibitors in pregnancy. Drugs, 73, 229-247. doi: $10.1007 / \mathrm{s} 40265-013-0017-3$

Borkan, J. (1999). Immersion/Crystallization. In B.F. Crabtree \& W.L. Miller (Eds.), Doing qualitative research (pp. 179-194). Thousand Oaks, CA: Sage.

Brown, L., Trujillo, L., \& Macintyre, K. (2001). Interventions to reduce HIV/AIDS stigma: what have we learned? New York: The Population Council Inc.

Derlega, V. J., Winstead, B. A., Greene, K., Serovich, J., \& Elwood, W. N. (2004). Reasons for HIV disclosure/nondisclosure in close relationships: Testing a model of HIV-disclosure decision making. Journal of Social and Clinical Psychology, 23, 747-767. doi: $10.1521 /$ jscp.23.6.747.54804

Dworkin, S. L., \& Ehrhardt, A. A. (2007). Going beyond “ABC” to include "GEM": Critical reflections on progress in the HIV/AIDS epidemic. American Journal of Public Health, 97, 13-18. doi: 10.2105/AJPH.2005.074591

Earnshaw, V. A., \& Chaudoir, S. R. (2009). From conceptualizing to measuring HIV stigma: a review of HIV stigma mechanism measures. AIDS and Behavior, 13, 1160-1177. doi: $10.1007 / \mathrm{s} 10461-009-9593-3$

Elliott, D.E., Bjelajac, P., Fallot, R.D., Markoff, L.S., \& Reed, B.G. (2005). Trauma-informed or trauma-denied: Principles and implementation of trauma-informed services for women. Journal of Community Psychology, 33, 461-477. doi: 10.1002/jcop.20063

Emlet, C. A. (2006). An examination of the social networks and social isolation in older and younger adults living with HIV/AIDS. Health \& Social Work, 31, 299-308. doi:

$10.1093 / \mathrm{hsw} / 31.4 .299$ 


\section{HEALTH CARE PROVIDERS AND HIV}

Fox, D., Prilleltensky, I., \& Austin, S. (2009). Critical psychology for social justice: concerns and dilemmas. In D. Fox, I. Prilleltensky, \& S. Austin (Eds.), Critical psychology: An introduction (pp. 3-19). Thousand Oaks, CA: Sage.

Freeman, M., Nikomo, N., Kafaar, Z., \& Kelly, K. (2007). Factors associated with prevalence of mental disorder in people living with HIV/AIDS in South Africa. AIDS Care, 19, 12011209. doi: 10.1080/09540120701426482

Greig, A., Peacock, D., Jewkes, R., \& Msimang, S. (2008). Gender and AIDS: time to act. AIDS, 22(suppl 2), S35-S43. doi: 10.1097/01.aids.0000327435.28538.18

Gupta, G.R., Parkhurst, J.O., Ogden, J.A., Aggleton, P., \& Mahal, A. (2008). Structural approaches to HIV prevention. The Lancet, 372, 764-775. doi: 10.1016/S01406736(08)60887-9

Harris, M., \& Fallot, R.D. (2001). Envisioning a trauma-informed service system: a vital paradigm shift. New Directions for Mental Health Services, 89, 3-22. doi: $10.1002 / y d .23320018903$

Herek, G. M., Capitanio, J. P., \& Widaman, K. F. (2002). HIV-related stigma and knowledge in the United States: prevalence and trends, 1991-1999. American Journal of Public Health, 92, 371-377. doi: 10.2105/AJPH.92.3.371

Ivanova, E. L., Hart, T. A., Wagner, A. C., Aljassem, K., \& Loutfy, M. R. (2012). Correlates of anxiety in women living with HIV of reproductive age. AIDS and Behavior, 16, 21812191. doi: 10.1007/s10461-001-0133-6

Kebaabetswe, P. M. (2007). Barriers to participation in the prevention of mother-to-child HIV transmission program in Gaborone, Botswana: a qualitative approach. AIDS Care, 19, 355-360. doi: 10.1080/09540120600942407 


\section{HEALTH CARE PROVIDERS AND HIV}

Kinsler, J. J., Wong, M. D., Sayles, J. N., Davis, C., \& Cunningham, W. E. (2007). The effect of perceived stigma from a health care provider on access to care among a low-income HIVpositive population. AIDS Patient Care and STDs, 21, 584-592. doi:

10.1089/apc.2006.0202

Kitzinger, J. (1995). Introducing focus groups. BMJ: British Medical Journal, 311, 299-302. doi: 10.1136/bmj.311.7000.299

Klitzman, R., Kirshenbaum, S., Kittel, L., Morin, S., Daya, S., Mastrogiacomo, M., \& RotheramBorus, M. J. (2004). Naming names: perceptions of name-based HIV reporting, partner notification, and criminalization of non-disclosure among persons living with HIV. Sexual Research \& Social Policy: Journal of NSRC, 1, 38-57. doi: $10.1525 /$ srsp.2004.1.3.38

Ko, S.J., Ford, J.D., Kassam-Adams, N., Berkowitz, S.J., Wilson, C., Wong, M., ... \& Layne, C.M. (2008). Creating trauma-informed systems: child welfare, education, first responders, health care, juvenile justice. Professional Psychology: Research and Practice, 39, 396-404. doi: 10.1037/0735-7028.39.4.396

Link, B. G., \& Phelan. J. C. (2001). Conceptualizing stigma. Annual Review of Sociology, 27, 363-385. doi: 10.1146/annurev.soc.27.1.363

Logie, C., \& Gadalla, T. M. (2009). Meta-analysis of health and demographic correlates of stigma towards people living with HIV. AIDS Care, 21, 742-753. doi: $10.1080 / 09540120802511877$

Logie, C.H., James, L., Tharao, W., \& Loutfy, M.R. (2012). HIV, Gender, Race, Sexual Orientation, and Sex Work: A Qualitative Study of Intersectional Stigma Experienced by 


\section{HEALTH CARE PROVIDERS AND HIV}

HIV-positive Women in Ontario, Canada. PLoS Medicine, 8, e1001124. doi:

10.1371/journal.pmed.1001124

Madill, A., Jordan, A., \& Shirley, C. (2000). Objectivity and reliability in qualitative analysis: realist, contextualist and radical constructionist epistemologies. British Journal of Psychology, 91, 1-20. doi: 10.1348/000712600161646

Mahajan, A. P., Sayles, J. N., Patel, V. A., Remien, R. H., Ortiz, D., Szekeres, G., \& Coates, T. J. (2008). Stigma in the HIV/AIDS epidemic: A review of the literature and recommendations for the way forward. AIDS, 22, S67-S79. doi: 10.1097/01.aids.0000327438.13291.62

Marshall, M.N. (1996). Sampling for qualitative research. Family Practice, 13, 522-525. doi: 10.1093/fampra/13.6.522

Mill, J.E., Edwards, N., Jackson, R.C., MacLean, L., \& Chaw-Kant, J. (2010). Stigmatization as a social control mechanism for persons living with HIV and AIDS. Qualitative Health Research, 20, 1469-1483. doi: 10.1177/1049732310375436

Ogden, J., \& Nyblade, L. (2005). Common at its core: HIV-related stigma across contexts. Washington, DC: International Center for Research on Women.

Parker, R., \& Aggleton, P. (2003). HIV and AIDS-related stigma and discrimination: a conceptual framework and implications for action. Social Science \& Medicine, 57, 13-24. doi: 10.1016/S0277-9536(02)00304-0

Peretti-Watel, P., Spire, B., Pierret, J., Lert, F., Obadia, Y., \& The Vespa Group. (2006). Management of HIV-related stigma and adherence to HAART: Evidence from a large representative sample of outpatients attending French hospitals (ANRS-EN12-VESPA 2003). AIDS Care, 18, 254-261. doi: 10.1080/09540120500456193 


\section{HEALTH CARE PROVIDERS AND HIV}

Prilleltensky, I. (1989). Psychology and the status quo. American Psychologist, 44, 795-802. doi: 10.1037/0003-066X.44.5.795

QSR International Pty Ltd. (2012). NVivo qualitative data analysis software, Version 10.

Radcliffe, J., Doty, N., Hawkins, L.A., Gaskins, C.S., Beidas, R., \& Rudy, B.J. (2010). Stigma and sexual health risk in HIV-positive African American young men who have sex with men. AIDS Patient Care and STDs, 24, 493-499. doi:10.1089/apc.2010.0020.

Reidpath, D.D., \& Chan, K.Y. (2005). A method for the quantitative analysis of the layering of HIV-related stigma. AIDS Care, 17, 425-432. doi: 10.1080/09540120412331319769

Rosenburg, N., Taliaferro, D., \& Ercole, P. (2012). HIV-related stigma among nursing students in Cameroon. Journal of the Association of Nurses in AIDS Care, 23, 170-176. doi: 10.1016/j.jana.2011.09.003

Skelton, J. A. (2006). How negative are attitudes towards persons with AIDS: examining the AIDS-leukemia paradigm. Basic and Applied Social Psychology, 28, 251-261. doi: 10.1207/s15324834basp2803_4

Skovdal, M., Campbell, C., Nyamukapa, C., \& Gregson, S. (2011). When masculinity interferes with women's treatment of HIV infection: a qualitative study about adherence to antiretroviral therapy in Zimbabwe. Journal of the International AIDS Society, 9, 29. doi: $10.1186 / 1758-2652-14-29$.

Thorsen, V. C., Sundby, J., \& Martinson, F. (2008). Potential initiators of HIV-related stigmatization: Ethical and programmatic challenges for PMTCT programs. Developing World Bioethics, 8, 43-50. doi: 10.1111/j.1471-8847.2008.00227.x 


\section{HEALTH CARE PROVIDERS AND HIV}

Thurston, W. E., Cove, L., \& Meadows, L. M. (2008). Methodological congruence in complex and collaborative mixed method studies. International Journal of Multiple Research Approaches, 2, 2-14. doi: 10.5172/mra.455.2.1.2

UNAIDS (2010). Report on the global HIV/AIDS epidemic 2010. Joint United Nations Programme on HIV/AIDS (UNAIDS), Geneva.

Varga, C., \& Brookes, H. (2008). Preventing mother-to-child HIV transmission among South African adolescents. Journal of Adolescent Research, 23, 172-206. doi: $10.1177 / 0743558407310771$

Wagner, A. C., Hart, T. A., Mohammed, S., Ivanova, E., Wong, J., \& Loutfy, M. R. (2010). Correlates of HIV stigma in HIV-positive women. Archives of Women's Mental Health, 13, 207-214. doi: 10.1007/s00737-010-0158-2

Worthington, C., \& Myers, T. (2003). Factors underlying anxiety in HIV testing: risk perceptions, stigma, and the patient-provider power dynamic. Qualitative Health Research, 13, 636655. doi: $10.1177 / 1049732303013005004$ 
HEALTH CARE PROVIDERS AND HIV

Study 2: Health Care Provider Attitudes and Beliefs about People Living with HIV - Initial Validation of the Health Care Provider HIV/AIDS Stigma Scale (HPASS)

Stigma is a socially constructed experience in which an aspect of the self is socially devalued (Goffman, 1963). Herek and Capitanio (1998) describe HIV stigma as "the prejudice, discounting, discrediting and discrimination directed at people perceived to have AIDS or HIV, their loved ones and associates and the groups and communities with which they are affiliated" (Herek \& Capitanio, 1998, p. 232). HIV stigma is an immense concern for those living with and affected by HIV, as it not only impacts quality of life for individuals living with HIV (Herek, Capitanio, \& Widaman, 2002), but also reduces positive social interaction (Emlet, 2006; PerettiWatel et al., 2006) and may impact adherence to medication regimes and access to health care services (Greig, Peacock, Jewkes, \& Msimang, 2008; Kebaabetswe, 2007). Providers are more likely to believe HIV stigma is not a concern if they have not had contact with patients living with HIV (Rosenburg, Taliaferro, \& Ercole, 2012), and perceived stigma from providers decreases the likelihood people living with HIV will access health care (Kinsler, Wong, Sayles, Davis, \& Cunningham, 2007). A recent survey at an urban Canadian university found that since the year 2000, there has been no decrease in fear regarding patients living with HIV among medical students, and sense of professional obligation to treat patients has decreased (Hoffart, Ibrahim, Lam, Minty, Theam, \& Schaefer, 2012). Clearly, a concerted effort to address the needs of people living with HIV by eradicating stigma in the health care system is essential to provide fair and just care.

Operationalized definitions of HIV stigma for health care providers are often ambiguous and inconsistent. The absence of a consistent operationalized definition, and tools to assess it, make measuring success in its eradication impossible. The inconsistent operationalization and 
HEALTH CARE PROVIDERS AND HIV

measurement of HIV stigma make it difficult to provide a strong empirical basis from which researchers and clinicians can develop models of mechanisms of action and to build effective HIV prevention and intervention programs (Devine et al., 1999; Mahajan et al., 2008). The current study aims to address this gap by operationally defining and measuring HIV stigma in health care provider trainees in Ontario, Canada.

\section{Divergent theories of HIV stigma}

The conceptualization of HIV stigma largely depends on the population being examined and for what purpose (e.g., Alonzo \& Reynolds, 1995; Deacon, 2006; Dowshen, Binns, \& Garofalo, 2009; Harrison et al., 1994; Mulford \& Lee, 1996; Pleck, O’Donnell, O’Donnell, \& Snarey, 1988). HIV stigma can be perceived and experienced, either internally or externally, by people living with HIV, and can be enacted by people who are HIV-negative (Link \& Phelan, 2001). A common thread, however, is the impact of social context on HIV stigma's development and maintenance. Herek and Capitanio's (1998) commonly cited definition of HIV stigma combines the cognitive process of prejudice with multiple forms of the behavioural act of discrimination on persons with HIV. Berger, Ferrans, and Lashley (2001) similarly offer a broad definition encompassing the perception of societal attitudes and personal experience, placing huge importance on social context.

Link and Phelan (2001) approach the conceptualization of HIV stigma in a more overtly theoretical manner compared to the applied and population-specific approaches of Herek and Capitanio (1998), and Berger and colleagues (2001). Link and Phelan (2001) suggest that four acts occur in a social context to create stigma: labeling, stereotyping, outgrouping (consisting of separation of the stigmatized group as "others" and status loss compared to non-others), and discrimination. This idea that multiple acts occur to create HIV stigma has been adopted and 
HEALTH CARE PROVIDERS AND HIV

integrated into more recent conceptualizations. Parker and Aggleton (2003) added that stigma occurs at the intersection of culture, power and difference, which is demonstrated by the groups most differentially affected by HIV (e.g., individuals involved in sex work, injection drug users, men who have sex with men). Link and Phelan's (2001) and Parker and Aggleton's (2003) descriptions both point to the interaction of structural conditions and social inequality as having led to HIV stigma.

\section{Individual-level model of HIV stigma}

Earnshaw and Chaudoir (2009), in their HIV Stigma Framework, discuss two different pathways to HIV stigma - one for HIV-negative individuals and one for HIV-positive individuals. Although understanding perceived and internalized HIV stigma from the perspective of HIV-positive individuals is ultimately extremely important to fully understand HIV stigma and its effects, the current analysis will focus on HIV stigma among HIV-negative individuals. From the theoretical standpoint of understanding HIV stigma from the position of an HIV uninfected individual, Earnshaw and Chaudoir (2009) delineated three mechanisms of action: prejudice, stereotypes and discrimination. Prejudice is operationally defined as an emotionally valenced attitude or reaction towards people living with HIV, stereotypes as the negative thoughts, cognitive schemas or beliefs regarding people living with HIV, and discrimination as the behavioural response to prejudicial reactions towards people living with HIV. Earnshaw and Chaudoir (2009) highlight the major outcomes associated with these mechanisms as being social distancing from people living with HIV, a lack of HIV testing, and the need for policy support to limit the expression of these mechanisms. For HIV-negative individuals, the theorized cognitive mechanism at play is the perceived threat to both health and morality associated with HIV. The 
HEALTH CARE PROVIDERS AND HIV

theory put forth by Earnshaw and Chaudoir (2009) is the culmination of an extensive and thorough review of the HIV stigma literature.

Collectively, the two pathways in Earnshaw and Chaudoir's (2009) model demonstrate how structural and social forces impact the individual on a sociocognitive level, defined as social processes influencing cognitive perceptions and interpretations, be the individual HIV-positive or HIV-negative. These individual experiences of stigma of one group interact to influence the experience of the other group.

\section{Structural-level model of HIV stigma}

Mahajan and colleagues (2008) posit that the individual sociocognitive perspective is necessary but not sufficient for a complete understanding of HIV stigma. Rather, the sociocognitive perspective needs to be integrated with the structural factors that influence HIV stigmatization as they relate to the self, society, and institutions, echoing Parker and Aggleton's (2003) discussion of HIV stigma as occurring at the confluence of culture, power, and difference. Mahajan and colleagues' (2008) theory argues that the complexity and diversity of HIV stigma in different cultural settings are what make it so difficult to tackle, and that without identifying the political, social, and economic dynamics that interplay to influence the sociocognitive factors, HIV stigma cannot be properly defined or eradicated. Mahajan et al. (2008) describe sociocognitive factors for HIV-negative individuals (their emotional reactions and attitudes, social distancing from HIV-positive individuals, and supporting coercive measures to ensure the unfair treatment of HIV-positive individuals) and HIV-positive individuals (perceived stigma and experienced stigma). These sociocognitive factors, in combination with their description of structural elements (being social processes and social inequality) create a dual-level framework, 


\section{HEALTH CARE PROVIDERS AND HIV}

described in Table 1. The current study therefore seeks to address structural-level influences on the individual health care provider and their expression of HIV stigma. 
HEALTH CARE PROVIDERS AND HIV

Table 1. Sociocognitive and structural factors (Mahajan et al., 2008).

Sociocognitive HIV-Negative Sociocognitive HIV-Positive $\quad$ Structural

\begin{tabular}{lll}
\hline Emotional Reactions/Attitudes & Perceived Stigma & Social Processes
\end{tabular}

Social Distancing $\quad$ Experienced Stigma $\quad$ Social Inequality

Support for Coercive

Measures 


\section{HEALTH CARE PROVIDERS AND HIV}

\section{HIV stigma and health care providers}

HIV stigma by health care providers has been defined in divergent ways, particularly in regard to the stigmatizing attitudes health care providers may have towards people living with HIV (e.g., Earnshaw \& Chaudoir, 2009; Logie \& Gadalla, 2009). This lack of consensus in the operationalization of HIV stigma among health care providers is demonstrated in the multitude of assessment tools used to attempt to measure HIV stigma. Early work in HIV necessitated an emergency research response to shift the care that was being received amongst patients who were not likely to survive, and was often not rooted in theory (e.g., Treichler, 1999). The vestiges of this rush, and therefore the creation and utilization of context-specific or population non-specific measures without full psychometric assessment and input from the community, coupled with theoretical development in the understanding of HIV stigma, have created multiple measures with multiple definitions of HIV stigma. Many stigma assessment tools have been created for a specific cultural context, the specific application or the desired outcome of the host study, or for the population being measured, and therefore items have often been created to fit the context or could be interpreted as extreme in another context. For example, Stein and Li (2008) created a scale specifically examining the HIV attitudes and behaviours of health care providers in China that is contextually very appropriate for the population it assesses, but may not necessarily generalize to other settings due to some items that may be interpreted as extreme, such as being fearful of patients living with HIV. The Multidimensional Stigma Scale (Stein \& Li, 2008) consists of five factors: Discrimination Intent at Work, Prejudiced Attitudes, Internalized Shame, Fear of AIDS, and Good Care for HIV patients. Comparatively, the AIDS Attitude Scale (AAS; Froman \& Owen, 1997), which has been used to examine the HIV attitudes and behaviours of nurses, is divided into two constructs: empathy and avoidance. 
HEALTH CARE PROVIDERS AND HIV

The unidimensional AIDS-Related Stigma Scale (Kalichman et al., 2005) was developed with a South African sample of HIV-negative community members. A recent paper published assessing HIV stigma amongst health care and social service providers in the United States utilized an amalgamation of two frameworks to assess stigma (Rutledge, White, Abell, Brown, \& Cesnales, 2011): a mindfulness model of stigma and Link and Phelan's four component model of labeling, stereotyping, outgrouping (a combination of loss of status and separation) and discriminating (Link \& Phelan, 2001).

If examined in the context of Earnshaw and Chaudoir's (2009) HIV Stigma Framework, acknowledging the scales' existence prior to the delineation of this model, the Multidimensional Stigma Scale (Stein \& Li, 2008) captures two of the three elements outlined in the HIV Stigma Framework for HIV-negative individuals: discrimination and prejudice. The AIDS-Related Stigma Scale (Kalichman et al., 2005) more fully adheres to Earnshaw and Chaudoir's (2009) model. The AIDS-Related Stigma Scale (Kalichman et al., 2005) captures prejudice, stereotypes, and discrimination in its measurement for HIV-negative individuals, specifically in a SubSaharan African context. The constructs of prejudice, stereotypes, and discrimination create a unidimensional factor structure. Rutledge and colleagues' (2011) measure does not specifically address prejudicial attitudes, but rather layers on another perspective of mindfulness which separates into its own subscale in the measure. The task for the current study is to determine the questions that need to be asked of participants to create a contextually appropriate tool in a Canadian health care provider context to achieve mutually distinct factor structures for prejudice, stereotypes, and discrimination.

Beyond concerns of operational definition, to fully address methodological rigour, scale development procedures should be closely followed. The current study follows the steps to scale 


\section{HEALTH CARE PROVIDERS AND HIV}

development and testing of theoretical structure recommended by Brown (2006), which are 1) expert consultation or group member survey to develop items, 2) development of a large pool of items that are presented back to the reference group of consultants/members for content and face validity check, 3) administration of the large pool of items to a sample of the population in question, 4) exploratory factor analysis to determine how many factors exist in the construct and which items need to be removed from the large pool of items to create a cohesive scale with independent factor loadings for each of the items, 5) test-retest reliability analysis, 6) convergent and divergent validity checks compared to scales assessing similar and different constructs, and 7) a confirmatory factor analysis to ensure the construct is stable.

In an effort to address the need for fair and just care for people living with HIV, the goal of the current study is to develop an HIV stigma scale (Health Care Provider HIV/AIDS Stigma Scale; HPASS) that rigorously assesses the attitudes, behaviours, and cognitions held by health care professionals towards people living with HIV and to examine its fit with the HIV stigma framework of stereotyping, prejudice, and discrimination (Earnshaw \& Chaudoir, 2009). The HPASS was developed from a ground-up approach, using focus group data, to ensure the unbiased current attitudes, behaviours, and cognitions of health care providers are captured, including any issues relevant to HIV as a chronic, as opposed to acute, illness. The HPASS aims to be a sensitive measure to ensure social desirability effects in responding are considered (Nyblade \& Kerry, 2006), and to be contextually relevant. It is hypothesized that the HPASS will have convergent validity with alternate measures of HIV stigma. 
HEALTH CARE PROVIDERS AND HIV

\section{Methods}

\section{Scale development}

Participants. A mixed-method study was conducted using both qualitative and quantitative approaches to create an empirically supported scale of HIV stigma from health care providers. Four focus groups were conducted with 1) HIV health care providers who had been providing care to people living with HIV for at least two years (i.e., physicians, nurses, midwives, psychologists, AIDS Service Organization case workers) $(n=6), 2)$ women living with HIV $(n=$ 5), 3) men living with HIV ( $=6)$, and 4) medical and nursing students who had been in their programs for at least one year $(n=9)$. Participants were recruited via targeted recruitment techniques (such as focused emails through key informants), as well as by email distribution to AIDS Service Organization listserv and student networks. The focus group sample is the same as the sample described in the first paper of this dissertation on page 6.

Procedure. The focus groups participants were each posed four open-ended questions with additional probing by the first author (as facilitator) to encourage discussion and further elucidate points. The focus groups were audiotaped and each lasted approximately 60 minutes. The participants provided informed consent to participate in the focus group and to be recontacted to provide feedback on the study outcomes, and were debriefed at the end of the session. The groups took place in a quiet and private seminar room at mid-size urban university. All participants were compensated $\$ 35$ for their time as well as $\$ 15$ for travel and childcare costs (for a total of $\$ 50$ per participant). Participants were re-contacted via email to provide feedback on the themes and items arising from the focus groups approximately ten weeks after the focus groups took place. 


\section{HEALTH CARE PROVIDERS AND HIV}

Conceptualization. The focus groups provided a pool of 93 potential questions to be used in the development of the scale. A critical psychology framework, which takes the perspective of challenging the societal status quo that embodies an individualized and apolitical approach to research and practice and denies inherent power structures in relationships, was used in the qualitative component of the study (Prilleltensky, 1989). This critical framework was used when formulating, asking, and analyzing the responses to the questions in the focus groups. The audiotapes of the focus groups were transcribed, and were analyzed by the first author and a graduate student using an immersion/crystallization approach (Borkan, 1999) to thematic analysis with a critical lens paying attention to context, power dynamics, inequality, and social injustice. An immersion/crystallization approach, fully described elsewhere (the first paper of this dissertation), involves the researcher immersing him or herself in the data without a preconceived thematic structure, acknowledging his or her own biases throughout the investigation and coding process, and allowing a synthesis of the data to crystallize upon reflection and analysis (Borkan, 1999).

Confirmation of the theoretical areas of prejudice, stereotyping, and discrimination was examined once the preliminary themes had crystallized. Content areas were created using an iterative process with a reference group. This reference group, with breadth as well as depth of experience, allowed for an external corroboration of findings. The reference group consisted of the first author, a PhD level psychologist with HIV expertise, a woman living with HIV with over a decade of involvement in HIV research, three graduate students, and several undergraduate-level research assistants. This iterative process was done through a series of meetings as the coding was completed. Using these themes, the HPASS was constructed to measure the theoretical areas of prejudice, stereotyping, and discrimination based on Earnshaw 
HEALTH CARE PROVIDERS AND HIV

and Chaudoir's (2009) HIV-Stigma Framework. A total of 93 items were initially created for the HPASS, each posed on a six-point Likert scale ranging from $1=$ Strongly Disagree to $6=$ Strongly Agree. The scale items were approved and face validity was checked by the reference group. Additionally, the scale items were sent electronically to the focus group participants to corroborate the findings. Participants were asked to provide feedback on the clarity and representativeness of the items, and did not identify any concerns regarding the HPASS' face validity.

\section{Scale psychometric assessment}

Participants. Following the development of the HPASS, medical and nursing students from across Canada were recruited to participate in an online questionnaire to assess the psychometric properties of the scale. Participants were recruited over email through student association listserves. Participants had to currently be enrolled in either a medical or nursing degree program to participate.

A total of 234 medical and nursing students from across Canada participated in the study. Ten participants were removed from the dataset due to non-completion of the HPASS items (reducing the initial sample size of 234 to 224). Participants ranged from 18 to 41 years of age $(M=23.28$, Median=23.00, $S D=3.55)$. Approximately one quarter of participants identified as male $(\mathrm{N}=52,23.2 \%)$ and $75.9 \%(\mathrm{~N}=170)$ of participants identified as female. Two participants $(0.9 \%)$ identified as being gender queer. Slightly under half of participants were in a nursing program $(\mathrm{N}=101,45.1 \%)$, while $54.9 \%$ were in a medical program $(\mathrm{N}=123)$. There were no mean group differences in terms of scores on the HPASS for participants based on program enrollment. Further information regarding participant demographics can be found in Table 2 . 
HEALTH CARE PROVIDERS AND HIV

Table 2. Descriptive characteristics.

\begin{tabular}{lcc}
\hline Variable & Mean & SD \\
\hline Age & 23.28 & 3.55 \\
Year in program & 2.44 & 1.15 \\
\hline & N (Yes) & $\%$ \\
\hline Volunteer work with HIV+ individuals & 47 & 21.0 \\
Clinical work with HIV+ individuals & 82 & 36.6 \\
Taken a class discussing HIV/AIDS in & 140 & 62.5 \\
$\quad$ current program & & 10.3 \\
Taken a class discussing HIV/AIDS for more & 23 & \\
$\quad$ than 25\% of the time in current & & \\
$\quad$ program & & 33.0 \\
Taken a workshop about HIV/AIDS in & 34 & \\
$\quad$ current program & & \\
Taken a workshop or course about & & \\
$\quad$ HIV/AIDS ever & 74 &
\end{tabular}

Gender

Female 170

Male

52

75.9

Gender Queer

2

0.9

Program

Nursing

45.1

Medicine

123

54.9 
HEALTH CARE PROVIDERS AND HIV

\begin{tabular}{|c|c|c|}
\hline \multicolumn{3}{|l|}{ Sexual orientation } \\
\hline Exclusively heterosexual & 188 & 83.9 \\
\hline Heterosexual, some homosexual & 13 & 5.8 \\
\hline \multicolumn{3}{|l|}{ experience } \\
\hline Bisexual & 7 & 3.1 \\
\hline Homosexual, some heterosexual & 3 & 1.3 \\
\hline \multicolumn{3}{|l|}{ experience } \\
\hline Exclusively homosexual & 8 & 3.6 \\
\hline Other & 4 & 1.8 \\
\hline \multicolumn{3}{|l|}{ Ethnicity† } \\
\hline European/North American & 125 & 53.5 \\
\hline East Asian & 96 & 41.0 \\
\hline South Asian & 22 & 9.4 \\
\hline Caribbean (Black/African, Indo and & 10 & 4.3 \\
\hline \multicolumn{3}{|l|}{ Other) } \\
\hline Middle Eastern/North African & 7 & 3.0 \\
\hline African & 5 & 2.1 \\
\hline Aboriginal & 5 & 2.1 \\
\hline Hispanic/Latino & 2 & 0.9 \\
\hline Other & 4 & 1.7 \\
\hline Born in Canada & 165 & 73.7 \\
\hline \multicolumn{3}{|l|}{ Setting raised } \\
\hline Rural setting & 23 & 10.3 \\
\hline
\end{tabular}


HEALTH CARE PROVIDERS AND HIV

\begin{tabular}{lcc}
\hline Suburban setting & 104 & 46.4 \\
Urban setting & 97 & 43.3 \\
Area of country currently reside & 125 & 56.1 \\
$\quad$ Toronto & 55 & 24.7 \\
Ontario, Quebec, Maritimes excluding & & \\
$\quad$ Toronto & 31 & 13.9 \\
Central Canada (Alberta, Manitoba, & & \\
$\quad$ Saskatchewan) & 12 & 5.4 \\
British Columbia &
\end{tabular}

$\dagger$ Participants were allowed to identify more than one ethnicity, therefore totals add up to greater than $100 \%$. The majority of participants who identified multiple ethnicities were of multiple Caucasian European and "North American" background $(\mathrm{N}=20)$. Eighteen participants identified being of other multiple ethnicities. 
HEALTH CARE PROVIDERS AND HIV

Procedure. Participants, upon receiving the recruitment email, followed a link to participate in the questionnaire online. Participants provided informed consent, and were given a resource sheet and debriefing form upon completion of the questionnaire (see Appendices D and E). Participants were compensated $\$ 15$ via electronic gift certificate for their participation. The first 39 participants were invited to indicate whether or not they could be re-contacted to participate in a second questionnaire. An initial goal of $10 \%$ of all study participants was used to establish test-retest reliability, and therefore closer to $20 \%$ were invited to participate in order to ensure $10 \%$ completed the questionnaire accounting for attrition. All 39 participants consented and were re-contacted one month following their initial participation to participate in the retest version of the questionnaire (see Appendices F and G for test-retest assessment informed consent and debriefing forms). Thirty-one participants participated in the test-retest reliability analysis of the HPASS. The mean age for participants in this sample was $23.90,64.5 \%(\mathrm{~N}=20)$ were female while $32.3 \%(\mathrm{~N}=10)$ were male and 3.2\% $(\mathrm{N}=1)$ identified as gender queer. One participant (3.2\%) was in a nursing program, while the remaining $96.8 \%(\mathrm{~N}=30)$ were in a medical program. Participants were compensated $\$ 10$ via an electronic gift certificate for participating in the retest portion of the study. All components of the current study were approved by the Ryerson University Research Ethics Board.

Measures. Along with the HPASS designed for the current study, participants also completed the following questionnaires:

Demographics. Demographic information collected included gender, ethnicity, age, stage of education, profession, and sexual orientation. Questions were also asked regarding academic courses taken in infectious diseases and experience working with and volunteering with people living with HIV. 
HEALTH CARE PROVIDERS AND HIV

Convergent and divergent validity. (Froman \& Owen, 1997; AIDS Attitude Scale, AAS).

The AAS has been validated with both nursing students and practicing nurses in the United States. The scale consists of 21 items which are measured on a six-point Likert scale from 1 (strongly disagree) to 6 (strongly agree). Sample items include "Patients with AIDS should be treated with the same respect as any other patient" and "I'm worried about getting AIDS from social contact with someone." The scale demonstrates strong internal consistency (Cronbach's alpha $=0.85$ and 0.90 for the empathy and avoidance subscales, respectively). In the current sample of medical and nursing students, AAS-Avoidance had acceptable internal consistency (Cronbach's $\alpha=0.76$ ) and AAS-Empathy had good internal consistency (Cronbach's $\alpha=0.86$ ). AAS-Avoidance is considered a measure of convergent validity as it measures HIV-related stigma, and specifically behavioural avoidance. AAS-Empathy is considered a measure of divergent validity as it measures positive feelings towards people living with the HIV, a construct that is not assessed by the HPASS.

Social desirability. The Marlowe-Crowne Social Desirability Scale Short Form (MC-SF; Strahan \& Gerbasi, 1972; Fischer \& Fick, 1993) is a 10-item scale. The scale assesses social desirability in respondents by asking questions with true/false answers, such as "I like to gossip at times". It is particularly important to assess social desirability when assessing stigmatizing attitudes and beliefs as an indication of the truthfulness of the participants' responses, as opposed to trying to give a positive impression. This short form has been validated with Canadian university students. The scale had low internal consistency (Cronbach's $\alpha=0.61$ ) in the current sample.

Analytic plan. All analyses were conducted using IBM SPSS Statistics 20.0 and SPSS AMOS (IBM, 2011). Initially, an exploratory factor analysis with three specified factors was run 


\section{HEALTH CARE PROVIDERS AND HIV}

as the constructs underlying the structure of HPASS were theoretically driven and it was likely that a pre-determined number of factors would best describe the data. Subsequently, both a fourfactor model and an unrestricted model were run to ensure the theorized three-factor model was indeed the best fit for the data. The scree plot run on each of the analyses indicated that the data had three strong factors as the break in the plot occurred at the fourth factor (see Figures 1 and 2 for scree plots). Therefore subsequent analyses were run constraining the model to the three factors. Maximum likelihood estimation was used for factor extraction to allow for missing data, as well as Direct Oblimin rotation, an oblique method of rotation that assumes the factors are correlated. The factor structure of the exploratory factor analysis was examined to determine whether factor loadings occurred separately for prejudice, stereotyping, and discrimination. Subjectively redundant items, items that did not load at a minimum of .50 on any factor, did not load at least $>.10$ on one factor than another, or did not fit conceptually with the factor structure were removed and the EFA was re-run. Test-retest reliability for the scale was evaluated using intraclass correlation coefficients. Internal consistency was evaluated using Cronbach's alpha. Convergent and divergent validity were examined via correlation of the HPASS, the alternate HIV stigma scales and a measure of social desirability. As the new measure specifically targets stigmatizing attitudes, cognitions and behaviours, as opposed to empathic ones (conceptualized as the positively valenced alternative to stigmatizing reactions), it was hypothesized that the new measure would be positively correlated with the AIDS Attitude Scale Avoidance subscale and negatively correlated with the AIDS Attitude Scale Empathy subscale (Froman \& Owen, 1997). It was also hypothesized that there would be no correlation between the Marlowe-Crowne Social Desirability Scale Short Form (Strahan \& Gerbasi, 1972; Fischer \& Fick, 1993) and the HPASS. 


\section{HEALTH CARE PROVIDERS AND HIV}

Finally, a confirmatory factor analysis (CFA) was run to examine the replicability of the threefactor structure. 


\section{Scree Plot}

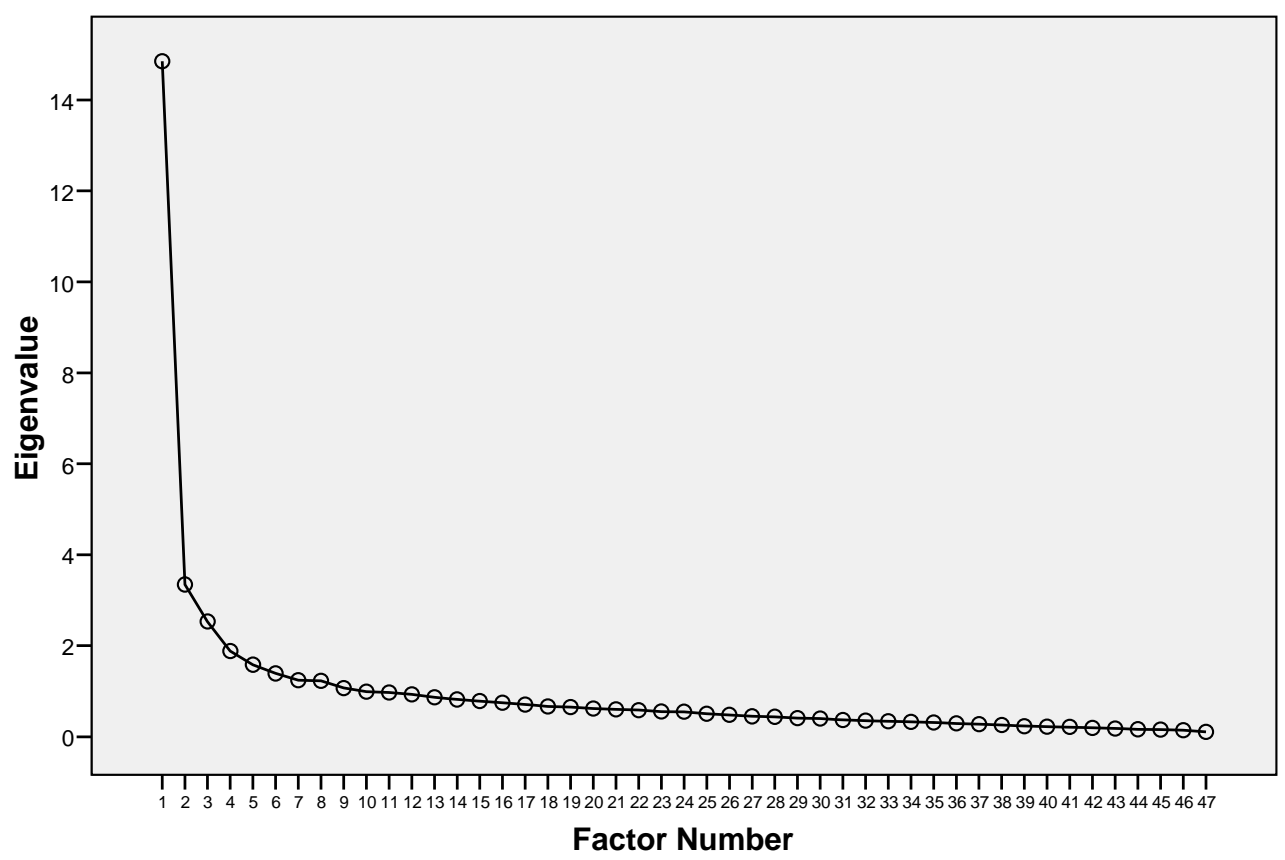

Figure 1. Scree plot for unrestricted factor loadings. 
HEALTH CARE PROVIDERS AND HIV

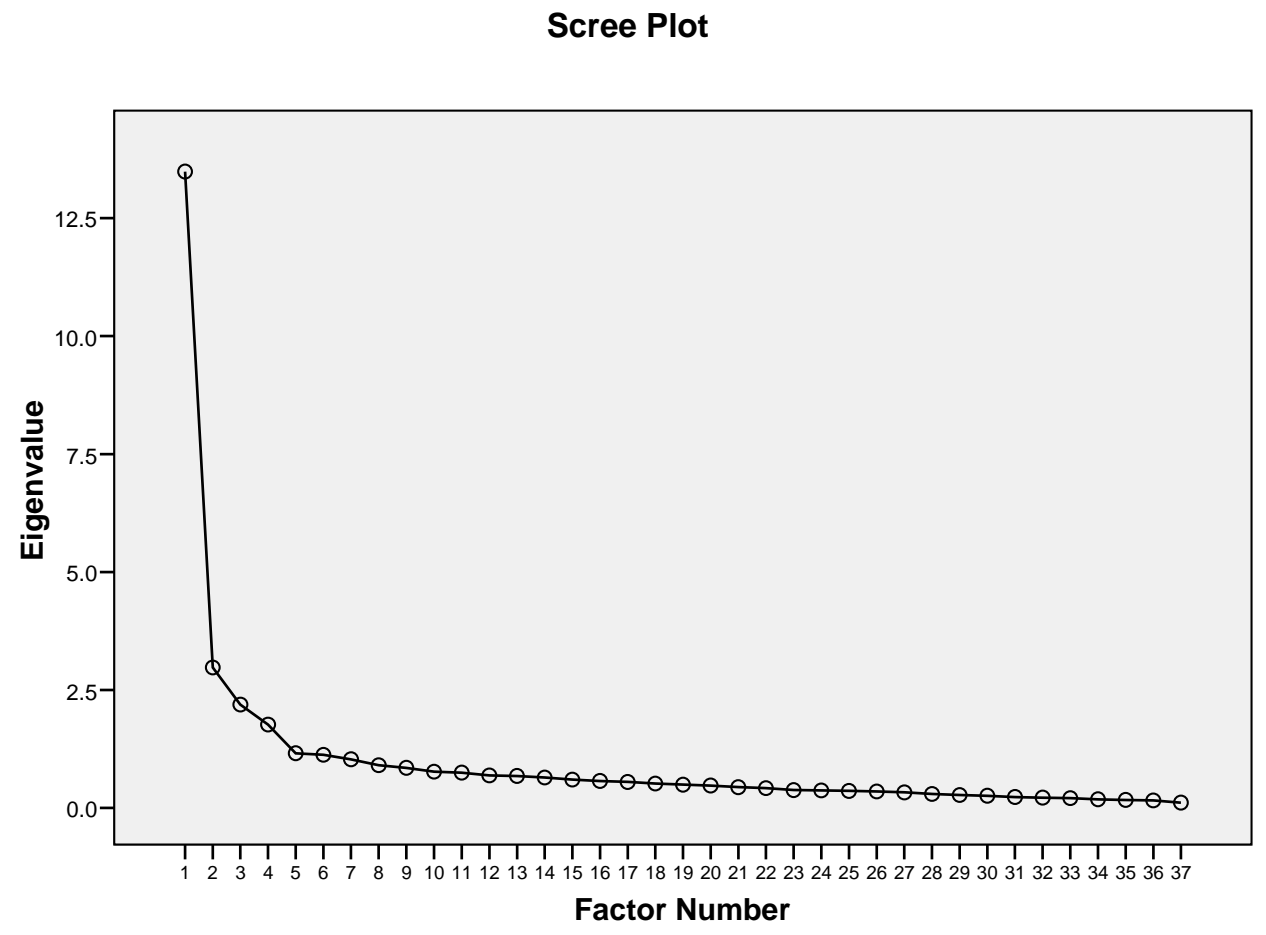

Figure 2. Scree plot for restricted four factor item loadings. 


\section{HEALTH CARE PROVIDERS AND HIV}

A CFA is considered to have a good model fit if three indicators of model fit meet appropriate cut-offs for suitability (Kline, 2005). For the current study, four fit indices were examined to ensure good model fit. The normed chi-square $\left(\chi^{2} / \mathrm{df}\right)$ is a sample-based measure of absolute model fit. Models with large sample sizes (determined to be over 200 cases in CFA) will typically have the model rejected if examining chi-square alone, as the model is overidentified (Kline, 2005). To reduce the sensitivity of the model to sample size, the chi-square is divided by the model's degrees of freedom. Values of the normed chi-square should be less than 2.0 or 3.0 to indicate good model fit (Bollen, 1989). The second fit index is the Steiger-Lind root mean square error of approximation (RMSEA; Steiger, 1990). This measure is a populationbased index that has an inherent correction for model complexity. This index will ensure the most parsimonious model is favoured, and does not assume a central chi-square distribution (Kline, 2005). The RMSEA therefore does not assume a model will be perfect, but rather that it is a close approximation of reality. A value of less than .08 is considered reasonable for the RMSEA (Browne \& Cudeck, 1993). RMSEA’s 90\% confidence interval should not cross zero (Kline, 2005). The third fit index is the Bentler comparative fit index (CFI; Bentler, 1990). The CFI assesses relative model fit through comparison of the suggested model over a baseline null model. The CFI also does not assume a perfect model fit, like the RMSEA (Kline, 2005). The CFI indicates good model fit with a value over .90 (Hu \& Bentler, 1999). Finally, the fourth model fit index is the standardized root mean square residual (SRMR). This measure assesses the overall difference between predicted correlations and observed correlations in the model. For good model fit, the SRMR should have a value of less than .10 (Kline, 2005). 


\section{Results}

\section{Item redundancy}

Ninety-three items were included in the initial administration of the HPASS (see Appendix H). Items were checked for floor and ceiling effects (defined as mean scores of either under 2.0 or over 5.0) and construct redundancy based on the HIV Stigma Framework after reviewing score distributions and bivariate correlations. Forty-six items were removed due to floor and ceiling effects, multi-collinearity of items correlated $>.90$, and construct redundancy, leaving a total of 47 items for the initial exploratory factor analysis.

\section{Factor structure}

EFA. The ability to create factors within the HPASS was examined. All items correlated at least .30 with another item, as items should be at least minimally associated in order to run a factor analysis (Tabachnick \& Fidell, 2007). Bartlett's test of sphericity examines whether the variables in the model are uncorrelated, and is used as a measure of the strength of the relationship among the variables, with a higher value indicating a stronger relationship (Tabachnick \& Fidell, 2007). Bartlett's test of sphericity was significant $\left(\chi^{2}(435)=3828.68, p\right.$ $<.001)$. The Kaiser-Meyer-Olkin measure of sampling adequacy, an index that compares observed and partial correlation coefficients, was .92. This is above the recommended value of .60 (Tabachnick \& Fidell, 2007). Additionally, the communalities of the items were all above .03 indicating that the items did share some variance. Collectively, these indicators suggest that factor analysis is appropriate.

Several iterations of factor structure were run to determine the best model fit. The threefactor theoretical model proposed by the HIV Stigma Framework was purported to be the best model. An EFA specifying three factors for the 47 items explained $39.95 \%$ of the total variance. 


\section{HEALTH CARE PROVIDERS AND HIV}

As detailed above, both four-factor and unrestricted models were also run to ensure an unbiased assessment of the factor structure. The four-factor model failed to converge. The unrestricted model yielded a nine-factor model explaining $52.88 \%$ of the total variance. Eigenvariate analysis indicated that this model was characterized by three strong factors with eigenvalues over 2 , followed by a fourth factor with an eigenvalue of 1.886 , and remaining factors with values $<1.6$ and accounting for minimal unique variance. Relying solely on the criterion of eigenvalues over 1 as a designation for inclusion as a factor has been questioned, as the distinction between over 1 and less than 1 is relatively arbitrary (Costello \& Osborne, 2005). Examining the scree plot of the factor loadings demonstrated that the bend in the plot occurred at the fourth factor. The added complexity of the fourth factor was not deemed to explain the model more fully. In sum, the unrestricted model accounted for less than 14\% more of the variance than the three-factor solution and only three strong factors emerged when examining the scree plot. Therefore the three-factor model was retained due to its parsimony, the leveling off effect of the unique contribution of each factor to the overall model, as well as the theoretical underpinnings of the scale. All further model refinement was conducted on the three-factor model.

Items that did not meet a conservative loading of at least .50 on any of the three factors and did not load at least $>.10$ on one factor than another were removed to create a more succinct measure defined by the items with the strongest factor loadings. This process yielded 30 items in the final three-factor model of the HPASS (see Table 3 for the final listing of items and factor loadings and Appendix I for the final HPASS). The total score of the scale items was normally distributed (skewness $=0.09, \mathrm{SE}=0.16$; kurtosis $=-0.69, \mathrm{SE}=0.32$ ) using KolmogorovSmirnov's test of normality $(\mathrm{K}-\mathrm{S}=0.047, p=.200)$. This revised model explained $48.61 \%$ of the total variance. The three factors were derived statistically and also fit with the predicted three- 


\section{HEALTH CARE PROVIDERS AND HIV}

factor model of HIV stigma, and were hence labeled Prejudice (M=31.09, SD=11.24), Stereotyping $(\mathrm{M}=28.61, \mathrm{SD}=8.92)$, and Discrimination $(\mathrm{M}=15.45, \mathrm{SD}=6.71)$. The factors Prejudice and Stereotyping correlated at $r=.562, p<.001$, Prejudice and Discrimination at $r$ $=.696, p<.001$, and Stereotyping and Discrimination at $r=.445, p<.001$. These inter-factor correlations support their coherence in assessing HIV stigma, but also their divergence as unique factors. 
Table 3. Item factor loadings.

\begin{tabular}{|c|c|c|c|}
\hline Item $\dagger$ & Factor 1 & Factor 2 & Factor 3 \\
\hline $\begin{array}{l}\text { HIV+ patients make me uncomfortable. } \\
(22)\end{array}$ & .790 & .325 & -.494 \\
\hline $\begin{array}{l}\text { I worry about contracting HIV from HIV+ } \\
\text { patients. }(20)\end{array}$ & .752 & .400 & -.465 \\
\hline $\begin{array}{l}\text { I would rather not come into physical } \\
\text { contact with HIV+ patients. (12) }\end{array}$ & .741 & .389 & -.427 \\
\hline $\begin{array}{l}\text { HIV+ patients present a threat to my } \\
\text { health. }(5)\end{array}$ & .733 & .384 & -.435 \\
\hline $\begin{array}{l}\text { It is a little scary to think I have touched } \\
\text { HIV+ patients. (24) }\end{array}$ & .715 & .336 & -.482 \\
\hline $\begin{array}{l}\text { I worry that universal precautions are not } \\
\text { good enough to protect me from HIV+ } \\
\text { patients. }(25)\end{array}$ & .693 & .395 & -.372 \\
\hline $\begin{array}{l}\text { I would rather see an HIV-negative patient } \\
\text { than see an HIV+ patient with non-HIV- } \\
\text { related concerns. (18) }\end{array}$ & .674 & .396 & -.495 \\
\hline $\begin{array}{l}\text { HIV+ patients present a threat to the health } \\
\text { of other patients. (6) }\end{array}$ & .653 & .436 & -.601 \\
\hline $\begin{array}{l}\text { I would be hesitant to send HIV+ patients } \\
\text { to get blood work done due to my fear of } \\
\text { others' safety. ( } 23)\end{array}$ & .647 & .286 & -.469 \\
\hline $\begin{array}{l}\text { I would feel uncomfortable knowing one of } \\
\text { my colleagues is HIV+. (26) }\end{array}$ & .631 & .358 & -.375 \\
\hline $\begin{array}{l}\text { I would be comfortable working alongside } \\
\text { another health care provider who has HIV. } \\
\text { (15) }\end{array}$ & .565 & .306 & -.416 \\
\hline $\begin{array}{l}\text { I would want to wear two sets of gloves } \\
\text { when examining HIV+ patients. (13) }\end{array}$ & .561 & .377 & -.438 \\
\hline $\begin{array}{l}\text { It would be hard to react calmly if a patient } \\
\text { tells me he or she is HIV+. }(30)\end{array}$ & .560 & .272 & -.481 \\
\hline $\begin{array}{l}\text { HIV }+ \text { patients tend to have numerous } \\
\text { sexual partners. }(10)\end{array}$ & .287 & .738 & -.261 \\
\hline $\begin{array}{l}\text { HIV+ patients who have acquired HIV } \\
\text { through sex are more at fault for } \\
\text { contracting HIV than HIV+ patients who } \\
\text { have acquired HIV through a blood } \\
\text { transfusion. (29) }\end{array}$ & .461 & .714 & -.279 \\
\hline $\begin{array}{l}\text { I think } \mathrm{HIV}+\text { patients have engaged in } \\
\text { risky activities despite knowing these risks. } \\
\text { (2) }\end{array}$ & .350 & .659 & -.229 \\
\hline $\begin{array}{l}\text { I often think HIV }+ \text { patients have caused } \\
\text { their own health problems. }(21)\end{array}$ & .449 & .654 & -.300 \\
\hline I think if people act responsibly they will & .358 & .635 & -.361 \\
\hline
\end{tabular}




\begin{tabular}{|c|c|c|c|}
\hline not contract HIV. (9) & & & \\
\hline $\begin{array}{l}\text { I believe most } \mathrm{HIV}+\text { patients acquired the } \\
\text { virus through risky behaviour. (1) }\end{array}$ & .212 & .612 & -.116 \\
\hline $\begin{array}{l}\text { I think many HIV+ patients likely have } \\
\text { substance abuse problems. (16) }\end{array}$ & .282 & .610 & -.218 \\
\hline $\begin{array}{l}\text { HIV+ patients should accept responsibility } \\
\text { for acquiring the virus. (19) }\end{array}$ & .315 & .567 & -.368 \\
\hline $\begin{array}{l}\text { I tend to think that HIV+ patients do not } \\
\text { share the same values as me. }(28)\end{array}$ & .447 & .564 & -.354 \\
\hline $\begin{array}{l}\text { I think people would not get HIV if they } \\
\text { had sex with fewer people. (4) }\end{array}$ & .364 & .551 & -.275 \\
\hline $\begin{array}{l}\text { HIV+ patients who have acquired HIV } \\
\text { through injection drug use are more at fault } \\
\text { for contracting HIV than HIV+ patients } \\
\text { who have acquired HIV through a blood } \\
\text { transfusion. (27) }\end{array}$ & .342 & .532 & -.159 \\
\hline $\begin{array}{l}\text { I believe I have the right to refuse to treat } \\
\text { HIV+ patients to protect myself. (14) }\end{array}$ & .608 & .387 & -.912 \\
\hline $\begin{array}{l}\text { I believe I have the right to refuse to treat } \\
\text { HIV+ patients if I feel uncomfortable. (11) }\end{array}$ & .566 & .326 & -.892 \\
\hline $\begin{array}{l}\text { I believe I have the right to refuse to treat } \\
\text { HIV+ patients if other staff members are } \\
\text { concerned about safety. ( } 7)\end{array}$ & .564 & .347 & -.826 \\
\hline $\begin{array}{l}\text { I believe I have the right to refuse to treat } \\
\text { HIV+ patients for the safety of other } \\
\text { patients. (3) }\end{array}$ & .535 & .311 & -.774 \\
\hline $\begin{array}{l}\text { I believe I have the right to refuse to treat } \\
\text { HIV+ patients if I am concerned about } \\
\text { legal liability. (17) }\end{array}$ & .512 & .335 & -.770 \\
\hline $\begin{array}{l}\text { I would avoid conducting certain } \\
\text { procedures on HIV+ patients. (8) }\end{array}$ & .590 & .380 & -.632 \\
\hline Eigenvalue & 11.305 & 2.932 & 1.771 \\
\hline Percentage Variance & $37.68 \%$ & $9.77 \%$ & $5.90 \%$ \\
\hline
\end{tabular}

Notes: † Item number in parentheses. 
HEALTH CARE PROVIDERS AND HIV

CFA. A confirmatory factor analysis was conducted on the three-factor model. The model was reasonably well-fitting: $\chi^{2} / \mathrm{df}=2.15, \mathrm{RMSEA}=.072(90 \% \mathrm{CI}=.065$ to .078$)$, but the CFI was .871 , just below the recommended cut-off of .90 . Modification indices indicated that the overall model fit could improve, as indexed by a decrease in the chi-square statistic, if covariances between some item error terms were allowed to be freely estimated (the default model set these as independent; Kline, 2005). Fifteen was chosen as a cut-off for considering modification indices, as those below this value provided minimal overall model change. Error covariances with modification indices above 15 and that fit conceptually were inserted into the model. These covariances were between items 12 and $15(16.05$, par change $=.23)$, and items 23 and $24(16.05$, par change $=.19)$ from the Prejudice factor, and items 27 and $29(70.77$, par change $=.70$ ) from the Stereotyping factor. Subsequently, the modified model yielded a well-

fitting model across all indices. More specifically, the $\chi^{2} / \mathrm{df}$ was 1.885 (criteria $<2$ for excellent fit; Bollen, 1989). The RMSEA was .063, indicating an excellent fit $(<.08$ recommended by Browne \& Cudeck, 1993). The $90 \%$ confidence interval for the RMSEA also did not cross zero $(\mathrm{CI}=.056-.070)$. Additionally, the CFI was .902, which indicated a good fit ( $>.900 ; \mathrm{Hu} \&$ Bentler, 1999). Finally, the SRMR was .062, below the recommended cut-off of .100 (Kline, 2005).

\section{Reliability}

Internal consistency. The final three-factor model determined by the EFA and confirmed by the CFA demonstrated excellent internal consistency. The total scale ( $\mathrm{N}=30$ items) had Cronbach's $\alpha=.940$. The Prejudice subscale, consisting of 13 items, had Cronbach's $\alpha$ $=.913$. The Stereotypes subscale, consisting of 11 items, had Cronbach's $\alpha=.871$. The Discrimination subscale, consisting of six items, had Cronbach's $\alpha=.917$. 
HEALTH CARE PROVIDERS AND HIV

Test-retest reliability. In the test-retest analysis, assessed with the original 47 scale items and with analyses conducted on the final 30 items, the total scale score had Cronbach's $\alpha$ $=.960$. The Prejudice subscale had Cronbach's $\alpha=.939$. The Stereotypes subscale had Cronbach's $\alpha=.923$. The Discrimination subscale had Cronbach's $\alpha=.918$. The total score intraclass correlation coefficient was $r=.933, p<.001$. The Prejudice subscale had a correlation of $r=.922, p<.001$. The Stereotypes subscale had a correlation of $r=.868, p<.001$. The Discrimination subscale had a correlation of $r=.796, p<.001$. These results demonstrate very strong one month test-retest reliability.

\section{Convergent and divergent validity}

Correlations were run to determine whether AAS-Avoidance, AAS-Empathy and the total score on the MC-SF were associated with the total score on the HPASS to assess convergent and divergent validity. As previously discussed, the AAS-Avoidance measures HIV stigma and was posited to correlate highly with the content on the HPASS. AAS-Avoidance was positively correlated with the HPASS total score $(r=.772, p<.001)$. Also as previously discussed, a negative correlation was expected between the AAS-Empathy and the HPASS, demonstrating divergent validity. This hypothesis was made as while similar content would be discussed regarding HIV and AIDS, the construct of empathy or positive attributes ended up not being explicitly presented in the HPASS. The hypothesis was confirmed, as AAS-Empathy was negatively correlated with the HPASS total score $(r=-.334, p<.001)$. The total score on the MC-SF did not correlate with the total score on the HPASS $(r=-.04, n s)$, as predicted. A multiple regression was run using the total scores of the AAS-Avoidance and AAS-Empathy to determine their relative weight in predicting the total score on the HPASS. AAS-Avoidance significantly predicted HPASS total (standardized $\beta=.76, p<.001$ ), demonstrating convergent 
HEALTH CARE PROVIDERS AND HIV

validity. AAS-Empathy did not significantly predict HPASS total in the multiple regression (standardized $\beta=-.02, n s$ ), demonstrating divergent validity.

\section{Discussion}

The current study examines the structure and validity of a new scale to assess health care providers' HIV stigma, the HPASS. The development of this measure addresses a gap in the literature assessing HIV stigma amongst health care providers in North America using not only a well-established stigma theory (Link \& Phelan, 2001) but also a more recently developed theoretical framework based on this theory (Earnshaw \& Chaudoir, 2009). In addition to being theoretically sound, our scale development was methodologically rigorous, following the validation steps outlined by Brown (2006). The changing nature of HIV care in North America, as well as the decline of research regarding health care provider HIV stigma, necessitate a renewed focus on enhancing quality of care for people living with HIV. The HPASS works to address this goal by providing an accurate picture of the attitudes and beliefs held by health care providers.

The final scale consists of 30 items and both EFA and CFA support its subdivision into three separate subscales consistent with the three areas of stigma outlined in Earnshaw and Chaudoir's (2009) HIV Stigma Framework: prejudice, stereotyping and discrimination. The scale demonstrates excellent internal consistency and stable test-retest reliability. A strong positive correlation with a measure of AIDS-related stigma (the AAS Avoidance subscale; Froman \& Owen, 1997) indicates good convergent validity, while a negative correlation with the AAS Empathy subscale (Froman \& Owen, 1997) demonstrated divergent validity, as the HPASS was not designed to assess empathy. 
HEALTH CARE PROVIDERS AND HIV

\section{Prejudice, stereotyping and discrimination}

The HPASS is unique in its explicit delineation of prejudice, stereotyping and discrimination amongst health care providers. The process of developing the measure addressed institutional and societal factors, and acknowledged their impact on the expression of individuallevel stigmatizing attitudes and beliefs, but did not conflate their influence with their assessment by the measure. Additionally, overlapping forms of stigmatization (e.g., homophobia, racism, bias against injection drug users) with HIV stigma were discussed during scale development. The substantive contribution of overlapping stigmas on the experience of HIV stigma was so strongly highlighted during scale development that it was deemed necessary to measure these overlapping stigmas separately and explicitly from HIV stigma, as opposed to cursorily attempting to capture them within this measure.

The findings from the current study support the model of HIV stigma proposed by Earnshaw and Chaudoir's (2009) HIV Stigma Framework. To our knowledge, this is the first scale that explicitly measures the constructs of discrimination, stereotyping and prejudice as three components of HIV stigma. These findings suggest that HIV stigma can be measured, assessed and targeted as these three components of stigmatizing behaviours, cognitions, and affect. By demonstrating this distinction, HIV stigma can be conceptualized as a less amorphous entity and more readily targeted phenomenon by specific, concrete tactics, such as identifying which stereotypes and which behaviours are endorsed by providers. Pending a cross-validation to confirm its psychometric properties, the HPASS could be used at the beginning of training, throughout training, and possibly to assess change before and after stigma reduction interventions or with increased clinical experience. The HPASS can be given by trainers, 


\section{HEALTH CARE PROVIDERS AND HIV}

professors, clinical preceptors, by health care management, and by program leads to assess areas for intervention and improvement, which can then inform educational interventions.

\section{Future directions and limitations}

The current study is a preliminary validation of the HPASS, and therefore requires future validation. Specifically, we recommend confirmatory factor analysis in another sample of medical and nursing students to cross-validate the measurement model. Additional measures of convergent and divergent validity will further define the bounds of assessment of the HPASS, as well as its unique variability beyond other measures of HIV stigma. This preliminary validation was done with Canadian medical and nursing students, as the measure was designed to assess HIV stigma in the North American context. However, further validation should also be undertaken with samples in other countries and possibly with other professions of trainees (e.g., psychology, social work, midwifery, pharmacy) and to extend its validation to fully trained health care providers to determine the measure's reliability with these groups. Moreover, the measure will require validation with health care professionals working in the field, as opposed to solely trainees, to see if the measure is sensitive for samples with significant experience and education.

Limitations to the current study include the use of a self-selecting sample, who were reporting their beliefs using self-report measures. The findings therefore may not be generalizable to the entire trainee population and may under-represent stigmatizing attitudes and beliefs. Additionally, the geographic distribution of the sample was not even across the country, and may not have captured experiences working with Aboriginal or newcomer populations to Canada, which may have influenced responding. The EFA and CFA analyses were conducted on 
HEALTH CARE PROVIDERS AND HIV

the same sample, and would benefit from being conducted on additional samples to ensure the results are replicable and generalizable.

The strong psychometric properties of the HPASS reflect the rigour of its development and validation. Using items derived explicitly from focus groups with health care providers, trainees, and men and women living with HIV give the items authenticity as well as construct validity. Iterative development of the items with input from the research reference group as well as focus group participants ensured item integrity. Additionally, the measure is succinct and brief, disallowing for ambiguity in question interpretation that other measures may encounter. The scale was also administered on a 6-point Likert scale, making "midline" responding impossible by having no measure centre point, and therefore reducing the likelihood respondents will answer ambiguously in the "middle". The measure may be useful for highlighting areas that require intervention for trainees and professionals, as well as acting as an important tool for selfreflection by respondents. In these regards, the measure also holds promise for future applications to assess changes in stigmatizing attitudes and beliefs over time, following accrual of experience and anti-stigma education.

\section{Conclusion}

In summary, the HPASS is a psychometrically valid measure of HIV stigma for health care providers in North America. It correlates highly with other measures of AIDS-related stigma, and scores are not determined by social desirability. The measure demonstrates excellent internal consistency and strong test-retest reliability. The measure offers a useful tool for assessing and determining areas to intervene with health care providers in terms of prejudice, stereotyping and discrimination. 
HEALTH CARE PROVIDERS AND HIV

\section{References}

Alonzo, A.A., \& Reynolds, N.R. (1995). Stigma, HIV and AIDS: an exploration and elaboration of a stigma trajectory. Social Science \& Medicine, 41, 303-315. doi: $10.1016 / 02779536(94) 00384-6$

Bentler, P. M. (1990). Comparative fit indexes in structural models. Psychological Bulletin, 107, 238-246. doi: 10.1037/0033-2909.107.2.238

Berger, B.E., Ferrans, C.E., \& Lashley, F.R. (2001). Measuring stigma in people with HIV: psychometric assessment of the HIV stigma scale. Research in Nursing Health, 24, 518529. doi: 10.1002/nur.10011

Bollen, K. A. (1989). Structural equations with latent variables. New York: Wiley.

Borkan, J. (1999). Immersion/Crystallization. In B.F. Crabtree \& W.L. Miller (Eds.), Doing qualitative research (pp. 179-194). Thousand Oaks, CA: Sage.

Brown, T. (2006). Confirmatory factor analysis. New York: Guilford.

Browne, M. W., \& Cudeck, R. Alternative ways of assessing model fit. In K. A. Bollen \& J. S. Long (Eds.), Testing structural equation models (pp. 136-161). Newbury Park, CA: Sage.

Costello, A. B., \& Osborne, J. (2005). Best practices in exploratory factor analysis: four recommendations for getting the most from your analysis. Practical Assessment Research \& Evaluation, 10. Available online: http://pareonline.net/getvn.asp?v=10\&n=7

Deacon, H. (2006). Towards a sustainable theory of health-related stigma: Lessons from the HIV/AIDS literature. Journal of Community \& Applied Social Psychology, 16, 418-425. doi: $10.1002 /$ casp.900

Devine, P.G., Plant, E.A., \& Harrison, K. (1999). The problem of "us" versus "them" and AIDS stigma. American Behavioral Scientist, 42, 1212-1228. doi: 10.1177/00027649921954732 


\section{HEALTH CARE PROVIDERS AND HIV}

Dowshen, N., Binns, H.J., \& Garofalo, R. (2009). Experiences of HIV-related stigma among young men who have sex with men. AIDS Patient Care and STDs, 23, 371-376. doi: 10.1089/apc. 2008.0256

Earnshaw, V.A., \& Chaudoir, S.R. (2009). From conceptualizing to measuring HIV stigma: a review of HIV stigma mechanism measures. AIDS and Behavior, 13, 1160-1177. doi: 10.1007/s10461-009-9593-3

Emlet, C.A. (2006). An examination of the social networks and social isolation in older and younger adults living with HIV/AIDS. Health \& Social Work, 31, 299-308. doi: $10.1093 / \mathrm{hsw} / 31.4 .299$

Fischer, D. G., \& Fick, C. (1993). Measuring social desirability: short forms of the MarloweCrowne Social Desirability Scale. Educational and Psychological Measurement, 53, 417424. doi: $10.1177 / 0013164493053002011$

Froman, R.D., \& Owen, S.V. (1997). Further validation of the AIDS Attitude Scale. Research in Nursing \& Health, 20, 161-167. doi: 0160-6891/97/020161-07

Goffman, E. (1963). Stigma: Notes on the management of spoiled identity. Englewood Cliffs, NJ: Prentice-Hall.

Greig, A., Peacock, D., Jewkes, R., \& Msimang, S. (2008). Gender and AIDS: time to act. AIDS, 22(suppl 2), S35-S43. doi: 10.1097/01.aids.0000327435.28538.18

Harrison, M., Fusilier, M.R., \& Worley, J.K. (1994). Development of a measure of nurses’ AIDS attitudes and conservative views. Psychological Reports, 74, 1043-1048. doi: 10.2466/pr0.1994.74.3.1043 


\section{HEALTH CARE PROVIDERS AND HIV}

Herek, G.M., \& Capitanio, J.P. (1998). Symbolic prejudice or fear of infection? A functional analysis of AIDS-related stigma among heterosexual adults. Basic Applied Social Psychology, 20, 230-241. doi: 10.1207/15324839851036705

Herek, G.M., Capitanio, J.P., \& Widaman, K.F. (2002). HIV-related stigma and knowledge in the United States: prevalence and trends, 1991-1999. American Journal of Public Health, 92, 371-377. doi: 10.2105/AJPH.92.3.371

Hoffart, S., Ibrahim, G. M., Lam, R. A., Minty, E. P., Theam, M., \& Schaefer, J. P. (2012). Medical students' attitudes towards treating patients with HIV: A 12-year follow-up study. Medical Teacher, 34, 254-254. doi: 10.3109/0142159X.2012.652710

Hu, L., \& Bentler, P. M. (1999). Cutoff criteria for fit indexes in covariance structure analysis: conventional criteria versus new alternatives. Structural Equation Modeling: A Multidisciplinary Journal, 6, 1-55. doi: 10.1080/10705519909540118

IBM Corp. Released 2011. IBM SPSS Statistics for Windows, Version 20.0. Armonk, NY: IBM Corp.

Kalichman, S.C., Simbayi, L.C., Cloete, A., Mthembu, P.P., Mkhonta, R.N., \& Ginindza, T. (2009). Measuring AIDS stigmas in people living with HIV/AIDS: the Internalized AIDSRelated Stigma Scale. AIDS Care, 21, 87-93. doi: 10.1080/09540120802032627

Kebaabetswe, P.M. (2007). Barriers to participation in the prevention of mother-to-child HIV transmission program in Gaborone, Botswana: a qualitative approach. AIDS Care, 19, 355360. doi: 10.1080/09540120600942407

Kinsler, J. J., Wong, M. D., Sayles, J. N., Davis, C., \& Cunningham, W. E. (2007). The effect of perceived stigma from a health care provider on access to care among a low-income HIV- 
HEALTH CARE PROVIDERS AND HIV

positive population. AIDS Patient Care and STDs, 21, 584-592. doi:

10.1089/apc.2006.0202

Kline, R. B. (2005). Principles and practice of structural equation modeling (2 ${ }^{\text {nd }}$ edition). New York: Guilford.

Link, B.G., \& Phelan. J.C. (2001). Conceptualizing stigma. Annual Review of Sociology, 27, 363-385. doi: 10.1146/annurev.soc.27.1.363

Logie, C., \& Gadalla, T.M. (2009). Meta-analysis of health and demographic correlates of stigma towards people living with HIV. AIDS Care, 21, 742-753. doi:

$10.1080 / 09540120802511877$

Mahajan, A.P., Sayles, J.N., Patel, V.A., Remien, R.H., Sawires, S.R., Ortiz, D.J., ... \& Coates, T.J. (2008). Stigma in the HIV/AIDS epidemic: a review of the literature and recommendations for the way forward. AIDS, 22, S67-S79. doi:

10.1097/01.aids.0000327438.13291.62

Mulford, C.L., \& Lee, M.Y. (1996). Reliability and validity of AIDS victim blaming scales. Psychological Reports, 79, 191-201. doi: 10.2466/pr0.1996.79.1.191

Nyblade, L., \& Kerry, M. Q. (2006). Can we measure HIV/AIDS-related stigma and discrimination? Current knowledge about quantifying stigma in developing countries. Washington, DC: ICRW Publications.

Parker, R., \& Aggleton, P. (2003). HIV and AIDS-related stigma and discrimination: a conceptual framework and implications for action. Social Science \& Medicine, 57, 13-24. doi: 10.1016/S0277-9536(02)00304-0

Peretti-Watel, P., Spire, B., Pierret, J., Lert, F., Obadia, Y., \& The Vespa Group. (2006). Management of HIV-related stigma and adherence to HAART: Evidence from a large 
HEALTH CARE PROVIDERS AND HIV

representative sample of outpatients attending French hospitals (ANRS-EN12-VESPA 2003). AIDS Care, 18, 254-261. doi: 10.1080/09540120500456193

Pleck, J.H., O’Donnell, L., O’Donnell, C., \& Snarey, J. (1988). AIDS-phobia, contact with AIDS, and AIDS-related job stress in hospital workers. Journal of Homosexuality, 15, 41-54. doi: 10.1300/J082v15n03_02

Prilleltensky, I. (1989). Psychology and the status quo. American Psychologist, 44, 795-802. doi: 10.1037/0003-066X.44.5.795

Rosenburg, N., Taliaferro, D., \& Ercole, P. (2012). HIV-related stigma among nursing students in Cameroon. Journal of the Association of Nurses in AIDS Care, 23, 170-176. doi: 10.1016/j.jana.2011.09.003

Rutledge, S. E., Whyte, J., Abell, N., Brown, K. M., \& Cesnales, N. I. (2011). Measuring stigma among health care and social service providers: the HIV/AIDS Provider Stigma Inventory. AIDS Patient Care and STDs, 25, 673-682. doi: 10.1089/apc.2011.0008

Steiger, J. H. (1990). Structural model evaluation and modification: an interval estimation approach. Multivariate Behavioral Research, 25, 173-180. doi:

$10.1207 / \mathrm{s} 15327906 \mathrm{mbr} 2502 \_4$

Stein, J.A., \& Li, L. (2008). Measuring HIV-related stigma among Chinese service providers: confirmatory factor analysis of a multidimensional scale. AIDS and Behavior, 12, 789-795. doi: $10.1007 / \mathrm{s} 10461-007-9339-\mathrm{z}$

Strahan, R., \& Gerbasi, K. C. (1972). Short, homogeneous versions of the Marlowe-Crowne Social Desirability Scale. Journal of Clinical Psychology, 28, 191-193. doi: 10.1002/10974679(197204)28:2<191::AID-JCLP2270280220>3.0.CO;2-G 


\section{HEALTH CARE PROVIDERS AND HIV}

Tabachnick, B. G., \& Fidell, L. S. (2007). Using multivariate statistics, $5^{\text {th }}$ ed. Boston: Pearson Education Inc.

Treichler, P. A. (1999). How to have theory in an epidemic. Durham, NC: Duke University Press. 
HEALTH CARE PROVIDERS AND HIV

Study 3: HIV-Related Stigma and Overlapping Stigmas among Health Care Trainees in Canada Human Immunodeficiency Virus/Acquired Immunodeficiency Syndrome (HIV/AIDS) has become a global pandemic in the past 30 years (UNAIDS, 2010). From the first recorded cases in the early 1980 s to a current high of over 34 million people living with the virus worldwide, and with an estimated 1.7 million HIV-related deaths in 2011 alone, HIV has left an indelible mark on the world (UNAIDS, 2012). In Canada, HIV incidence has risen from an estimated 64,000 people living with HIV in 2008 to an estimated 71,300 in 2011 (Public Health Agency of Canada, 2012). The phenomenon of HIV is particularly remarkable due to the fear, misunderstanding, secrecy, and assumptions surrounding it. HIV has been inextricably linked to sex, sexual orientation, injection drug use, and gender and status imbalances. The context in which HIV exists therefore creates an environment ripe for misperception and judgment that ultimately impacts how people living with HIV experience the world and their caregivers in it (Aranda-Naranjo, 2004; Carr \& Gramling, 2004; Devine, Plant, \& Harrison, 1999; Emlet, 2006; Orner, 2006). The current study examines HIV stigma within the context of its overlapping stigmas amongst Canadian health care trainees to determine how much these overlapping stigmas account for the phenomenon of "HIV stigma". This investigation considers overlapping stigmas from the perspective of intersectionality, hypothesizing that the cumulative impact of these factors are greater than the sum of their parts.

\section{Who HIV affects - the context for stigmatization}

Although the communities worldwide with high HIV prevalence are incredibly discrepant in many characteristics, these groups frequently share in common a minority status and greater likelihood of being impoverished. In Canada, the groups at highest risk of contracting HIV are men who have sex with men (MSM), injection-drug users, individuals involved in sex trade, and 


\section{HEALTH CARE PROVIDERS AND HIV}

recent immigrants from high HIV prevalence countries (UNAIDS, 2008; PHAC, 2012). The majority of people who have been recently diagnosed with HIV continue to be men who have sex with men (PHAC, 2012). However, nearly $24 \%$ of new infections are in women, and many of these women are from countries with high HIV prevalence rates (PHAC, 2012). Between 2008 and 2011, there has been a significant rise in the number of heterosexual transmissions of HIV, both to men and women (PHAC, 2012). Additionally, 16\% of new HIV infections in 2011 were identified as being via injection drug use (PHAC, 2012). People of Aboriginal descent are disproportionately affected by HIV in Canada, making up $8.9 \%$ of the prevalence of HIV in Canada, despite being 3.8\% of the general Canadian population (PHAC, 2012).

Each group faces multiple challenges that may contribute to not only HIV stigma, but also other overlapping stigmas, such as homophobia, bias against drug users, racist biases, and bias against sex workers (Earnshaw \& Chaudoir, 2009; Logie \& Gadalla, 2009; Reidpath \& Chan, 2005). Comparatively to the early years of the epidemic in Canada, when the vast majority of individuals with HIV were men who have sex with men (PHAC, 2012), the factors influencing how people living with HIV are perceived, and the stigmas they may face, have changed. Due to the changing epidemiology of the epidemic in Canada, with more and more people living with HIV being recent immigrants from developing countries, the dynamics, precipitating and perpetuating factors inherent to the epidemic in developing countries, such as Sub-Saharan Africa, also need to be considered (e.g., Treichler, 1999).

Sub-Saharan Africa is of particular interest to the Canadian epidemic as many new immigrants to Canada living with HIV are from this region. In developing areas in the world, such as Sub-Saharan Africa and Southeast Asia, the face of the epidemic looks remarkably different. The majority of those infected are of childbearing age, the route of transmission is 


\section{HEALTH CARE PROVIDERS AND HIV}

heterosexual, and women are disproportionately affected (Kalichman et al., 2009; National AIDS Control Organization, 2010; UNAIDS, 2008). The promotion of gender equality and universal HIV testing have been recommended to reduce the rate of transmission (UNAIDS, 2008). These, however, are extremely broad-based solutions and require large-scale structural interventions. Addressing the gender and status imbalances that contribute greatly to the spread of HIV in developing countries, from the challenge in negotiating condom use for women in assumed monogamous relationships but whose partners have multiple partners, to the fluid nature of sexual transactions for migrant and seasonal workers who engage in survival sex (e.g., transactional sex for food or shelter), sets the stage for the context within which both the spread of HIV and its stigmatization occur (Logie \& Gadalla, 2009; UNAIDS, 2008).

\section{HIV and overlapping stigmas}

HIV stigma, defined as the prejudicial attitudes, stereotyping and discrimination against people living with HIV (Earnshaw \& Chaudoir, 2009), has been extensively documented in the literature and has myriad negative effects on people living with HIV, such as decreased access to services, reduced quality of life and increased mental health concerns (e.g., Greig, Peacock, Jewkes, \& Msimang, 2008; Kebaabetswe, 2007; Herek, Capitanio, \& Widaman, 2002). As mentioned previously, HIV stigma does not exist independently of competing contextual concerns, including the role of sex, race and ethnicity, sex work and injection drug use (Reidpath \& Chan, 2005). Each of these factors has been documented to elicit stigmatizing reactions, including discriminatory behaviors, prejudicial attitudes and stereotyped thoughts (e.g., Yoder \& McDonald, 1997; Saucier \& Miller, 2003; Liu et al., 2011; Ahern, Stuber, \& Galea, 2007). Coupled with the presence, or threat, of HIV, the interacting role of these factors must be considered (Logie \& Gadalla, 2009; Nyblade, 2006; Reidpath \& Chan, 2005). Logie, James, 


\section{HEALTH CARE PROVIDERS AND HIV}

Tharao, and Loutfy (2011) have proposed a model of overlapping stigmas. This model was developed using qualitative data from women living with HIV in Canada, and therefore exists within that specific cultural and gendered perspective. The model describes the role of micro or individual level factors such as knowledge, skills, and attitudes, meso or community level factors such as norms, cultural values, beliefs and support systems, and macro or structural level factors such as organizational policies and laws contributing to HIV stigma, mirroring the emphasis seen on both individual level factors and structural or contextual factors described in Earnshaw and Chaudoir (2009) and Mahajan and colleagues (2008), respectively. These three levels of influence are proposed to interact while being buffered by individual-level resiliency factors held by people living with HIV.

\section{Integrative frameworks - HIV stigma and the role of intersectionality}

To understand the possible overlapping nature of stigmas associated with HIV stigma, the concept of intersectionality is proposed as a framework. Intersectionality can be conceptualized as the interaction of multiple elements of social identity, social systems and processes (e.g., sexism, racism) (e.g., Crenshaw, 1989; Hankivsky \& Cormier, 2009). Stratifications exist due to these often marginalizing elements of social identity, systems and processes. The intersection of these elements creates an outcome different than the sum of their parts, and therefore this intersectionality needs to be considered in research, policy and intervention (Hancock, 2007). This integrative framework is investigated in conjunction with Logie and colleagues (2011) model of overlapping stigmas (HIV stigma, racism, sexism, homophobia/transphobia, stigma against sex work) with the addition of stigma against injection drug use, as cited in the literature (e.g., Reidpath \& Chan, 2005). Logie and colleagues' (2011) description of micro, meso and macro level factors contributing to the experience of stigma for people living with HIV fits with 


\section{HEALTH CARE PROVIDERS AND HIV}

an integrative model of Earnshaw and Chaudoir (2009) and Mahajan and colleagues' (2008) work. Intersectionality in terms of HIV-related stigma raises the question: how much stigma that is experienced by people living with HIV is stigma specifically related to HIV, and how much is due to overlapping stigmas, such as race/ethnicity or sexual orientation? Stigma reduction interventions will often target these overlapping stigmas in an effort to reduce HIV stigma when their differential influence may not be known. Understanding how much these overlapping stigmas predict HIV stigma, if measured separately from its intersectional components, will inform how stigma reduction interventions will need to target attitudes and beliefs in order to reduce the experience of HIV stigma for people living with HIV.

\section{Current study}

Logie and colleagues' (2011) model of overlapping stigmas was developed with women living with HIV and their perceptions and experiences of stigma with people who are HIVnegative. One such group, with enormous influence on the lives of people living with HIV, is health care providers. Health care providers interact with people living with HIV in a vulnerable context laden with power differences, and these interactions influence the quality of life, care and medical prognosis of people living with HIV (e.g., Kinsler, Wong, Sayles, Davis, \& Cunningham, 2007). Particularly important are the views of health care provider trainees, as they are the providers who will be entering the field, and also represent a group that could be targeted for early stigma reduction interventions. The current study seeks to investigate whether the individual level factors outlined in Logie and colleagues' (2011) model (homophobia, racism, sexism, and stigma against sex work), as well as stigma against injection drug use, as highlighted by Reidpath and Chan (2005), exist for health care provider trainees in the same context of Ontario, Canada, and whether they predict HIV stigma. The current study examines this 
HEALTH CARE PROVIDERS AND HIV

intersectional idea from a simplified perspective, first establishing which forms of overlapping stigma contribute to HIV stigma, in order to build the basis to understand the intersection more fully.

The first goal of the current study is to assess how HIV stigma is associated with demographic characteristics, contextual factors such as stage of training and training program, and the overlapping stigmas unique to the HIV pandemic (homophobia, racism, sexism, stigma against injection drug use and stigma against sex work; Logie et al., 2011; Reidpath \& Chan, 2005). The second goal is to examine if and how much these overlapping stigmas account for HIV stigma. It is hypothesized that:

1. Higher levels of HIV stigma will be associated with higher levels of overlapping stigmas. Specifically, higher levels of homophobia, racism, sexism, stigma against injection drug use and stigma against sex work will be associated with higher levels of HIV stigma.

2. The intersectional model of overlapping HIV-related stigmas will fit for a sample of North American health care providers, and that the overlapping stigmas will account for a significant portion of HIV stigma.

Additionally, exploratory analyses will investigate whether the intersectional model of overlapping HIV-related stigmas also predict each of three subscales of HIV stigma: prejudice, stereotyping, and discrimination (see earlier in this dissertation; Earnshaw \& Chaudoir, 2009).

\section{Methods}

Two hundred and thirty four medical and nursing students from across Canada participated in the study, and were the same sample as for Study 2. They were recruited to participate in an online study to examine health care trainee attitudes and beliefs about HIV and related variables. Participants were recruited over email from medical and nursing programs 


\section{HEALTH CARE PROVIDERS AND HIV}

through student association listserves, and had to be enrolled in either a medical or nursing program to participate. A link to the online questionnaire was provided in the recruitment email, and participants who followed the link provided informed consent (see Appendix D). Upon completion of the questionnaire, participants were given a resource sheet, debriefing form, and were compensated $\$ 15$ via electronic gift certificate (see Appendix E). The study was approved by the Ryerson University Research Ethics Board.

Participants were between the ages of 18 and $41(M=23.28$, Median=23.00), and predominantly female (75.9\%). Slightly more than half of participants were medical students $(54.9 \%)$ and the remainder were nursing students. The mean year of program enrollment was

$2.44(S D=1.15)$. There were no mean group differences in terms of scores on the measure of HIV stigma for participants based on program enrollment. Full demographic characteristics can be found in Table 1. 
HEALTH CARE PROVIDERS AND HIV

Table 1. Descriptive characteristics.

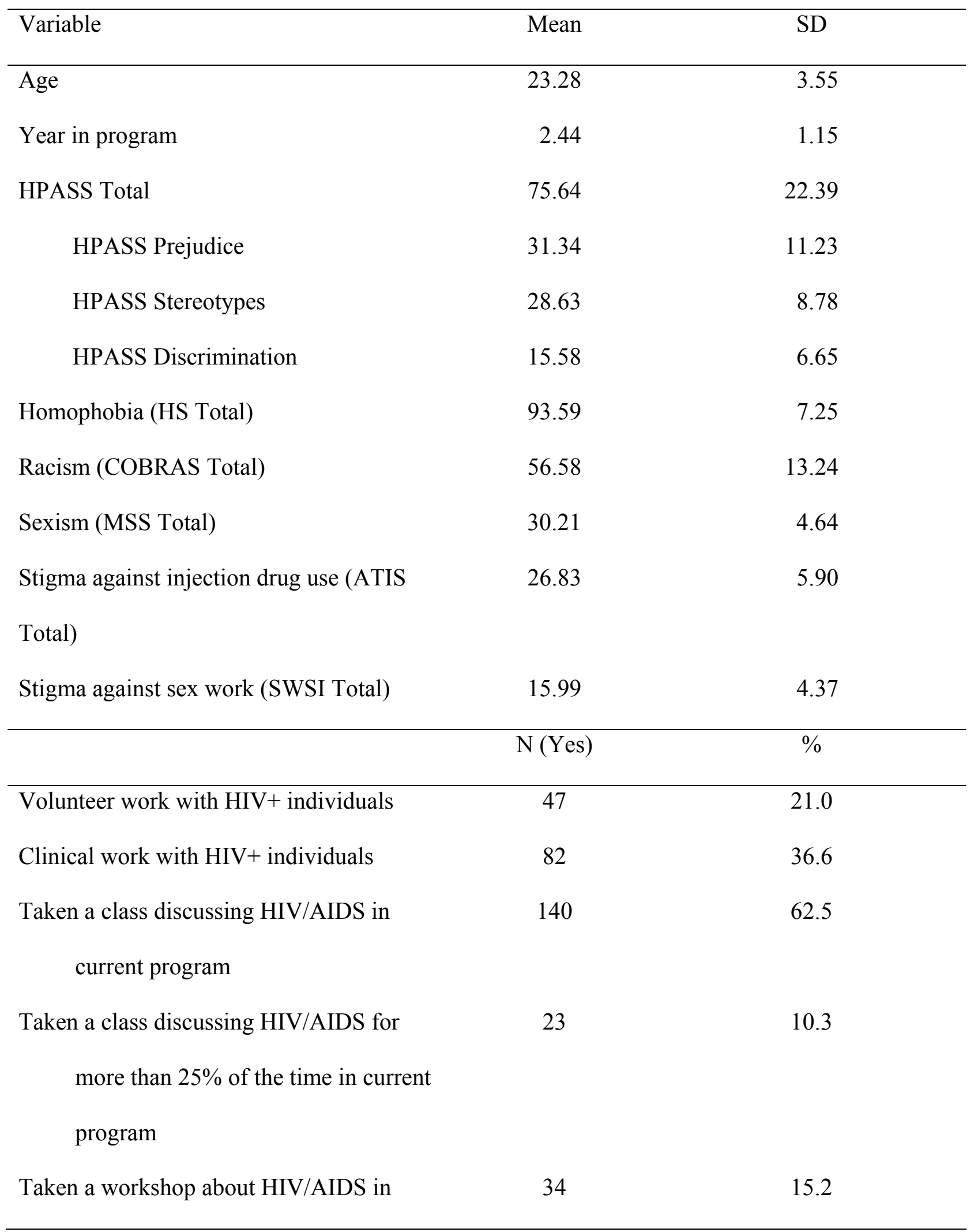


HEALTH CARE PROVIDERS AND HIV

current program

Taken a workshop or course about

HIV/AIDS ever

Gender

Female

Male

Gender Queer

Program

Nursing

101

Medicine

123

Sexual orientation

Exclusively heterosexual

188

Heterosexual, some homosexual

experience

Bisexual

Homosexual, some heterosexual

experience

Exclusively homosexual

Other

Ethnicity†

European/North American

East Asian

96

41.0

South Asian

22

9.4 
HEALTH CARE PROVIDERS AND HIV

Caribbean (Black/African, Indo and

10

4.3

Other)

Middle Eastern/North African

7

3.0

African

5

2.1

Aboriginal

5

Hispanic/Latino

2

0.9

Other

Born in Canada

165

Setting raised

Rural setting

23

10.3

Suburban setting

104

46.4

Urban setting

97

43.3

Area of country currently reside

Toronto

125

56.1

Ontario, Quebec, Maritimes excluding

55

Toronto

Central Canada (Alberta, Manitoba,

Saskatchewan)

British Columbia

12

5.4

$\dagger$ Participants were allowed to identify more than one ethnicity, therefore totals add up to greater than $100 \%$. The majority of participants who identified multiple ethnicities were of multiple Caucasian European and "North American" background $(\mathrm{N}=20)$. Eighteen participants identified being of other multiple ethnicities. 
HEALTH CARE PROVIDERS AND HIV

\section{Measures}

Participants completed the following questionnaires:

Demographics. Demographic information collected included age, gender, stage of education, and program of enrollment. Questions were also asked regarding academic courses taken in infectious diseases and experience working with and volunteering with people living with HIV.

HIV Stigma. (Health Care Provider HIV/AIDS Stigma Scale (HPASS); Wagner et al., earlier in this dissertation). The HPASS is a 30-item measure assessed on a 6-point Likert scale (from 1 strongly disagree to 6 strongly agree, with one reverse coded item). The HPASS has three subscales: prejudice, stereotypes and discrimination. The scale was developed and confirmatory analyses were run with medical and nursing students in Canada. In the current study, the total scale demonstrated excellent internal consistency (Cronbach's alpha $=.94$ ), as did each subscale (Cronbach's alphas $=.91, .82$, and .92 for prejudice, stereotypes and discrimination, respectively). The scale has demonstrated good test-retest reliability $(r=.93, p$ $<.001$ ), convergent validity with other measures of HIV stigma, and divergent validity with a scale of empathy associated with HIV.

Racism (Color-Blind Racial Attitudes Scale (CoBRAS); Neville, Lilly, Duran, Lee, \& Browne, 2000). The CoBRAS consists of 20 items assessed on a 6-point Likert scale (from 1 strongly disagree to 6 strongly agree). The CoBRAS assesses racial attitudes irrespective of ethnicity, and consists of three factors: unawareness of racial privilege, institutional discrimination and blatant racial issues. The scale has demonstrated strong internal validity as well as strong convergent validity with other scales of racial prejudice and racial and gender intolerance. This scale was edited for a Canadian audience. The scale demonstrated good internal 
HEALTH CARE PROVIDERS AND HIV

consistency in the current study (Cronbach's alpha $=.85)$.

Sexism (Modern Sexism Scale; MSS; Swim, Aikin, Hall, \& Hunter, 1995). The MSS is an eight-item scale measured on a five-point Likert scale $(1=$ strongly agree to $5=$ strongly disagree) and demonstrates good internal consistency in the current study (Cronbach's alpha $=.81)$. It was validated with samples of U.S. undergraduate students, and yielded the same structure and comparable internal consistency upon re-test. Items cover denial of continuing discrimination, antagonism toward women's demands, and resentment about special favors for women. The measure shows divergent validity from scales of racism and convergent validity with other scales of sexism. A sample item is "It is rare to see women treated in a sexist manner on television." This scale was edited from "American" references to "Canadian". For example, the item stating "Discrimination against women is no longer a problem in the United States" was changed to state "Discrimination against women is no longer a problem in Canada".

Homophobia (Homophobia Scale (HS); Wright, Adams, \& Bernat, 1999). The Homophobia Scale is a 25-item, three factor (negative cognitions, negative affect and avoidance, and negative affect and aggression) scale which demonstrates excellent internal consistency and test-retest reliability (Cronbach's alpha $=.94$ and $r=.96$ ), as well as good concurrent validity with other measures of homophobia. It was validated with a sample of undergraduate university students. In the current study, the scale also demonstrated good internal consistency (Cronbach's alpha $=.74)$. A sample item is "I would feel comfortable having a gay roommate." Item number 19 was removed "I would hit a homosexual for coming on to me" because of violent content.

Attitudes towards sex work (an adapted version of the Sex Worker Stigma Index; SWSI; Liu et al., 2011). The SWSI is a 10-item scale examining perceived stigma by sex workers. The scale had good internal consistency in the current study (Cronbach's alpha $=.85$ ). 


\section{HEALTH CARE PROVIDERS AND HIV}

The scale was developed and confirmed with a sample of female sex workers in India. Because no other scale exists to specifically assess attitudes towards sex work, this measure was adapted to be administered as an assessment for a general population. A sample item is "I feel that if I disclosed being a sex worker to my family, they would treat me differently" that was adapted to "If a family member disclosed they were a sex worker, I would treat them differently." Items 4 and 6 ("I feel that if someone disclosed to me they were a sex worker, I would threaten them with violence" and "I feel that if my partner disclosed to me they were a sex worker, I would hit him/her") were removed because of violent content.

Attitudes toward injection drug use (Attitudes Toward Injection Drug Use Scale (ATIS); Brener \& von Hippel, 2008). The Attitudes Toward Injection Drug Use Scale consists of 10 items adapted from the Attitudes Toward Gay and Lesbians Scale (Herek, 1994), the Heterosexual Attitudes Toward Homosexuality Scale (Larsen, Reed, \& Hoffman, 1980), and the Attitudes Toward Homosexuals Scale (Altemeyer \& Hunsberger, 1992). The scale demonstrated good internal consistency in the current study (Cronbach's alpha $=.80$ ). The ATIS is assessed on a five-point Likert scale ranging from 1 (strongly disagree) to 5 (strongly agree). It was originally assessed with Australian undergraduate students and has been validated in confirmatory factor analyses with health care workers. This scale shows a strong correlation with measures of social conservatism. A sample item is: "People should feel sympathetic and understanding of injecting drug users".

\section{Analytic Plan}

Univariate analyses were conducted (Pearson and Spearman correlations) to determine the relationships between HIV-stigma and demographic, education and work experience 
HEALTH CARE PROVIDERS AND HIV

characteristics, racism, sexism, homophobia, attitudes towards sex work, and attitudes toward injection drug use.

Subsequently, a multiple linear regression using the five predicted overlapping stigmas was run to predict HIV stigma. The model was then tailored to four predicted overlapping stigmas. Multiple linear regression analyses were run using these four overlapping stigmas to predict the total score of the HPASS, as well as each of the subscale total scores of the HPASS to determine any difference between them. As five regressions were run, $\alpha$ was set at 0.01 to control for Type I error. A minimum sample of 200 participants was established accounting for ten participants per pathway between predictor and outcome variable, per moderately conservative estimation (e.g., Schreiber, Nora, Stage, Barlow, \& King, 2006).

\section{Results}

In bivariate associations, ever having done volunteer work with people living with HIV, having had a class that discussed HIV in their current program, and having been born outside of Canada were associated with lower HIV stigma (see Table 2). Age, year in training program, ever having done clinical work with people living with HIV, gender and program of study were not associated with HIV stigma. Each of the overlapping stigmas was associated with the HPASS total scale score and each of the HPASS subscales. The correlations were all in the hypothesized direction, with HPASS scores being positively associated with higher stigmatizing attitudes for each of the other stigmas (for a full report of bivariate correlations, see Table 3 for overlapping stigmas and HPASS, and Table 4 for overlapping stigmas and HPASS subscales). 
HEALTH CARE PROVIDERS AND HIV

Table 2. Correlations between demographic characteristics and HPASS total.

Demographic variable

Correlation with HPASS total

\begin{tabular}{lc}
\hline Age & $n s$ \\
Year in program & $n s$ \\
Volunteer work with HIV+ individuals & $-.15^{*}$ \\
Clinical work with HIV+ individuals & $n s$ \\
Taken a class discussing HIV/AIDS in current & $-.16^{*}$ \\
program & \\
Gender & $n s$ \\
Program & $n s$ \\
Born in Canada & $-.14^{*}$ \\
\hline Notes: * $p<.05$. Ethnicity and sexual orientation were not included due to small group cell sizes.
\end{tabular}


HEALTH CARE PROVIDERS AND HIV

Table 3. Correlations between overlapping stigmas and HPASS total.

\begin{tabular}{|c|c|c|c|c|c|c|}
\hline & 1. & 2. & 3. & 4. & 5. & 6. \\
\hline 1. HIV stigma (HPASS & - & & & & & \\
\hline \multicolumn{7}{|l|}{ Total) } \\
\hline 2. Homophobia (HS) & $-.40 * * *$ & - & & & & \\
\hline 3. Racism (COBRAS) & $.35^{* * *}$ & $-.15 * *$ & - & & & \\
\hline 4. Sexism (MSS) & $-.25 * * *$ & $.22 * *$ & $-.55 * * *$ & - & & \\
\hline 5. Stigma against & $.49 * * *$ & $-.33 * * *$ & $.30 * * *$ & $-.20 * *$ & - & \\
\hline \multicolumn{7}{|l|}{ injection drug use (ATIS) } \\
\hline 6. Stigma against sex & $.47 * * *$ & $-.33 * * *$ & $.12 * *$ & $-.09 *$ & $.48 * * *$ & - \\
\hline work (SWSI) & & & & & & \\
\hline
\end{tabular}

Notes. $n=205$ for all correlations. ${ }^{*} p<.10,{ }^{* *} p<.05,{ }^{* * *} p<.001$. The HS and MSS scales are reverse scored, therefore higher scores indicate less stigmatizing attitudes. 
HEALTH CARE PROVIDERS AND HIV

Table 4. Correlations between overlapping stigmas and HPASS subscales.

\begin{tabular}{llllll}
\hline & $\begin{array}{l}\text { Homophobia } \\
\text { (HS) }\end{array}$ & $\begin{array}{l}\text { Racism } \\
\text { (COBRAS) }\end{array}$ & $\begin{array}{l}\text { Sexism } \\
\text { (MSS) }\end{array}$ & $\begin{array}{l}\text { Stigma } \\
\text { against } \\
\text { injection drug } \\
\text { use (ATIS) }\end{array}$ & $\begin{array}{l}\text { Stigma } \\
\text { against sex } \\
\text { work (SWSI) }\end{array}$ \\
\hline HPASS & $-.36^{* *}$ & $.29^{* *}$ & $-.22^{*}$ & $.43^{* *}$ & $.44^{* *}$ \\
Prejudice & & & & & \\
HPASS & $-.34^{* *}$ & $.34^{* *}$ & $-.24^{* *}$ & $.43^{* *}$ & $.36^{* *}$ \\
Stereotypes & & & & & $.37^{* *}$ \\
HPASS & $-.30^{* *}$ & $.22^{* *}$ & $-.18^{*}$ & & \\
Discrimination & & & & & \\
\hline
\end{tabular}

Notes. $n=208$ for Prejudice; 209 for Stereotypes and Discrimination. HPASS Prejudice $=$ prejudice subscale score. HPASS Stereotypes $=$ stereotypes subscale score. HPASS Discrimination $=$ discrimination subscale score. ${ }^{* *} p<.001,{ }^{*} p<.01$. The HS and MSS scales are reverse scored, therefore higher scores indicate less stigmatizing attitudes. 


\section{HEALTH CARE PROVIDERS AND HIV}

In the multiple regression predicting HPASS total with five overlapping stigmas, the model was significant (see Table 5). Each variable was significant except for sexism. Thus, the model was re-run excluding sexism. In this model with four overlapping stigmas, the model was also significant (adjusted $\left.R^{2}=0.39, F(4,202)=33.84, p<0.001\right)$. Homophobia, racism, stigma against injection drug use, and stigma against sex work were each uniquely associated with HIV stigma, accounting for $3.73 \%, 4.16 \%, 3.53 \%$ and $5.43 \%$ of the variance, respectively (see Table 6). Separate regression analyses were also run predicting each of the subscales and each model was significant, indicating that the overlapping stigmas significantly predicted the subscale scores of Prejudice, Stereotypes and Discrimination, respectively (see Table 5). 
HEALTH CARE PROVIDERS AND HIV

Table 5. Summary of additional regression analyses.

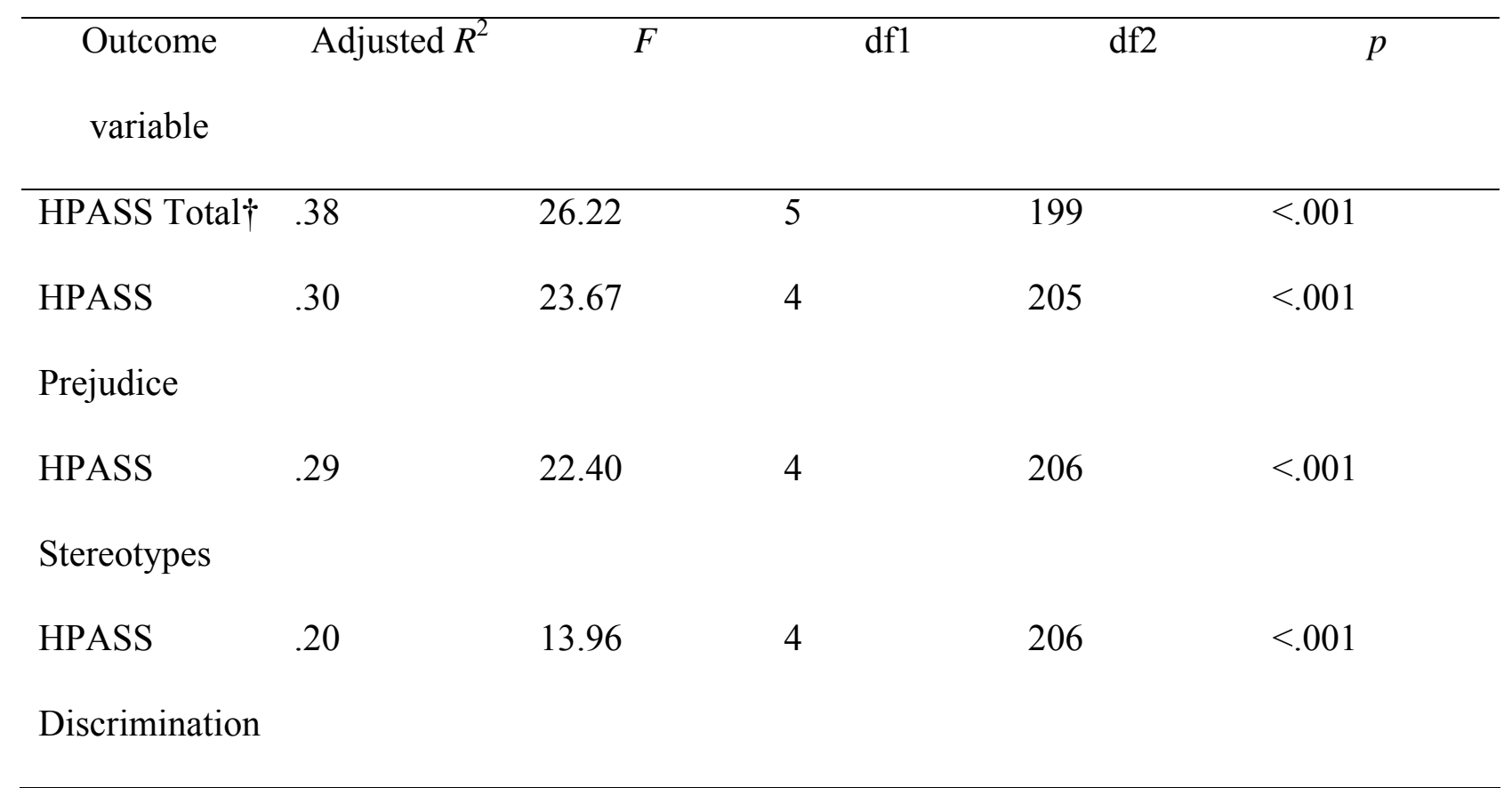

$†$ Model included five overlapping stigmas. 
HEALTH CARE PROVIDERS AND HIV

Table 6. Four variable overlapping stigmas regression model.

\begin{tabular}{lcccccc}
\hline \multicolumn{1}{c}{ Variable } & B & SE & $\beta$ & t & Part & $p$ \\
\hline Homophobia (HS) & -0.65 & .18 & -.21 & -3.55 & -.19 & $<.001$ \\
Racism & 0.36 & .10 & .22 & 3.76 & .20 & $<.001$ \\
(COBRAS) & & & & & & \\
Stigma against sex & 1.40 & .33 & .27 & 4.27 & .23 & $<.001$ \\
work (SWSI) & & & & & & \\
Stigma against & 0.86 & .25 & .23 & 3.45 & .19 & .001 \\
injection drug use & & & & & & \\
(ATIS) & & & & & &
\end{tabular}

Notes. Adjusted $R^{2}=0.39, F(4,202)=33.84, p<.001$. 
HEALTH CARE PROVIDERS AND HIV

\section{Discussion}

The current study provides evidence that the intersectional model of overlapping stigmas predicts HIV stigma. The overlapping stigmas together account for nearly $40 \%$ of the total variance of HIV stigma, suggesting that overlapping stigmas play a significant role in determining HIV stigma, but not completely. The remaining $60 \%$ of the variance unaccounted for suggests that there is indeed a unique aspect to HIV that creates stigma above and beyond the overlapping stigmas assessed, and was not explicitly accounted for by demographic variables, as determined by the bivariate correlations. Intersectionality is suggested due to the overlapping stigmas' strong role in predicting HIV stigma, as the sum of the parts of the model account for more than HIV stigma or each measure of stigma individually, creating a phenomenon of stigma beyond what each factor alone could create (Hankivsky \& Cormier, 2009; Hancock, 2007). The overlapping stigmas accounted for nearly $17 \%$ of the variance the model accounted for, suggesting the additional $22 \%$ accounted for by the model but not by each factor individually are due to their intersection. Within this intersectionality, stigma against sex work accounted for the largest percentage of the variance. This is particularly concerning, as health care providers may marginalize individuals engaged in sex work and prevent open and honest discussion of health concerns that are unique to individuals engaged in this work. Secrecy regarding involvement in sex work may therefore also be inadvertently encouraged, and individuals involved in sex work may feel unable or unwilling to discuss safety and mental health concerns related to their work. Racism accounted for the second largest percentage of the variance, and is worth exploring in further detail in terms of how race interacts with the other overlapping stigmas such as stigma against injection drug use or sex work, as in Canada, individuals of Aboriginal, African and Caribbean descent are disproportionately represented in these groups (PHAC, 2012). 


\section{HEALTH CARE PROVIDERS AND HIV}

Homophobia and stigma against injection drug use also both contributed nearly $4 \%$ of the variance each, suggesting other areas strongly worth investigating in terms of intervention for health care trainees, as perhaps the new trainees have not been exposed to the key information central to the early years of the epidemic.

Sexism is not a significant predictor of HIV stigma in this sample. Logie and colleagues' (2012) model was developed with women living with HIV, and therefore offered a specific perspective on the experience of being a woman and experiencing HIV stigma. In this broader study of health care provider trainees, looking at HIV stigma generally, it is possible that HIV continues to be linked to men more than to women, also demonstrated by Canada's epidemiological HIV statistics (PHAC, 2012). Sexism in this sample, while being associated with HIV stigma in bivariate associations, does not predict HIV stigma significantly when examined with homophobia, racism, stigma against injection drug use and stigma against sex work, which appear to be central issues in determining HIV stigma. This distinction demonstrates that high HIV stigma does not necessarily equate to high stigmatizing attitudes and behaviours in all areas. This distinction demonstrates that HIV stigma is not purely a result of having blanket stigmatizing and discriminatory attitudes.

Additional analyses examined whether the model of overlapping stigmas predicted each of the three components that create HIV stigma - prejudice, stereotyping, and discrimination. The results demonstrate that the same model does hold in predicting each of these components, showing that these attitudes, cognitions, and behaviours are similarly associated to other forms of stigma. This finding suggests that interventions to reduce HIV stigma could be developed that target each of these three areas, ensuring comprehensive assessment and intervention of all components of HIV stigma. Generally, the pattern of prediction and weight of the predictors was 


\section{HEALTH CARE PROVIDERS AND HIV}

similar across each subscale, suggesting that they are similarly constructed. For the prejudice and discrimination subscales, the relative contribution of each form of overlapping stigma was nearly the same as for the total scale (1) sex work, 2) racism and homophobia tied, 4) injection drug use for prejudice; 1) sex work, 2) homophobia, 3) racism and drug use tied for discrimination). For the stereotypes subscale, the relative contribution of the overlapping stigmas was different (1) racism, 2) drug use, 3) homophobia, 4) sex work). These findings suggest that stronger stereotypes may be associated with race and injection drug use, but more stigmatizing attitudes and behaviours may be associated with sex work in the context HIV stigma.

Together, these results suggest that HIV stigma is highly, but not completely, predicted by overlapping stigmas. These results support the literature on overlapping models of stigma for HIV (e.g., Reidpath \& Chan, 2005; Logie et al., 2012), as well as theoretical developments conceptualizing HIV stigma as encompassing three distinct components: prejudice, stereotyping and discrimination (Earnshaw \& Chaudoir, 2009). These findings suggest that each of these overlapping stigmas and stigma related to HIV itself can therefore be targeted in order to effectively reduce HIV stigma. Additionally, this model provided a simplified model of intersectionality, establishing primary forms of overlapping stigmas, but also suggesting that additional variables, such as health anxiety or classism, could be considered to further understand this intersection and interactions between variables. The extent of the cumulative and temporal effect of overlapping stigmas should be examined in further detail.

The current study has a number of limitations. The study is based on self-report of stigmas, which may underrepresent the views of the participants. The majority of participants were female, and were not evenly distributed across the country. Relatively low levels of each of the overlapping stigmas and HIV stigma were found for the sample, which may or may not be 


\section{HEALTH CARE PROVIDERS AND HIV}

representative of attitudes and behaviours enacted in practice. While a measure of social desirability was included in the study, it had very low internal consistency amongst this sample, and therefore any results drawn from its associations would be tenuous at best. Additionally, the study likely did not capture ideas held by trainees representatively across the country or in areas such as Aboriginal communities. Future studies should extend the findings to external assessment of stigmatizing behaviours, such as within health care trainee practical assessments like the Objective Structured Clinical Examination (e.g., Sloan et al., 1996). Objective Structured Clinical Examinations are observed scenarios between health care trainees and real or actorpatients, allowing a clinical preceptor to observe the interaction in situ and provide feedback on behaviours beyond diagnostics. This type of assessment would allow for the evaluation of interactions with clients or actor-clients in a real world context, and could serve to strengthen or further elucidate which interactions and what information produce stigmatizing reactions. Additionally, stigmatizing behaviours could be intervened upon in the moment during the examination to allow for in vivo learning.

Additionally, these results call for the integration of stigma-informed care not only regarding HIV stigma, but also regarding the impact of the compounding effect of these overlapping stigmas and their detrimental impact on care for people living with HIV. It is possible that health care providers may further marginalize people living with HIV due to these stigmas. Conversely, these results suggest that it may be possible to reduce HIV stigma by addressing these overlapping stigmas, too. Intervention programs to reduce HIV stigma should therefore also include training regarding the four overlapping stigmas of stigma against sex work, racism, homophobia and stigma against injection drug use. 


\section{HEALTH CARE PROVIDERS AND HIV}

HIV continues to exist in a marginalizing context due to the lack of preemptive and remedial intervention on stigmatizing attitudes, behaviours and cognitions. As we move forward, we need to be reminded that although treatment has improved, HIV remains a significant public health concern and HIV stigma can have a large and detrimental effect on people's quality of life, mental health, and physical health outcomes, and that the relationship with health care providers is a significant factor in these outcomes (Aranda-Naranjo, 2004; Carr \& Gramling, 2004; Devine, Plant, \& Harrison, 1999; Emlet, 2006; Orner, 2006). Overlapping stigmas significantly predict HIV stigma, and need to be addressed within health care provider training and evaluated and intervened upon during practice. 
HEALTH CARE PROVIDERS AND HIV

\section{References}

Ahern, J., Stuber, J., \& Galea, S. (2007). Stigma, discrimination and the health of illicit drug users. Drug and Alcohol Dependence, 88, 188-196. doi: 10.1016/j.drugalcdep.2006.10.014

Altemeyer, B., \& Hunsberger, B. (1992). Authoritarianism, religious fundamentalism, quest, and prejudice. The International Journal for the Psychology of Religion, 2, 113-133. doi: 10.1207/s15327582ijpr0202_5

Aranda-Naranjo, B. (2004). Quality of life in the HIV-positive patient: implications and consequences. Journal of the Association of Nurses in AIDS Care, 15, 20S-27S. doi: $10.1177 / 1055329004269183$

Brener, L., \& von Hippel, W. (2008). Measuring attitudes toward injecting drug users and people with Hepatitis C. Substance Use and Misuse, 43, 295-302. doi: $10.1080 / 10826080701202627$

Carr, R.L., \& Gramling, L.F. (2004). Stigma: a health barrier for women with HIV/AIDS. Journal of the Association of Nurses in AIDS Care, 15, 30-39. doi: $10.1177 / 1055329003261981$

Crenshaw, K. (1991). Mapping the margins: intersectionality, identity politics, and violence against women of color. Stanford Law Review, 43, 1241-1299. doi: 10.2307/1229039

Devine, P.G., Plant, E.A., \& Harrison, K. (1999). The problem of "us" versus "them" and AIDS stigma. American Behavioral Scientist, 42, 1212-1228. doi: 10.1177/00027649921954732

Earnshaw, V.A., \& Chaudoir, S.R. (2009). From conceptualizing to measuring HIV stigma: a review of HIV stigma mechanism measures. AIDS and Behavior, 13, 1160-1177. doi: $10.1007 / \mathrm{s} 10461-009-9593-3$ 


\section{HEALTH CARE PROVIDERS AND HIV}

Emlet, C.A. (2006). An examination of the social networks and social isolation in older and younger adults living with HIV/AIDS. Health \& Social Work, 31, 299-308. doi: $10.1093 / \mathrm{hsw} / 31.4 .299$

Greig, A., Peacock, D., Jewkes, R., \& Msimang, S. (2008). Gender and AIDS: time to act. AIDS, 22(suppl 2), S35-S43. doi: 10.1097/01.aids.0000327435.28538.18

Hancock, A.M. (2007). When multiplication doesn't equal quick addition: examining intersectionality as a research paradigm. Perspectives on Politics, 5, 63-78. doi: $10.1017 / \mathrm{S} 1537592707070065$

Hankivsky, O., \& Cormier, R. (2009). Intersectionality: Moving women’s health and policy forward. Vancouver: Women's Health Research Network.

Herek, G.M. (1994). Assessing heterosexuals' attitudes toward lesbians and gay men: a review of empirical research with the ATLG scale. In B. Greene \& G.M. Herek (Eds.), Psychological perspectives on lesbian and gay issues. Newbury Park, CA: Sage.

Herek, G.M., Capitanio, J.P., \& Widaman, K.F. (2002). HIV-related stigma and knowledge in the United States: prevalence and trends, 1991-1999. American Journal of Public Health, 92, 371-377. doi: 10.2105/AJPH.92.3.371

Kalichman, S.C., Simbayi, L.C., Cloete, A., Mthembu, P.P., Mkhonta, R.N., \& Ginindza, T. (2009). Measuring AIDS stigmas in people living with HIV/AIDS: the Internalized AIDSRelated Stigma Scale. AIDS Care, 21, 87-93. doi: 10.1080/09540120802032627

Kebaabetswe, P.M. (2007). Barriers to participation in the prevention of mother-to-child HIV transmission program in Gaborone, Botswana: a qualitative approach. AIDS Care, 19, 355360. doi: 10.1080/09540120600942407 


\section{HEALTH CARE PROVIDERS AND HIV}

Kinsler, J.J., Wong, M.D., Sayles, J.N., Davis, C., \& Cunningham, W.E. (2007). The effect of perceived stigma from a health care provider on access to care among a low-income HIVpositive population. AIDS Patient Care and STDs, 21, 584-592. doi: 10.1089/apc.2006.0202

Larsen, K.S., Reed, M., \& Hoffman, S. (1980). Attitudes of heterosexuals toward homosexuality; a Likert-type scale and construct validity. Journal of Sex Research, 19, 105-118. doi: $10.1080 / 00224498009551081$

Liu, S-H., Srikrishnan, A.K., Zelaya, C.E., Solomon, S., Celentano, D.D., \& Sherman, S.G. (2011). Measuring perceived stigma in female sex workers in Chennai, India. AIDS Care, 23, 619-627. doi: 10.1080/09540121.2010.525606

Logie, C., \& Gadalla, T.M. (2009). Meta-analysis of health and demographic correlates of stigma towards people living with HIV. AIDS Care, 21, 742-753. doi: $10.1080 / 09540120802511877$

Logie, C.H., James, L., Tharao, W., \& Loutfy, M.R. (2012). HIV, Gender, Race, Sexual Orientation, and Sex Work: A Qualitative Study of Intersectional Stigma Experienced by HIV-positive Women in Ontario, Canada. PLoS Medicine, 8, e1001124. doi: 10.1371/journal.pmed.1001124

Mahajan, A.P., Sayles, J.N., Patel, V.A., Remien, R.H., Sawires, S.R., Ortiz, D.J., ... \& Coates, T.J. (2008). Stigma in the HIV/AIDS epidemic: a review of the literature and recommendations for the way forward. AIDS, 22, S67-S79. doi: 10.1097/01.aids.0000327438.13291.62

National AIDS Control Organization. (2010). Department of AIDS control ministry of health \& family welfare annual report 2009-10. National AIDS Control Organization, Government of India, India. 


\section{HEALTH CARE PROVIDERS AND HIV}

Neville, H.A., Lilly, R.L., Duran, G., Lee, R.M., \& Browne, L. (2000). Construction and initial validation of the Color-Blind Racial Attitudes Scale (CoBRAS). Journal of Counseling Psychology, 47, 59-70. doi: 10.1037/0022-0167.47.1.59

Nyblade, L.C. (2006). Measuring HIV stigma: Existing knowledge and gaps. Psychology, Health \& Medicine, 11, 335-345. doi: 10.1080/13548500600595178

Orner, P. (2006). Psychosocial impacts on caregivers of people living with AIDS. AIDS Care, 18, 236-240. doi: 10.1080/09540120500456565

Public Health Agency of Canada (2012). Summary: estimates of HIV prevalence and incidence in Canada, 2011. Public Health Agency of Canada, Ottawa, Canada.

Reidpath, D.D., \& Chan, K.Y. (2005). A method for the quantitative analysis of the layering of HIV-related stigma. AIDS Care, 17, 425-432. doi: 10.1080/09540120412331319769

Saucier, D.A., \& Miller, C.T. (2003). The persuasiveness of racial arguments as a subtle measure of racism. Personality and Social Psychology Bulletin, 29, 1303-1315. doi: $10.1177 / 0146167203254612$

Schreiber, J.B., Nora, A., Stage, F.K., Barlow, E.A., \& King, J. (2006). Reporting structural equation modeling and confirmatory factor analysis results: a review. The Journal of Educational Research, 99, 323-338. doi: 10.3200/JOER.99.6.323-338

Sloan, D.A., Donnelly, M.B., Schwartz, R.W., Felts, J.L., Blue, A.V., \& Strodel, W.E. (1996). The use of the Objective Structured Clinical Examination (OSCE) for evaluation and instruction in graduate medical education. Journal of Surgical Research, 63, 225-230. doi: 10.1006/jsre.1996.0252 
HEALTH CARE PROVIDERS AND HIV

Swim, J.K., Aikin, K.J., Hall, W.S., \& Hunter, B.A. (1995). Sexism and racism: old-fashioned and modern prejudices. Journal of Personality and Social Psychology, 68, 199-214. doi: $10.1037 / 0022-3514.68 .2 .199$

Treichler, P. A. (1999). AIDS and HIV infection in the third world: a first world chronicle. In P. Treichler (Ed.), How to have theory in an epidemic. Durham, NC: Duke University Press. UNAIDS (2008). Report on the global HIV/AIDS epidemic 2008. Joint United Nations Programme on HIV/AIDS (UNAIDS), Geneva.

UNAIDS (2010). Report on the global HIV/AIDS epidemic 2010. Joint United Nations Programme on HIV/AIDS (UNAIDS), Geneva.

UNAIDS (2012). Report on the global HIV/AIDS epidemic 2012. Joint United Nations Programme on HIV/AIDS (UNAIDS), Geneva.

Wright, L.W., Adams, H.E., \& Bernat, J. (1999). Development and validation of the Homophobia Scale. Journal of Psychopathology and Behavioral Assessment, 21, 337-347. Yoder, J.D., \& McDonald, T.W. (1997). The generalizability and construct validity of the Modern Sexism Scale: some cautionary notes. Sex Roles, 36, 655-663. 


\section{HEALTH CARE PROVIDERS AND HIV}

\section{Summary Discussion}

The three studies discussed in this dissertation range from exploratory, qualitative, and based on critical epistemology, to theory-driven, quantitative and from a positivist lens. The goal of combining these methodologies and approaches was to use the benefits inherent in both to create a meaningful, contextually-relevant, timely and critical base on which to build pragmatic tools and modeling in order to inform change. Specifically, a critical, qualitative method (Prilleltensky, 1989) was used in Study 1 to understand the current perception of health care provider attitudes and beliefs in the health care system related to HIV stigma to question the “improved" nature of care and determine whether HIV stigma continues to exist. Positivist methods were used in Study 2 and Study 3 to empirically evaluate the presence and structure of the stigma identified in Study 1, as well as overlapping stigmas.

Study 1 examined perceptions of health care provider attitudes towards people living with HIV from a critical, qualitative perspective in focus groups. This study highlighted the ongoing and sometimes insidious nature of HIV stigma within the health care system, and that relationships with health care providers continue to be important for the well-being of people living with HIV. Study 2 used the themes of the focus groups to develop a questionnaire to assess health care provider attitudes and beliefs towards people living with HIV, thereby extending the exploratory work into a theory-based and measurement-driven model. The scale that was created, the Health Care Provider HIV/AIDS Stigma Scale (HPASS) is contextuallyappropriate for Canadian health care providers. The HPASS is designed to be subtle in order to avoid response bias, for example, by not asking about dislike of people living with HIV but instead asking about willingness to treat people living with HIV.

Study 3 used the HPASS as a measure of HIV stigma to examine overlapping stigmas. This study examined whether the hypothesized overlapping stigmas (e.g., racism, homophobia, 


\section{HEALTH CARE PROVIDERS AND HIV}

stigma against injection drug use; Logie, James, Tharao, \& Loutfy, 2012; Reidpath \& Chan, 2005) were indeed associated with HIV stigma, and whether they accounted for all of the variance of HIV stigma, or if variance existed above and beyond these variables. This study found that the overall contribution of the overlapping stigmas to predicting HIV stigma was greater than the sum of their parts, indicating intersectionality (e.g., Crenshaw, 1989; Hankivsky \& Cormier, 2009), and that also while the overlapping stigmas contributed significantly to HIV stigma, that there is indeed something unique to HIV stigma beyond those predictors, be it related to HIV itself or additional variables yet to be considered.

Collectively, this work supports the recent conceptualization of HIV stigma as comprising the three components of prejudice, stereotypes, and discrimination (Earnshaw \& Chaudoir, 2009). This conceptualization of HIV stigma allows for not only more precise measurement, but also for intervention strategies targeting each of the components in order to reduce the impact and presence of HIV stigma. HIV stigma can specifically be defined as emotionally-valenced attitudes (prejudice), cognitions (stereotypes) and behaviours (discrimination). Institutional factors were highlighted during the focus groups, as is discussed in the literature (e.g., Mahajan et al., 2008), and would be important elements to assess and address alongside the individual components identified in the HIV stigma framework. Individual and institutional factors are likely to be intertwined, as intervening on the individual-level variables for health care providers, such as stereotypes regarding routes of transmission, may reduce institutional barriers to good, stigma-free care, should enough providers be operating from a stigma-informed perspective (e.g., Radcliffe, Doty, Hawkins, Gaskins, Beidas, \& Rudy, 2010).

There are other themes raised in the three studies that warrant further consideration. Among these, one is the perception of positive, neutral and negative interactions between health 


\section{HEALTH CARE PROVIDERS AND HIV}

care providers and people living with HIV. An interaction that may be perceived as neutral by a health care provider may, to a person living with HIV who has already been exposed to stigmatizing interactions, be perceived as negative. Indeed, differences in the emotional valence of an interaction and subsequent interpretation of the interaction have been found in the literature both within health care research (Beck, Daughtridge, \& Sloane, 2002), clinical psychology (Amir, Beard, \& Bower, 2005; Leppanen, Milders, Bell, Terriere, \& Hietanen, 2004) and social psychology (Isen \& Shalker, 1982). For example, a systematic review of physician-patient interactions specifically outlined the ambiguous nature of many verbal and non-verbal interactions, but consistently highlighted the importance of globally perceived positive interactions on health outcomes (Beck et al., 2002).

Findings from Study 1 suggesting differences in the emotional valence of health care interactions between people living with HIV and their providers highlight both the role of perception on the part of the person living with HIV, and more importantly, the need for the health care provider to be stigma-informed (e.g., Radcliffe et al., 2010). In brief, stigmainformed health care would include the provider being sensitive to the experiences of the person living with HIV and the power differential between the patient and provider. Additionally, the point was raised that providers who make assumptions are viewed as more conservative and less open-minded. The role of refraining from generalizations and instead addressing personally-held beliefs, such as regarding sex and sexuality, is recommended. Finally, the point was raised that experience does not equate to knowledge, but that increased experience working with people living with HIV usually leads to better outcomes, including less fear and misunderstanding, and therefore less stigma. The role of the positive, de-stigmatizing provider as a beacon of hope and 


\section{HEALTH CARE PROVIDERS AND HIV}

support was highlighted in the studies, demonstrating the role of providers to not only eliminate HIV stigma, but also to enhance quality of life for people living with HIV.

This work found that the overlapping stigmas of homophobia, racism, stigma against injection drug use and stigma against sex work account for nearly $40 \%$ of HIV stigma as it was assessed in this study. This finding then raises the question: What else may be contributing to HIV stigma beyond these variables and HIV as a virus itself? Judgment or perceived stigmatization due to presence of a chronic illness has been found for other sexually transmitted infections, and hepatitis C and other chronic illnesses, such as diabetes (Shiu, Kwan, \& Wong, 2003; Lichtenstein, 2003; Golden, O’Dwyer, \& Conroy, 2005). High rates of stigma are often associated with communicable diseases, such as sexually transmitted infections and hepatitis $\mathrm{C}$ (Lichtenstein, 2003; Butt, 2008), suggesting both the possible contribution of health anxiety on the part of the health care provider as well as stigmatizing attitudes about sex and injection drug use. Stigma has been found to affect disease outcomes for diabetes (such as engaging in selfmanagement of the illness, Shiu et al., 2003), access to health care services for sexually transmitted infections (Lichtenstein, 2003), and mental health outcomes associated with poor health for people living with hepatitis C (Golden et al., 2005). Class and socioeconomic differences have been found as factors associated with discrepant health care outcomes in sexually transmitted infections, diabetes and cardiovascular disease (Lichtenstein, 2003; Everson, Maty, Lynch, \& Kaplan, 2002; Kaplan \& Keil, 1993), and due to the demographic assumptions related to people living with HIV, could therefore also be potential areas to examine in the future in relation to HIV stigma.

The results from the model of overlapping stigmas suggest the presence of intersectionality, and emphasize the importance of intersectionality in HIV work (Bredstrom, 


\section{HEALTH CARE PROVIDERS AND HIV}

2006). Intersectionality, and specifically the interaction between the forms of stigma, should be examined further and with larger sample sizes in order to have enough power to conduct interaction analyses. It is possible that controlling for these overlapping stigmas in other measures of HIV stigma would yield much different assessments of what is actually HIV stigma and what are other forms of prejudice, stereotyping and discrimination. Assessing these distinctions allows for the creation of more specific, and therefore hopefully more effective, stigma reduction programs. These programs could target attitudes around race, sexual orientation, drug use and sex work, for example. Aspects of HIV that have been assessed in other anti-stigma interventions, could still be addressed, such as myths and facts about transmission (e.g., Nyblade, 2006). The findings extend the model of overlapping stigmas proposed by Logie and colleagues (2012) by confirming the influence of homophobia, racism and stigma against sex work, and adds stigma against injection drug use. The findings from Study 3 augment the model of overlapping stigmas by demonstrating its presence amongst health care provider trainees, confirming the perception of the women living with HIV from Logie and colleagues' study (2012). This quantitative assessment is the first, to our knowledge, among health care providers in Canada. The cumulative and temporal effect of overlapping stigmas has yet to be explicitly examined in relation to these overlapping stigmas, and should be investigated next to understand their interaction more intricately.

While there are inherent tensions between the methodologies used in the studies, the line of research demonstrates that they can be used in an interconnected, mutually informative, and symbiotic manner. The critical psychology lens used for Study 1 laid the foundation for a reflexive, ground-up assessment of the current status of HIV stigma in the healthcare system. The information from Study 1, and its reflexive position, therefore created the basis for Studies 2 


\section{HEALTH CARE PROVIDERS AND HIV}

and 3 , informing the work and therefore creating a richer and more nuanced assessment of HIV stigma. Additionally, a similar trajectory is seen in the use of an individual-level model to assess stigma then being used to inform suggestions for structural level change, building on the idea that individuals comprise society, but that individual-level change is not enough to combat the societal level problem of HIV stigma and its perpetuation.

A limitation to all three studies was the use of self-selecting samples of participants. In terms of the focus groups, participants were clearly comfortable with participating in a group forum and were interested in sharing their experiences. Although not assessed formally, many group participants in the groups of people living with HIV disclosed that they were diagnosed with HIV several years ago. It is therefore unlikely that the focus groups captured the experience of individuals newly diagnosed with HIV or newcomers to Canada, who may not have been comfortable or able to access the groups. For the provider and trainee populations, an inherent interest in discussing HIV was clearly present for group participants, suggesting that the results may not be generalizable to all providers or trainees. Additionally, a group format may have created some response bias on the part of the participants, who may have been influenced in what stories or experiences they shared based on the experiences shared by other group members. The focus groups only lasted for approximately one hour, and therefore the depth of information from each participant may not have been has great compared to if they had taken part in an individual interview. Participants in Studies 2 and 3 would also have had an inherent interest in participating in a study on HIV.

Further limitations to the studies included a relatively small sample of participants to run a confirmatory factor analysis on the HPASS. Larger sample sizes will help establish further scale validity. While participants for Studies 2 and 3 were recruited from across the country, 


\section{HEALTH CARE PROVIDERS AND HIV}

relatively small numbers of participants responded from areas outside of Ontario and very few from outside urban centers. Additionally, addressing people living with HIV as a homogeneous group in name on the HPASS, while allowing for the development of a broader measure, may result in less specific understanding of gender differences with the HPASS.

Future research should begin to examine how HIV stigma is expressed and potentially enacted by health care trainees, and can be done in assessments such as the Objective Structured Clinical Examination (OSCE; e.g., Sloan et al., 1996). OSCE assessments allow a preceptor to see the actions of the trainee in a simulated patient encounter, which offers a rich opportunity for assessment and intervention far beyond what is possible in self-report scenarios. Positive, neutral and negative interactions can be delineated and reviewed, allowing for a wealth of possibilities in terms of intervention and future research.

The focus groups conducted in Study 1 provided rich and important information regarding perceptions of HIV stigma, and suggest several areas for further investigation. Specifically, more focus groups could be conducted for each type of group (e.g., additional groups of women living with HIV and men living with HIV) to ensure total theme saturation occurs. Additionally, having more than one focus group for each population sampled would allow for further sub-analysis by group membership. Particularly of relevance and note, considering the intersectionality of gender and HIV on an individual's experience of stigma, would be to conduct further sex and gender-based analyses on a bigger sample. These analyses would allow differences and similarities in experience to be examined more explicitly between the groups, and would help inform intervention that could have greater specificity. Using more focus groups would also help to support the understanding that people living with HIV do not form a homogeneous group. 


\section{HEALTH CARE PROVIDERS AND HIV}

Additionally, future research should further examine the HPASS measure created for this study. The HPASS measure has been determined to have excellent internal consistency and testretest reliability within a sample of Canadian medical and nursing students, and should be crossvalidated with a larger sample of health care trainees. The measure could also be tested with other types of trainees (e.g., social work, psychology, dentistry, pharmacy, midwifery). To explore the attitudes and beliefs of current clinicians, the HPASS should also be tested with practicing clinicians, with future research to examine similarities and differences among different disciplines of providers. Should gender-based analyses from additional focus groups demonstrate a need for subdivision of the assessment of HIV stigma by gender, possible changes could also be made to the HPASS to test its validity if the questions were worded differently to be about men or women living with HIV. Understanding how and if providers respond differently to the HPASS with gender specific terminology would further help inform the need to address the intersectionality between HIV-related prejudice, stereotypes and discrimination and gender.

Within training for health care providers, stigma-informed care should be emphasized (Radcliffe et al., 2010). Acknowledging the power and privilege the provider has in relation to the patient is fundamental (e.g., Worthington \& Myers, 2003), but it is also important to acknowledge the potential lived experience of the person living with HIV, and how that experience might affect interactions with and perception of behaviours and attitudes of the health care provider. Stigma-informed training can occur at both the trainee and professional level, and use of the HPASS to assess HIV stigma prior to and following these interventions can be tested to determine the measure's ability to assess change, and any changes that occur due to the intervention. 


\section{HEALTH CARE PROVIDERS AND HIV}

The results speak to the need for policy-level change in terms of health care provider training. They emphasize the need for the development of time and cost efficient, pragmatic training programs integrated into already existing clinical programs to specifically address HIV stigma and related stigmas. Having HIV stigma modules mandated within training would ensure self-selection of participants is not an issue, and would make sure the contextual factors associated with HIV are not ignored by simply treating it like "any other chronic health condition". Additionally, training at the professional level through the use of CME credits could also occur. The results of Study 1 demonstrate that there is concern with a complacency or covert stigmatization among more experienced providers, and infusing stigma-informed training will help to combat this. Modules consisting of in vivo practice with actor-patients representing people living with HIV, teaching regarding negative, neutral and positive interactions, and the dispelling of myths to decrease fear reactions should be developed and tested. Integrating these actionable outcomes from the research into professional practice requirements for health care providers supports the critical lens through which Study 1 was conducted and is further supported by the positivist methodologies in Studies 2 and 3. Beyond training policies, policies regarding mandated disclosure of HIV status in health care contexts where they are not necessary (as discussed in emergency room settings by participants in Study 1) should be re-examined to determine their legitimacy and the detrimental impact of their stigmatizing effect.

In summary, Study 1 affirms that HIV stigma continues to be a major concern in the Canadian health care system, and one which can be addressed through targeted intervention on attitudes, cognitions and behaviours. Study 2 demonstrates a new way to assess HIV stigma amongst health care providers, and Study 3 demonstrates that HIV stigma is partially accounted for by overlapping stigmas. The findings suggest the presence of intersectionality in overlapping 


\section{HEALTH CARE PROVIDERS AND HIV}

stigmas, and emphasize the need for a critical perspective in order to address power dynamics and enact stigma-informed care within the health care system. 
HEALTH CARE PROVIDERS AND HIV

\section{References}

Amir, N., Beard, C., \& Bower, E. (2005). Interpretation bias and social anxiety. Cognitive Therapy and Research, 29, 433-443. doi: 10.1007/s10608-009-9258-6

Beck, R.S., Daughtridge, R., \& Sloane, P.D. (2002). Physician-patient communication in the primary care office: a systematic review. Journal of the American Board of Family Medicine, $15,25-38$.

Bredstrom, A. (2006). Intersectionality: a challenge for feminist HIV/AIDS research? European Journal of Women's Studies, 13, 229-243. doi: 10.1177/1350506806065754

Butt, G. (2008). Stigma in the context of hepatitis C: concept analysis. Journal of Advanced Nursing, 62, 712-724. doi: 10.1111/j.1365-2648.2008.04641.x

Crenshaw, K. (1991). Mapping the margins: intersectionality, identity politics, and violence against women of color. Stanford Law Review, 43, 1241-1299. doi: 10.2307/1229039

Earnshaw, V.A., \& Chaudoir, S.R. (2009). From conceptualizing to measuring HIV stigma: a review of HIV stigma mechanism measures. AIDS and Behavior, 13, 1160-1177. doi: $10.1007 / \mathrm{s} 10461-009-9593-3$

Everson, S.A., Maty, S.C., Lynch, J.W., \& Kaplan, G.A. (2002). Epidemiologic evidence for the relation between socioeconomic status and depression, obesity, and diabetes. Journal of Psychosomatic Research, 53, 891-895. doi: 10.1016/S0022-3999(02)00303-3

Golden, J., O’Dwyer, A.M., \& Conroy, R.M. (2005). Depression and anxiety in patients with hepatitis C: prevalence, detection rates and risk factors. General Hospital Psychiatry, 27, 431-438. doi: 10.1016/j.genhosppsych.2005.06.006

Hankivsky, O., \& Cormier, R. (2009). Intersectionality: Moving women’s health and policy forward. Vancouver: Women's Health Research Network. 


\section{HEALTH CARE PROVIDERS AND HIV}

Isen, A.M., \& Shalker, T.E. (1982). The effect of feeling state on evaluation of positive, neutral, and negative stimuli: when you "accentuate the positive" do you "eliminate the negative"? Social Psychology Quarterly, 45, 58-63. doi: 10.2307/3033676

Kaplan, G.A., \& Keil, J.E. (1993). Socioeconomic factors and cardiovascular disease: a review of the literature. Circulation, 88, 1973-1998. doi: 10.1161/01.CIR.88.4.1973

Leppanen, J.M., Milders, M., Bell, J.S., Terriere, E., \& Hietanen, J.K. (2004). Depression biases the recognition of emotionally neutral faces. Psychiatry Research, 128, 123-133. doi: 10.1016/j.psychres.2004.05.020

Lichtenstein, B. (2003). Stigma as a barrier to treatment of sexually transmitted infections in the American deep south: issues of race, gender and poverty. Social Science \& Medicine, 57, 2438-2445. doi: 10.1016/j.socscimed.2003.08.002

Logie, C.H., James, L., Tharao, W., \& Loutfy, M.R. (2011). HIV, Gender, Race, Sexual Orientation, and Sex Work: A Qualitative Study of Intersectional Stigma Experienced by HIV-positive Women in Ontario, Canada. PLoS Medicine, 8, e1001124. doi: 10.1371/journal.pmed.1001124

Mahajan, A.P., Sayles, J.N., Patel, V.A., Remien, R.H., Sawires, S.R., Ortiz, D.J., ... \& Coates, T.J. (2008). Stigma in the HIV/AIDS epidemic: a review of the literature and recommendations for the way forward. AIDS, 22, S67-S79. doi: 10.1097/01.aids.0000327438.13291.62

Nyblade, L.C. (2006). Measuring HIV stigma: Existing knowledge and gaps. Psychology, Health \& Medicine, 11, 335-345. doi: 10.1080/13548500600595178

Prilleltensky, I. (1989). Psychology and the status quo. American Psychologist, 44, 795-802. doi: 10.1037/0003-066X.44.5.795 


\section{HEALTH CARE PROVIDERS AND HIV}

Radcliffe, J., Doty, N., Hawkins, L.A., Gaskins, C.S., Beidas, R., \& Rudy, B.J. (2010). Stigma and sexual health risk in HIV-positive African American young men who have sex with men. AIDS Patient Care and STDs, 24, 493-499. doi:10.1089/apc.2010.0020

Reidpath, D.D., \& Chan, K.Y. (2005). A method for the quantitative analysis of the layering of HIV-related stigma. AIDS Care, 17, 425-432. doi: 10.1080/09540120412331319769

Shiu, A.T.Y., Kwan, J.J.Y.M., \& Wong, R.Y.M. (2003). Social stigma as a barrier to diabetes self-management: self-management: implications for multi-level interventions. Journal of Clinical Nursing, 12, 149-150.

Sloan, D.A., Donnelly, M.B., Schwartz, R.W., Felts, J.L., Blue, A.V., \& Strodel, W.E. (1996). The use of the Objective Structured Clinical Examination (OSCE) for evaluation and instruction in graduate medical education. Journal of Surgical Research, 63, 225-230. doi: $10.1006 /$ jsre. 1996.0252

Worthington, C., \& Myers, T. (2003). Factors underlying anxiety in HIV testing: risk perceptions, stigma, and the patient-provider power dynamic. Qualitative Health Research, 13, 636-655. doi: $10.1177 / 1049732303013005004$ 


\section{RYERSONUNIVERSITY}

\section{Consent Agreement \\ Health Care Provider Attitudes and Beliefs Towards People Living with HIV Focus Group}

You are being asked to participate in a research study. Before you give your consent to be a volunteer, it is important that you read the following information and ask as many questions as necessary to be sure you understand what you will be asked to do.

\section{Investigators:}

Trevor Hart, Ph.D., C. Psych.

Associate Professor

Department of Psychology

Ryerson University
Anne Wagner, M.A.

PhD Student

Department of Psychology

Ryerson University

\section{Purpose of the Study:}

The purpose of this project is to examine health care provider attitudes and beliefs about people living with HIV. The goal is to understand the full spectrum of attitudes and beliefs that exist, including examples of thoughts, feelings and behaviours which may be stigmatizing, and to do so by first asking those who know best: men living with HIV, women living with HIV, HIV expert health care providers and health care trainees. There will be 24 people who will be recruited to participate in focus groups, with six participants in each focus group (see the four groups outlined above). Each of the four groups will be interviewed separately (e.g., only health care trainees will be interviewed in one focus group, only men living with HIV in another). Following the focus groups, participants who consent to be re-contacted will be sent a document with the outcomes of the conversations for their comments and approval. To be included, participants must be 18 years or older and be either HIV-positive, be an HIV expert health care provider (i.e., have treated people living with HIV for at least two years), or be a health care trainee currently registered in a program.

Description of the Study: As part of this study, you will be asked to participate in a focus group with about five other people. The focus group will last between 60 and 90 minutes and will take place at Ryerson University. During the focus group, you will be asked a series of questions about the types of attitudes and beliefs health care providers have about people living with HIV, including attitudes and beliefs that may be either positive or stigmatizing. For example, you will be asked "What are health care providers' thoughts about HIV-positive patients?".

None of the procedures [focus group] used in this study are experimental in nature. The only experimental aspect of this study is the gathering of information for the purpose of analysis. You 
will be given access to the results of the study first via email description of the outcomes of the focus groups for your consideration, and the full published, de-identified manuscript will be available to be read should you be interested in learning the results upon study completion.

If you agree to be re-contacted, you will be emailed preliminary results from the focus groups approximately two months after the focus group, and you will be asked to provide your opinion about the outcomes presented by emailing the study team back. Providing feedback will likely take 15-20 minutes.

Risks or Discomforts: It is possible that during this study you will become uncomfortable because of the nature of the questions being asked or other peoples' comments. If you begin to feel uncomfortable, you may discontinue participating and leave the focus group altogether or take a break and return later.

Benefits of the Study: You may receive some benefits from being in this study by hearing others' opinions and experiences. We cannot guarantee, however, that you will receive any benefits from participating in this study. The findings of this study will be used to establish a new way to assess health care provider attitudes and beliefs about people living with HIV.

Confidentiality: Confidentiality will be respected and no information that discloses your identity will be released or published without consent, unless required by law. The focus group will be audiorecorded and transcribed. The audiorecorded and printed transcripts will be kept in a locked file cabinet at Ryerson University. The files with the transcripts will be saved on computers that are password protected and audiotapes will be destroyed after we have confirmed all vital information (2-3 years). Only study staff will have access to these data. After 10 years, all information will be destroyed.

Confidentiality cannot be ensured during the focus groups since they take place in a group setting. However, every precaution possible will be taken to ensure confidentiality of the data collected. This includes emphasizing the importance of keeping information private once participants leave the group and removing names from all transcripts and notes. These names will be replaced with codes for each participant. The code legend will be kept separately from the transcripts and notes. Additionally, audio recordings will be kept in a different place from the transcripts, notes and code legend.

Confidentiality will not be kept in the case of information being revealed that requires mandatory reporting. These circumstances consist of: a participant indicating that they may be a harm to themselves or someone else, that a child is currently being abused or neglected, that abuse or misconduct has occurred by a health care professional, or if these records are subpoenaed by a court.

\section{Incentives to Participate:}

After completion of this focus group you will be given $\$ 50$ as compensation for you participation. If, at any point in the interview, you don't want to answer a particular question, feel that you need to withdraw from the study, or take a break, you will still be given $\$ 50$. Should you agree to be re-contacted, no compensation will be given for feedback given on the preliminary outcomes of the focus groups. 
Voluntary Nature of Participation: Participation in this study is voluntary. Your choice of whether or not to participate will not influence your future relations with Ryerson University, or any AIDS Service Organization. If you decide to participate, you are free to withdraw your consent and to stop your participation at any time without penalty or loss of benefits to which you are allowed. At any particular point in the study, you may refuse to answer any particular question or stop participation altogether.

Questions about the Study: If you have any questions about the research now, please ask. If you have questions later about the research, you may contact.

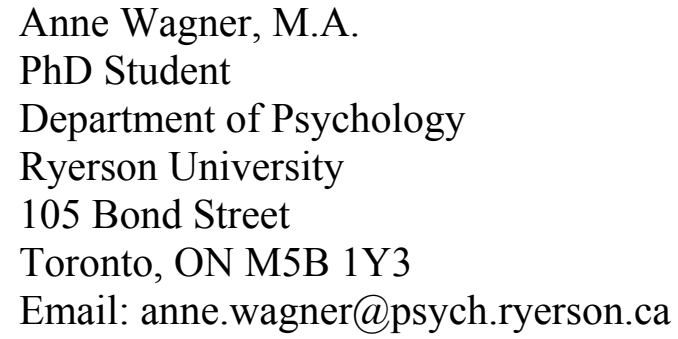

If you have questions regarding your rights as a human subject and participant in this study, you may contact the Ryerson University Research Ethics Board for information.

Dr. Nancy Walton, Chair of the Research Ethics Board c/o Office of the Vice President, Research and Innovation Ryerson University 350 Victoria Street

Toronto, ON M5B 2K3

Email: rebchair@ryerson.ca

\section{Agreement:}

Your signature below indicates that you have read the information in this agreement and have had a chance to ask any questions you have about the study. Your signature also indicates that you agree to be in the study, to be recontacted via email or mail after the focus group for your opinion about the outcomes of the focus groups, and have been told that you can change your mind and withdraw your consent to participate at any time. You have been given a copy of this agreement.

You have been told that by signing this consent agreement you are not giving up any of your legal rights.

Name of Participant (please print) 
HEALTH CARE PROVIDERS AND HIV

Signature of Participant

Date

Signature of Investigator

Date

I agree to be re-contacted by email to provide feedback on the preliminary outcomes of the study.

Email Address

Your signature below indicates that you have read and understand that you will be audiorecorded for only the purposes of this study. Your signature indicates that you agree to be audiorecorded and have been told that you can change your mind and withdraw this consent at any time.

Name of Participant (please print)

Signature of Participant

Date

Signature of Investigator

Date

This study will contribute to the fulfilment of Ms. Wagner's $\mathrm{PhD}$ requirements. 
Appendix B

\section{Focus Group Questions}

Welcome - thank you so much for joining us here today!

We have asked you here today to get your opinions on all types of attitudes and beliefs health care providers have about people living with HIV.

We are here to listen to your discussion, and will occasionally break in with a question or two, and will take some notes. We are audiotaping the session so that we can go back and listen to the sessions again when we are coming up with the next stage of our research.

1) What are health care providers' thoughts about HIV-positive patients?

We want to hear about the whole range of attitudes and beliefs you feel like people may have everything you can think of.

Can you think of any examples or stories you have heard of either from other people or from your own experience?

2) When we talk about negative views held by an individual towards someone who has HIV, often times this gets lumped into one big category. From previous research in the area, the negative views have been broken down into three areas.

2a.) The first is prejudice, or the feelings someone has about someone living with HIV. HIV.

2b.) The second is stereotyping, or the thoughts people have about people living with with HIV.

2c.) The third is discrimination, or the behaviours people show towards people living

Can you think of examples of any of these?

3) We have discussed how individuals might think, feel and act towards people living with HIV, but how do you think organizations or settings (like hospitals, community health clinics, AIDS service organizations, etc.) think, feel and act towards people living with HIV?

Are there rules or norms these organizations or settings have that might be either positive or negative for people living with HIV? 


\section{Appendix C \\ Debriefing Form \\ Health Care Provider Attitudes and Beliefs Towards People Living with HIV Focus Group}

You have participated in a research study conducted by Anne Wagner, MA, and Dr. Trevor Hart, from the Department of Psychology at Ryerson University, Toronto, Ontario.

Purpose of the Study: The purpose of this project is to examine health care provider attitudes and beliefs about people living with HIV. The goal is to understand the full spectrum of attitudes and beliefs that exist, including examples of thoughts, feelings and behaviours which may be stigmatizing, and to do so by first asking those who know best: men living with HIV, women living with HIV, HIV expert health care providers and health care trainees.

Design of the Study: As part of this study, participants take part in a focus group with about five other people. The focus group lasts between 60 and 90 minutes and takes place at Ryerson University. During the focus group, participants are asked a series of questions about the types of attitudes and beliefs health care providers have about people living with HIV, including attitudes and beliefs that may be either positive or stigmatizing. For example, participants will be asked "What are health care providers' thoughts about HIV-positive patients?".

None of the procedures [focus group] used in this study are experimental in nature. The only experimental aspect of this study is the gathering of information for the purpose of analysis. You will be given access to the results of the study first via email description of the outcomes of the focus groups for your consideration, and the full published, de-identified manuscript will be available to be read should you be interested in learning the results upon study completion. If you have agreed to be re-contacted, you will be emailed preliminary results from the focus groups approximately two months after the focus group, and you will be asked to provide your opinion about the outcomes presented by emailing the study team back. Providing feedback will likely take 15-20 minutes.

Expected Results: We will be using the information generated in these focus groups to generate items to create a scale measuring health care provider attitudes towards people living with HIV. Should you agree to be re-contacted, your input will be sought to determine whether or not we have accurately captured the ideas from the focus group and whether or not the way we have worded them makes sense.

Questions and Concerns: If participating in the focus group has caused you psychological distress or discomfort, please contact:

The Toronto Distress Centre

Phone: 416-408-4357 Website: http://www.torontodistresscentre.com/index.shtml

If you have questions about this study or would like to remove your data from the study, please contact one of the below investigators:

Anne Wagner anne.wagner@psych.ryerson.ca

Dr. Trevor Hart trevor.hart@psych.ryerson.ca

If you have questions regarding your rights as a human subject and participant in this study, you may contact the Ryerson University Research Ethics Board for information: 
HEALTH CARE PROVIDERS AND HIV

Dr. Nancy Walton, Chair of the Research Ethics Board c/o Office of the Vice President, Research and Innovation Ryerson University 350 Victoria Street

Toronto, ON M5B 2K3

Email: rebchair@ryerson.ca

Thank you for your participation. This study will contribute to the fulfilment of Ms. Wagner's $\mathrm{PhD}$ requirements. 


\section{RYERSONUNIVERSITY}

\section{Consent Agreement \\ Health Care Provider Attitudes and Beliefs Towards People Living with HIV Questionnaire}

You are being asked to participate in a research study. Before you give your consent to be a volunteer, it is important that you read the following information to be sure you understand what you will be asked to do.

\section{Investigators:}

Trevor Hart, Ph.D., C. Psych.

Associate Professor

Department of Psychology

Ryerson University

\author{
Anne Wagner, M.A. \\ PhD Student \\ Department of Psychology \\ Ryerson University
}

\section{Purpose of the Study:}

The purpose of this project is to examine health care trainee attitudes and beliefs about people living with HIV. The goal is to understand the full spectrum of attitudes and beliefs that exist, including examples of thoughts, feelings and behaviours regarding HIV and topics that may be relevant to people living with HIV, such as questions about sexuality, gender, race, injection drug use, and sex work. Additionally, participant demographic information will be collected, including information about education, age, gender, sexuality, and religiosity to examine how these variables might influence attitudes about HIV and related topics. A total of 300 nursing and medical students will be invited to participate in the study. To participate, participants must be a health care trainee currently registered in a medical or nursing program.

Description of the Study: As part of this study, you will be asked to complete an online questionnaire administered through the program Qualtrics. The questionnaire typically takes between 45 and 60 minutes to complete. You will be asked about some demographic information, including questions about your age, gender, education, sexuality, and religious views. You will be asked about attitudes and beliefs that you may not have thought a lot about, or that may be difficult to answer. You will be asked about your attitudes and beliefs about HIV and related topics, including sexuality, gender, race, discrimination, religion, injection drug use, and sex work. There are no right or wrong answers, and your answers are completely anonymous. If you provide your email address at the end of the questionnaire in order to receive a gift certificate, there will be a temporary link between your data and your email address, and that link will be destroyed immediately once your gift certificate has been sent. Subsequently, your answers will never be linked to you and your health care program will never know how you responded. 
Should you wish to see the de-identified results of the study once the data have been analyzed, information will be available on our lab's website about where to obtain this information: http://www.ryerson.ca/thart/lab/index.html

Risks or Discomforts: It is possible that during this study you will become uncomfortable because of the nature of the questions being asked. If you begin to feel uncomfortable, you may discontinue participating or take a break. If, at any time, you wish to skip a particular question, you can easily do so. Further, if you want to discontinue participation, you can do so by simply closing your browser and no data will be submitted on your behalf.

Benefits of the Study: You may receive some benefits from being in this study by examining your own opinions and attitudes. We cannot guarantee, however, that you will receive any benefits from participating in this study. The findings of this study will be used to establish a new way to assess health care provider attitudes and beliefs about people living with HIV.

Confidentiality: Participation in the study is anonymous and your data will never be linked with any identifying information. Confidentiality cannot be ensured, however, if you complete the questionnaire on a computer in a public place. The data files will be saved on computers that are password protected. Only study staff will have access to these data. After 10 years, all information will be destroyed. Data are collected through the online program Qualtrics which has extensive security features, such as data only being accessible to the researcher and features to prevent breaches in the security of the data.

\section{Incentives to Participate:}

After completion of the questionnaire, you will be given the opportunity to provide your email address to receive $\$ 15$ via electronic gift certificate as compensation for your participation. It may take up to 72 hours to have the gift certificate arrive in your email inbox and after the gift certificate is issued, your e-mail will not be saved by the research team. A temporary link between your data and your email address will exist, and that link will be destroyed immediately once your gift certificate has been sent.

Voluntary Nature of Participation: Participation in this study is voluntary. Your choice of whether or not to participate will not influence your future relations with Ryerson University or your program of study. If you decide to participate, you are free to withdraw your consent and to stop your participation at any time without penalty or loss of benefits to which you are allowed. At any particular point in the study, you may refuse to answer any particular question or stop participation altogether.

Questions about the Study: If you have questions about the research, you may contact:

Anne Wagner, M.A.

PhD Student, Department of Psychology

Ryerson University

105 Bond Street

Toronto, ON M5B 1Y3

Email: anne.wagner@psych.ryerson.ca 
Trevor Hart, Ph.D., C.Psych.

Associate Professor, Department of Psychology

Ryerson University

Jorgenson Hall, 350 Victoria Street

Toronto, ON M5B 2K3

Email: trevor.hart@psych.ryerson.ca

If you have questions regarding your rights as a human subject and participant in this study, you may contact the Ryerson University Research Ethics Board for information.

\author{
Dr. Nancy Walton, Chair of the Research Ethics Board \\ c/o Office of the Vice President, Research and Innovation \\ Ryerson University \\ 350 Victoria Street \\ Toronto, ON M5B 2K3 \\ Email: rebchair@ryerson.ca
}

\title{
Agreement:
}

Checking the box below indicates that you have read the information in this agreement. Checking the box also indicates that you agree to be in the study, and have been told that you can change your mind and withdraw your consent to participate at any time. You may print a copy of this agreement for your records.

$\square$ I agree to participate in this study.

Anne Wagner

Signature of Investigator

This study will contribute to the fulfilment of Ms. Wagner's $\mathrm{PhD}$ requirements. 


\section{Appendix E \\ Debriefing Form \\ Health Care Provider Attitudes and Beliefs Towards People Living with HIV Questionnaire}

You have participated in a research study conducted by Anne Wagner, MA, and Dr. Trevor Hart, from the Department of Psychology at Ryerson University, Toronto, Ontario. Thank you for your participation.

Purpose of the Study: The purpose of this project was to examine health care trainee attitudes and beliefs about people living with HIV. The goal was to try to understand the full spectrum of attitudes and beliefs that exist, including examples of thoughts, feelings and behaviours regarding HIV and topics that may be relevant to people living with HIV. The study examined how different attitudes interact to create stigmatizing attitudes towards people living with HIV, and to determine whether individual characteristics, such as religiosity or education, influence that relationship.

Expected Results: We will be using the information gathered to validate a model of the relationship between variables such as attitudes about sexuality, gender, race, injection drug use and sex work and HIV stigma. We hope to determine the variables that are most highly associated with stigmatizing attitudes towards people living with HIV in order to develop better interventions to target them and therefore improve both medical and nursing education as well as quality of life for individuals living with HIV. News about research results and publications related to the data in aggregate form will be able to be found on the HIV Prevention Lab's website: http://www.ryerson.ca/thart/lab/index.html

Questions and Concerns: If completing the questionnaire has caused you psychological distress or discomfort, please contact:

The Toronto Distress Centre

Phone: 416-408-4357 Website: http://www.torontodistresscentre.com/index.shtml

If you would like more information about HIV and related topics, please visit the Canadian AIDS Treatment Information Exchange (CATIE) website:

www.catie.ca

If you have additional questions about this study OR would like to remove your data from the study, please contact one of the below investigators:
Anne Wagner
anne.wagner@psych.ryerson.ca
Dr. Trevor Hart
trevor.hart@psych.ryerson.ca

If you have questions regarding your rights as a human subject and participant in this study, you may contact the Ryerson University Research Ethics Board for information:

Dr. Nancy Walton, Chair of the Research Ethics Board

c/o Office of the Vice President, Research and Innovation

Ryerson University, 350 Victoria Street

Toronto, ON M5B 2K3

Email: rebchair@ryerson.ca 


\section{HEALTH CARE PROVIDERS AND HIV}

Thank you for your participation. Please print a copy of this debriefing form for your records. This study will contribute to the fulfilment of Ms. Wagner's PhD requirements. 


\section{RYERSONUNIVERSITY}

\section{Consent Agreement \\ Health Care Provider Attitudes and Beliefs Towards People Living with HIV Questionnaire-Second Questionnaire}

You are being asked to participate in a research study. Before you give your consent to be a volunteer, it is important that you read the following information to be sure you understand what you will be asked to do.

\section{Investigators:}

Trevor Hart, Ph.D., C. Psych.

Associate Professor

Department of Psychology

Ryerson University
Anne Wagner, M.A.

PhD Student

Department of Psychology

Ryerson University

\section{Purpose of the Study:}

The purpose of this project is to examine health care trainee attitudes and beliefs about people living with HIV. The goal is to determine whether one of the scales you completed in the original questionnaire regarding attitudes and beliefs about people living with HIV is still valid one month later. Your data from this portion of the study will be added to your original data that included thoughts, feelings and behaviours regarding HIV and topics that may be relevant to people living with HIV, such as questions about sexuality, gender, race, injection drug use, and sex work. Additionally, your participant demographic information was collected, including information about education, age, gender, sexuality, and religiosity to examine how these variables might influence attitudes about HIV and related topics. A total of 50 nursing and medical students will be invited to participate in the second questionnaire portion of the study. To participate, participants must be a health care trainee currently registered in a medical or nursing program.

Description of the Study: As part of this study, you will be asked to complete an online questionnaire administered through the program Qualtrics. The questionnaire typically takes between 10 and 15 minutes to complete. You will be asked about attitudes and beliefs that you may not have thought a lot about, or that may be difficult to answer. You will be asked about your attitudes and beliefs about HIV. There are no right or wrong answers, and your answers are completely anonymous. If you provide your email address at the end of the questionnaire in order to receive a gift certificate, there will be a temporary link between your data and your email address, and that link will be destroyed immediately once your gift certificate has been sent. Subsequently, your answers will never be linked to you and your health care program will never know how you responded. 
Should you wish to see the de-identified results of the study once the data have been analyzed, information will be available on our lab's website about where to obtain this information: http://www.ryerson.ca/thart/lab/index.html

Risks or Discomforts: It is possible that during this study you will become uncomfortable because of the nature of the questions being asked. If you begin to feel uncomfortable, you may discontinue participating or take a break. If, at any time, you wish to skip a particular question, you can easily do so. Further, if you want to discontinue participation, you can do so by simply closing your browser and no data will be submitted on your behalf.

Benefits of the Study: You may receive some benefits from being in this study by examining your own opinions and attitudes. We cannot guarantee, however, that you will receive any benefits from participating in this study. The findings of this study will be used to establish a new way to assess health care provider attitudes and beliefs about people living with HIV.

Confidentiality: Participation in the study is anonymous and your data will never be linked with any identifying information. Confidentiality cannot be ensured, however, if you complete the questionnaire on a computer in a public place. The data files will be saved on computers that are password protected. Only study staff will have access to these data. After 10 years, all information will be destroyed. Data are collected through the online program Qualtrics which has extensive security features, such as data only being accessible to the researcher and features to prevent breaches in the security of the data.

\section{Incentives to Participate:}

After completion of the questionnaire, you will be given the opportunity to provide your email address to receive $\$ 10$ via electronic gift certificate as compensation for your participation. It may take up to 72 hours to have the gift certificate arrive in your email inbox and after the gift certificate is issued, your e-mail will not be saved by the research team. A temporary link between your data and your email address will exist, and that link will be destroyed immediately once your gift certificate has been sent.

Voluntary Nature of Participation: Participation in this study is voluntary. Your choice of whether or not to participate will not influence your future relations with Ryerson University or your program of study. If you decide to participate, you are free to withdraw your consent and to stop your participation at any time without penalty or loss of benefits to which you are allowed. At any particular point in the study, you may refuse to answer any particular question or stop participation altogether.

Questions about the Study: If you have questions about the research, you may contact:

Anne Wagner, M.A.

PhD Student, Department of Psychology

Ryerson University

105 Bond Street

Toronto, ON M5B 1Y3

Email: anne.wagner@psych.ryerson.ca 
Trevor Hart, Ph.D., C.Psych.

Associate Professor, Department of Psychology

Ryerson University

Jorgenson Hall, 350 Victoria Street

Toronto, ON M5B 2K3

Email: trevor.hart@psych.ryerson.ca

If you have questions regarding your rights as a human subject and participant in this study, you may contact the Ryerson University Research Ethics Board for information.

\author{
Dr. Nancy Walton, Chair of the Research Ethics Board \\ c/o Office of the Vice President, Research and Innovation \\ Ryerson University \\ 350 Victoria Street \\ Toronto, ON M5B 2K3 \\ Email: rebchair@ryerson.ca
}

\title{
Agreement:
}

Checking the box below indicates that you have read the information in this agreement. Checking the box also indicates that you agree to be in the study, and have been told that you can change your mind and withdraw your consent to participate at any time. You may print a copy of this agreement for your records.

$\square$ I agree to participate in this study.

Anne Wagner

Signature of Investigator

This study will contribute to the fulfilment of Ms. Wagner's $\mathrm{PhD}$ requirements. 


\section{Appendix G \\ Debriefing Form \\ Health Care Provider Attitudes and Beliefs Towards People Living with HIV Questionnaire-Second Questionnaire}

You have participated in a research study conducted by Anne Wagner, MA, and Dr. Trevor Hart, from the Department of Psychology at Ryerson University, Toronto, Ontario. Thank you for your participation.

Purpose of the Study: The purpose of this project was to examine health care trainee attitudes and beliefs about people living with HIV. The goal is to establish the validity of a new scale for health care providers designed to measure the full spectrum of attitudes and beliefs that exist, including examples of thoughts, feelings and behaviours regarding people living with HIV. Expected Results: We will be using the information gathered to validate a scale assessing the attitudes and opinions of health care providers towards people living with HIV. We hope to determine the variables that are most highly associated with stigmatizing attitudes towards people living with HIV in order to develop better interventions to target them and therefore improve both medical and nursing education as well as quality of life for individuals living with HIV. News about research results and publications related to the data in aggregate form will be able to be found on the HIV Prevention Lab's website:

http://www.ryerson.ca/thart/lab/index.html

Questions and Concerns: If completing the questionnaire has caused you psychological distress or discomfort, please contact:

The Toronto Distress Centre

Phone: 416-408-4357 Website: http://www.torontodistresscentre.com/index.shtml

If you would like more information about HIV and related topics, please visit the Canadian AIDS Treatment Information Exchange (CATIE) website:

www.catie.ca

If you have additional questions about this study OR would like to remove your data from the study, please contact one of the below investigators:

Anne Wagner anne.wagner@psych.ryerson.ca

Dr. Trevor Hart trevor.hart@psych.ryerson.ca

If you have questions regarding your rights as a human subject and participant in this study, you may contact the Ryerson University Research Ethics Board for information:

Dr. Nancy Walton, Chair of the Research Ethics Board

c/o Office of the Vice President, Research and Innovation

Ryerson University, 350 Victoria Street

Toronto, ON M5B 2K3

Email: rebchair@ryerson.ca

Thank you for your participation. Please print a copy of this debriefing form for your records. This study will contribute to the fulfilment of Ms. Wagner's $\mathrm{PhD}$ requirements. 
Appendix $\mathrm{H}$

Original 93 Items for the HPASS

Below is a list of ideas about HIV+ patients. Some of the ideas may be true for you, and some of them may not. People hold a wide range of ideas about HIV+ patients, and we are interested in your particular ideas. Please answer the questions honestly - your responses are completely anonymous.

\begin{tabular}{|c|c|c|c|c|c|}
\hline 1 & 2 & 3 & 4 & 5 & 6 \\
\hline $\begin{array}{l}\text { Strongly } \\
\text { Disagree }\end{array}$ & Disagree & $\begin{array}{c}\text { Somewhat } \\
\text { Disagree }\end{array}$ & $\begin{array}{c}\text { Somewhat } \\
\text { Agree }\end{array}$ & Agree & $\begin{array}{c}\text { Strongly } \\
\text { Agree }\end{array}$ \\
\hline
\end{tabular}

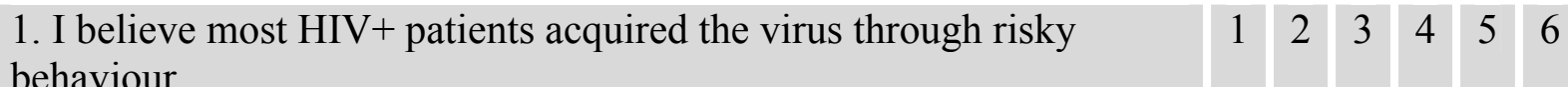
2. When a patient is HIV+, other diagnoses are not important.

$\begin{array}{llllll}1 & 2 & 3 & 4 & 5 & 6\end{array}$

3. I have a distinct picture in my mind of who contracts HIV.

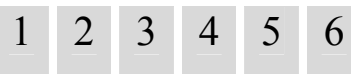

4. I think it is important for a provider to discuss a patient's HIV

$\begin{array}{llllll}1 & 2 & 3 & 4 & 5 & 6\end{array}$ status with other providers to ensure the safety of the providers.

5. I think HIV+ patients have engaged in risky activities despite knowing these risks.

6. I think it is important for HIV+ patients to feel comfortable and $\quad \begin{array}{lllllll}1 & 2 & 3 & 4 & 5 & 6\end{array}$ supported by their health care providers.

7. I believe HIV+ patients all have the same problems.

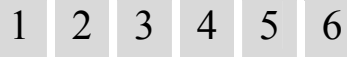

8. I believe I have the right to refuse to treat $\mathrm{HIV}+$ patients for the

$\begin{array}{llllll}1 & 2 & 3 & 4 & 5 & 6\end{array}$ safety of other patients.

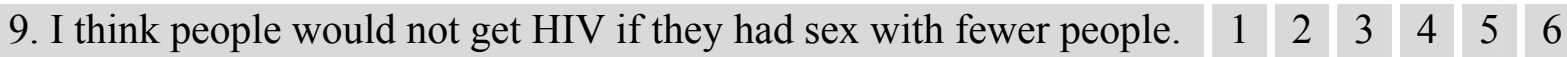

10. HIV+ patients present a threat to my health.

$\begin{array}{llllll}1 & 2 & 3 & 4 & 5 & 6\end{array}$

\begin{tabular}{ll|l|l|l|l|l|l} 
11. I would ask HIV+ patients how they acquired HIV because I am & 1 & 2 & 3 & 4 & 5 & 6
\end{tabular} curious.

12. HIV + patients present a threat to the health of other patients.

$\begin{array}{llllll}1 & 2 & 3 & 4 & 5 & 6\end{array}$

13. I believe I have the right to refuse to treat HIV+ patients if other staff members are concerned about safety.

14. I would avoid conducting certain procedures on HIV+ patients.

\begin{tabular}{llllll|l}
1 & 2 & 3 & 4 & 5 & 6
\end{tabular}

15. I think if people act responsibly they will not contract HIV.

$\begin{array}{llllll}1 & 2 & 3 & 4 & 5 & 6\end{array}$

$\begin{array}{lllllll}1 & 2 & 3 & 4 & 5 & 6\end{array}$ 


\section{HEALTH CARE PROVIDERS AND HIV}

\begin{tabular}{|l|lllllll}
\hline 16. HIV+ patients tend to have numerous sexual partners. & 1 & 2 & 3 & 4 & 5 & 6
\end{tabular}

17. People can contract HIV for a lot of different reasons.

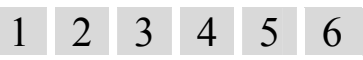

18. I think it is necessary to focus on the whole person rather than the $\quad \begin{array}{lllllll}1 & 2 & 3 & 4 & 5 & 6\end{array}$ HIV diagnosis.

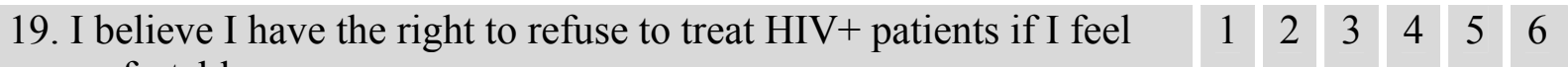
uncomfortable.

20. HIV+ patients come from diverse backgrounds and lifestyles.

$\begin{array}{llllll}1 & 2 & 3 & 4 & 5 & 6\end{array}$

\section{HIV+ individuals are difficult patients.}

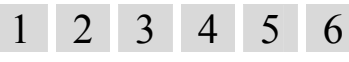

22. If an HIV+ heterosexual man told me the only HIV risk behaviour $\quad \begin{array}{llllllll}2 & 2 & 3 & 4 & 5 & 6\end{array}$ he had been exposed to was having sex with women, I would not believe him.

23. If an HIV+ patient is sick, it is usually due to HIV.

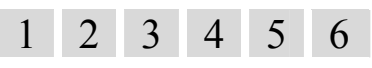

24. I believe there are many factors leading to someone contracting $\quad \begin{array}{llllllll}1 & 2 & 3 & 4 & 5 & 6\end{array}$ HIV.

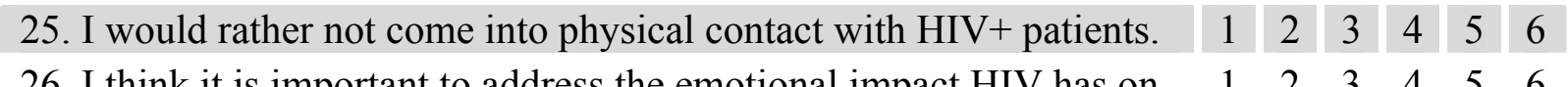

26. I think it is important to address the emotional impact HIV has on an HIV+ patient's life.

\begin{tabular}{|l|l|l|l|l|l|l|}
\hline 27. I would want to wear two sets of gloves when examining HIV+ & 1 & 2 & 3 & 4 & 5 & 6
\end{tabular} patients.

28. I believe I have the right to refuse to treat $\mathrm{HIV}+$ patients to protect $\quad \begin{array}{llllll}1 & 2 & 3 & 4 & 5 & 6\end{array}$ myself.

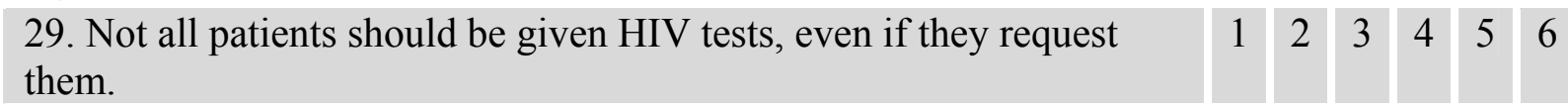

\begin{tabular}{l|l|l|l|l|l|l|}
\hline 30. I think almost all HIV+ people are gay men. & 1 & 2 & 3 & 4 & 5 & 6
\end{tabular}

\begin{tabular}{ll|l|l|l|l|l|l|} 
31. I think HIV+ patients form a group of very similar people. & 1 & 2 & 3 & 4 & 5 & 6
\end{tabular}

32. It is acceptable for an HIV+ patient not to disclose his or her HIV $\quad \begin{array}{lllllll}1 & 2 & 3 & 4 & 5 & 6\end{array}$ status to his or her family members.

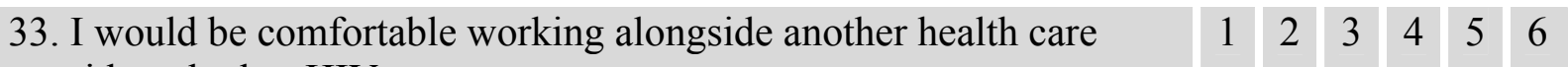
provider who has HIV.

34. I think it is acceptable to shake hands with an HIV+ patient. $\quad$\begin{tabular}{llllllll}
\hline 3 & 2 & 3 & 4 & 5 & 6
\end{tabular}

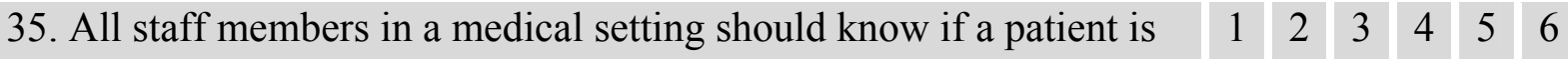
$\mathrm{HIV}+$.

36. HIV+ patients must accept that providing certain services to HIV+ $\quad \begin{array}{lllllll}1 & 2 & 3 & 4 & 5 & 6\end{array}$ patients is risky for health care providers.

\begin{tabular}{ll|l|l|l|l|l|l|} 
37. I think it is important to listen carefully to an HIV+ patient. & & 1 & 2 & 3 & 4 & 5 & 6
\end{tabular}

38. In order to protect both HIV+ patients and other patients, an HIV+ $\quad \begin{array}{lllllll}1 & 2 & 3 & 4 & 5 & 6\end{array}$ patient should be separated from HIV-negative patients.

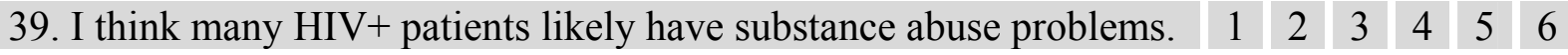

40. I believe extra protection beyond standard procedures is needed to $\quad \begin{array}{llllllll}1 & 2 & 3 & 4 & 5 & 6\end{array}$ prevent the transmission of HIV to health care providers.

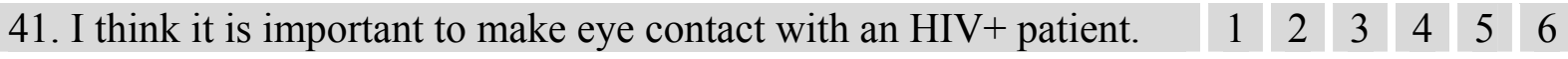




\section{HEALTH CARE PROVIDERS AND HIV}

42. I would not take extra precautions with a patient who is HIV+ to $\quad \begin{array}{llllll}1 & 2 & 3 & 4 & 5 & 6\end{array}$ prevent transmission to myself, colleagues, and other patients.

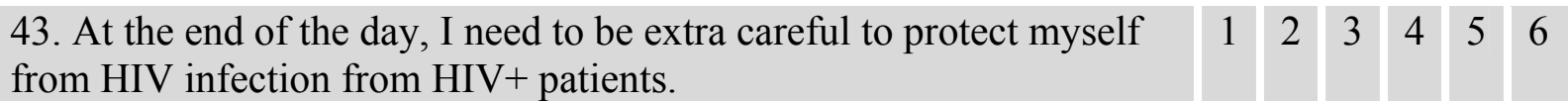

44. I would take the same precautions to prevent the transmission of $\quad \begin{array}{lllllll}1 & 2 & 3 & 4 & 5 & 6\end{array}$ diseases with HIV-negative and HIV+ patients.

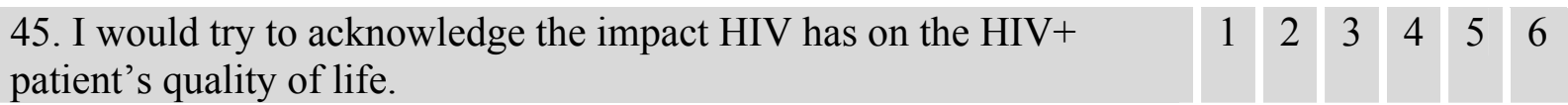

46. It is acceptable for an HIV+ patient not to disclose his or her HIV $\quad \begin{array}{llllll}1 & 2 & 3 & 4 & 5 & 6\end{array}$ status to me.

\begin{tabular}{|l|l|l|l|l|l|l|}
\hline 47. I believe I have the right to refuse to treat HIV+ patients if I am & 1 & 2 & 3 & 4 & 5 & 6
\end{tabular} concerned about legal liability.

48. I sometimes struggle making eye contact with HIV+ patients.

$\begin{array}{llllll}1 & 2 & 3 & 4 & 5 & 6\end{array}$

49. I think HIV+ patients should be treated the same way whether or not they disclose their HIV status.

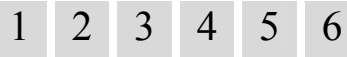

50. HIV+ patients cannot be trusted to disclose their status to sexual $\quad \begin{array}{lllllll}1 & 2 & 3 & 4 & 5 & 6\end{array}$ partners.

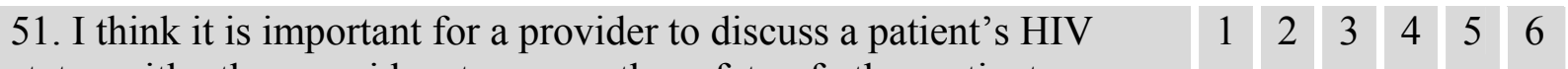
status with other providers to ensure the safety of other patients.

52. If someone does not fit the picture of an HIV+ patient, I would not $\quad 1 \quad \begin{array}{llllll}2 & 3 & 4 & 5 & 6\end{array}$ inquire about HIV.

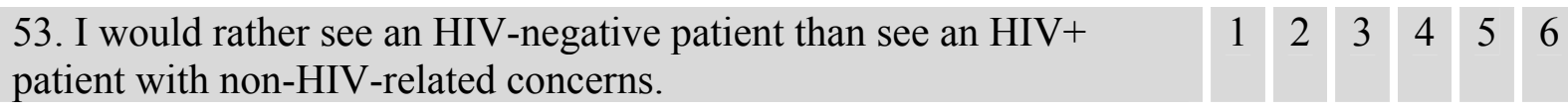

54. I think it is unnecessary for someone's HIV status to be $\quad \begin{array}{llllll}2 & 2 & 3 & 4 & 5 & 6\end{array}$ highlighted on his or her medical documents for safety concerns.

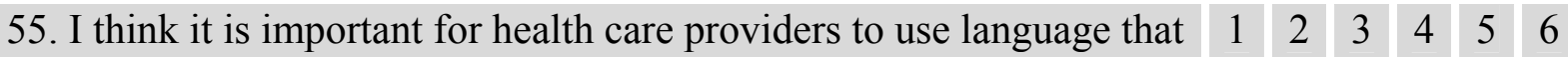
is accessible for HIV+ patients.

56. HIV+ patients should not have sex.

57. I think HIV+ patients should only have sex with other HIV+ people.

58. HIV+ patients should be discouraged from having children.

59. As a health care provider, I have a right to know how an HIV+ patient acquired HIV.

60. Normal people do not usually get HIV.

\begin{tabular}{|l|l|l|l|l|l|l|l|}
6 61. HIV+ patients should accept responsibility for acquiring the virus. & 1 & 2 & 3 & 4 & 5 & 6
\end{tabular}

62. I worry about contracting HIV from HIV+ patients.

$\begin{array}{llllll}1 & 2 & 3 & 4 & 5 & 6\end{array}$

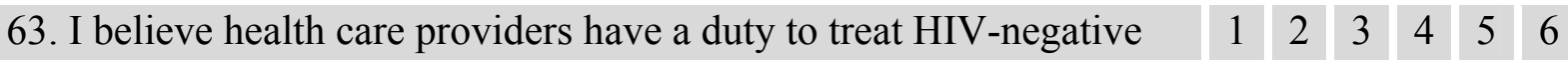
and HIV+ patients equally.

64. I often think HIV+ patients have caused their own health problems.

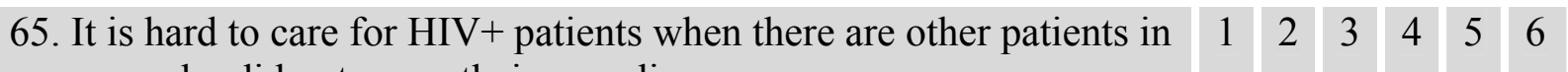
my care who did not cause their own disease.

66. It is upsetting that some HIV+ people knowingly put others at risk $\quad \begin{array}{llllll}1 & 2 & 3 & 4 & 5 & 6\end{array}$ 


\section{HEALTH CARE PROVIDERS AND HIV}

for contracting HIV.

\begin{tabular}{ll|l|l|l|l|l|} 
67. Health care providers for HIV+ patients should be advocates for & 1 & 2 & 3 & 4 & 5 & 6
\end{tabular} their patients.

68. HIV+ patients make me uncomfortable.

$\begin{array}{llllll}1 & 2 & 3 & 4 & 5 & 6\end{array}$

69. I would worry when using needles with HIV+ patients.

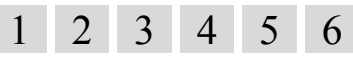

70. I would be hesitant to send HIV+ patients to get blood work done $\quad \begin{array}{llllllll}1 & 2 & 3 & 4 & 5 & 6\end{array}$ due to my fear of others' safety.

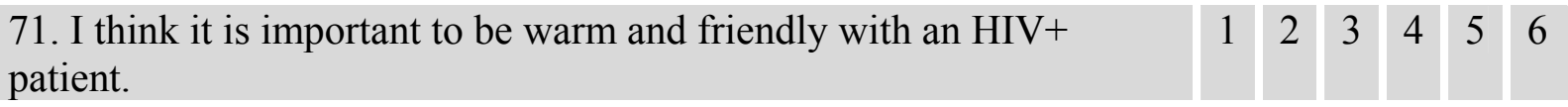

72. It is better to be safe than sorry when it comes to protecting myself $\quad \begin{array}{llllll}1 & 2 & 3 & 4 & 5 & 6\end{array}$ if I have a patient who is $\mathrm{HIV}+$.

73. I believe HIV+ patients are like all other patients.

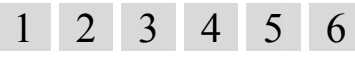

74. I believe HIV+ patients are at fault for contracting the virus.

$\begin{array}{llllll}1 & 2 & 3 & 4 & 5 & 6\end{array}$

75. I think it is important to provide support for HIV+ patients.

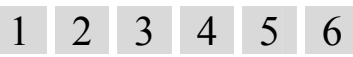

76. HIV+ patients cannot be trusted to take their medications.

$\begin{array}{llllll}1 & 2 & 3 & 4 & 5 & 6\end{array}$

77. I think many HIV+ women are likely involved in sex work.

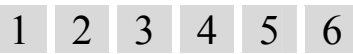

78. The majority of HIV+ patients have contracted HIV due to some $\quad \begin{array}{llllllll}1 & 2 & 3 & 4 & 5 & 6\end{array}$ kind of immoral behaviour.

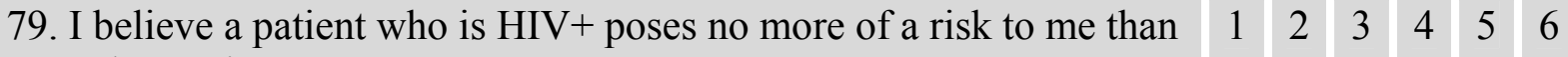
any other patient.

80. It is a little scary to think I have touched HIV+ patients.

81. I think it is more of a risk that I will contract HIV from an HIV+ patient than another communicable disease from another patient.

82. I worry that universal precautions are not good enough to protect $\quad \begin{array}{lllllll}1 & 2 & 3 & 4 & 5 & 6\end{array}$ me from $\mathrm{HIV}+$ patients.

\begin{tabular}{ll|l|l|l|l|l|l} 
83. I am able to separate my beliefs about HIV+ patients from how I & 1 & 2 & 3 & 4 & 5 & 6
\end{tabular} treat them.

84. I would feel uncomfortable knowing one of my colleagues is $\mathrm{HIV}+$.

\begin{tabular}{ll|l|l|l|l|l|} 
85. I think it is important for HIV+ patients to feel included in their & 1 & 2 & 3 & 4 & 5 & 6
\end{tabular} health care decisions.

86. I think most HIV+ women are of African descent.

$\begin{array}{llllll}1 & 2 & 3 & 4 & 5 & 6\end{array}$

87. I want HIV+ patients to feel comfortable disclosing their HIV status to me.

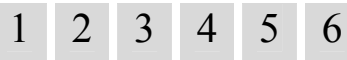

88. HIV+ patients who have acquired HIV through injection drug use $\quad \begin{array}{lllllll}1 & 2 & 3 & 4 & 5 & 6\end{array}$ are more at fault for contracting HIV than HIV+ patients who have acquired HIV through a blood transfusion.

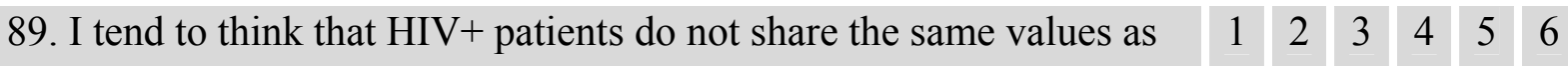
me.

90. I think it is important to react non-judgmentally if a patient tells $\quad \begin{array}{llllllll} & 1 & 2 & 3 & 4 & 5 & 6\end{array}$ me he or she is HIV+.

\begin{tabular}{ll|l|l|l|l|l|l} 
91. HIV+ patients who have acquired HIV through sex are more at & & 1 & 2 & 3 & 4 & 5 & 6
\end{tabular} 


\section{HEALTH CARE PROVIDERS AND HIV}

fault for contracting HIV than HIV+ patients who have acquired HIV through a blood transfusion.

92. I have sympathy for HIV+ patients.

$\begin{array}{llllll}1 & 2 & 3 & 4 & 5 & 6\end{array}$

93. It would be hard to react calmly if a patient tells me he or she is $\quad$\begin{tabular}{l|l|l|l|l|l|l}
\hline & 2 & 3 & 4 & 5 & 6
\end{tabular} $\mathrm{HIV}+$. 
Appendix I

The Healthcare Provider HIV/AIDS Stigma Scale (HPASS)

Below is a list of ideas about HIV+ patients. Some of the ideas may be true for you, and some of them may not. People hold a wide range of ideas about HIV+ patients, and we are interested in your particular ideas. Please answer the questions honestly - your responses are completely anonymous.

\begin{tabular}{|c|c|c|c|c|c|}
\hline 1 & 2 & 3 & 4 & 5 & 6 \\
\hline $\begin{array}{c}\text { Strongly } \\
\text { Disagree }\end{array}$ & Disagree & $\begin{array}{c}\text { Somewhat } \\
\text { Disagree }\end{array}$ & $\begin{array}{c}\text { Somewhat } \\
\text { Agree }\end{array}$ & Agree & $\begin{array}{c}\text { Strongly } \\
\text { Agree }\end{array}$ \\
\hline
\end{tabular}

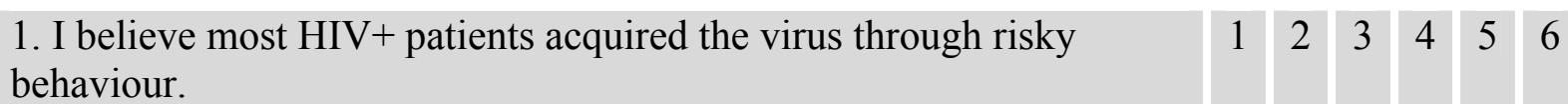

2. I think HIV+ patients have engaged in risky activities despite $\quad \begin{array}{lllllll}1 & 2 & 3 & 4 & 5 & 6\end{array}$ knowing these risks.

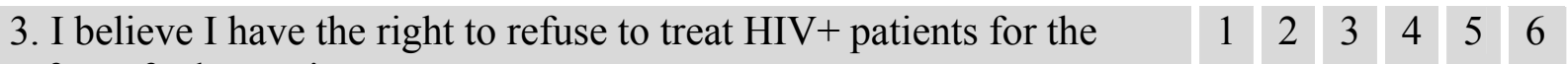
safety of other patients.

4. I think people would not get HIV if they had sex with fewer people. $\quad \begin{array}{lllllll}1 & 2 & 3 & 4 & 5 & 6\end{array}$

\begin{tabular}{|l|l|l|l|l|l|l|}
\hline 5. HIV+ patients present a threat to my health. & 1 & 2 & 3 & 4 & 5 & 6
\end{tabular}

6. HIV+ patients present a threat to the health of other patients. $\quad \begin{array}{llllll}2 & 3 & 4 & 5 & 6\end{array}$

\begin{tabular}{|l|l|l|l|l|l|l|} 
7. I believe I have the right to refuse to treat HIV+ patients if other & 1 & 2 & 3 & 4 & 5 & 6
\end{tabular} staff members are concerned about safety.

8. I would avoid conducting certain procedures on HIV+ patients. $\quad \begin{array}{lllllll}1 & 2 & 3 & 4 & 5 & 6\end{array}$

\begin{tabular}{|l|l|l|l|l|l|l|l|} 
9. I think if people act responsibly they will not contract HIV. & 1 & 2 & 3 & 4 & 5 & 6
\end{tabular}

10. HIV+ patients tend to have numerous sexual partners. $\quad \begin{array}{llllll} & 2 & 3 & 4 & 5 & 6\end{array}$

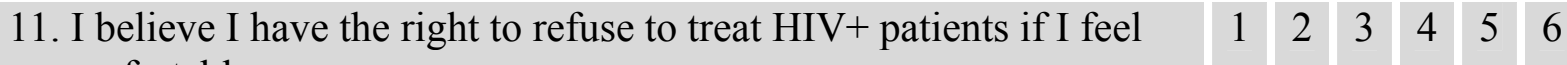
uncomfortable.

12. I would rather not come into physical contact with HIV+ patients. $\quad \begin{array}{llllll}1 & 2 & 3 & 4 & 5 & 6\end{array}$

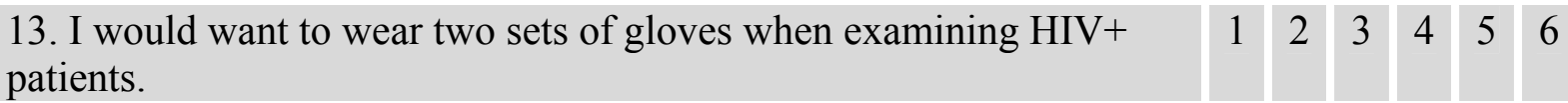

14. I believe I have the right to refuse to treat $\mathrm{HIV}+$ patients to protect $\quad \begin{array}{llllll}1 & 2 & 3 & 4 & 5 & 6\end{array}$ myself.

\begin{tabular}{|l|l|l|l|l|l|l|}
\hline 15. I would be comfortable working alongside another health care & 1 & 2 & 3 & 4 & 5 & 6
\end{tabular} provider who has HIV. 


\section{HEALTH CARE PROVIDERS AND HIV}

16. I think many HIV+ patients likely have substance abuse problems. $\quad \begin{array}{lllllll}1 & 2 & 3 & 4 & 5 & 6\end{array}$

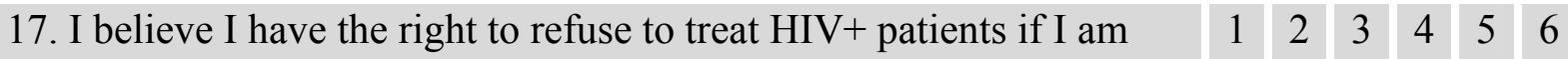
concerned about legal liability.

18. I would rather see an HIV-negative patient than see an HIV+ $\quad \begin{array}{llllllll} & 1 & 2 & 3 & 4 & 5 & 6\end{array}$ patient with non-HIV-related concerns.

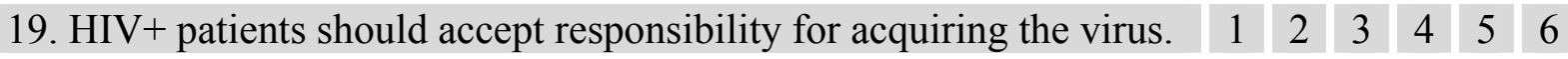

20. I worry about contracting HIV from HIV+ patients.

$\begin{array}{llllll}1 & 2 & 3 & 4 & 5 & 6\end{array}$

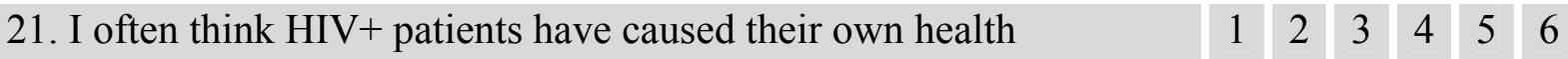
problems.

22. HIV+ patients make me uncomfortable.

23. I would be hesitant to send HIV+ patients to get blood work done due to my fear of others' safety.

24. It is a little scary to think I have touched HIV+ patients.

$\begin{array}{llllll}1 & 2 & 3 & 4 & 5 & 6\end{array}$

25 . I worry that universal precautions are not good enough to protect me from HIV+ patients.

26. I would feel uncomfortable knowing one of my colleagues is $\mathrm{HIV}+$.

\begin{tabular}{|l|l|l|l|l|l|l|}
\hline 27. HIV+ patients who have acquired HIV through injection drug use & 1 & 2 & 3 & 4 & 5 & 6
\end{tabular} are more at fault for contracting HIV than HIV+ patients who have acquired HIV through a blood transfusion.

28. I tend to think that HIV+ patients do not share the same values as $\quad \begin{array}{llllll}1 & 2 & 3 & 4 & 5 & 6\end{array}$ me.

29. HIV+ patients who have acquired HIV through sex are more at fault for contracting HIV than HIV+ patients who have acquired HIV through a blood transfusion.

30. It would be hard to react calmly if a patient tells me he or she is $\mathrm{HIV}+$.

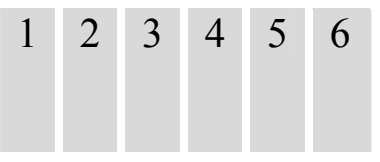

$\begin{array}{llllll}1 & 2 & 3 & 4 & 5 & 6\end{array}$ 